GUILHERME AUGUSTO PEDRÃO

Padrões de distribuição dos cocolitoforídeos no oeste do Atlântico Sul e sua relação com os parâmetros ambientais

Dissertação apresentada ao Instituto Oceanográfico da Universidade de São Paulo, como parte dos requisitos para o curso de Mestrado, no programa Oceanografia, área de concentração Oceanografia Geológica. Período: 2016/18

Orientador: Prof. Dr. Felipe Antonio de Lima Toledo

São Paulo 
Universidade de São Paulo

Instituto Oceanográfico

\section{Padrões de distribuição dos cocolitoforídeos no oeste do Atlântico Sul e sua relação com os parâmetros ambientais}

Guilherme Augusto Pedrão

Dissertação apresentada ao Instituto Oceanográfico da Universidade de São Paulo, como parte dos requisitos para obtenção do título de Mestre em Ciências, área de Oceanografia Geológica.

Julgada em

Conceito

$\operatorname{Prof}(\mathrm{a}) . \operatorname{Dr}(\mathrm{a})$.

Conceito

$\operatorname{Prof}(\mathrm{a}) . \operatorname{Dr}(\mathrm{a})$.

Conceito

$\operatorname{Prof}(a)$. Dr(a). 


\section{Sumário}

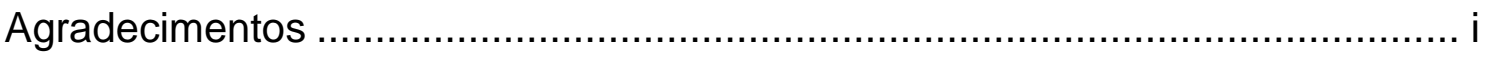

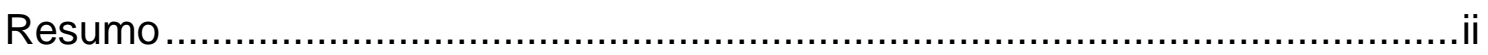

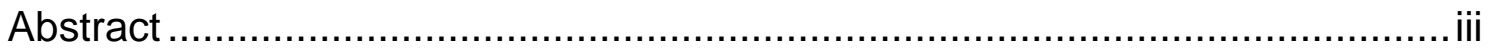

Lista de Siglas e Abreviaturas ..................................................................

Lista de Tabelas ....................................................................................... vii

Lista de Figuras ...................................................................................... viii

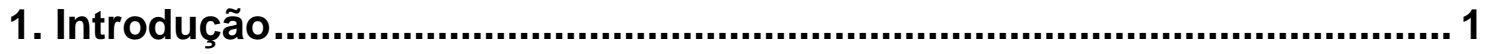

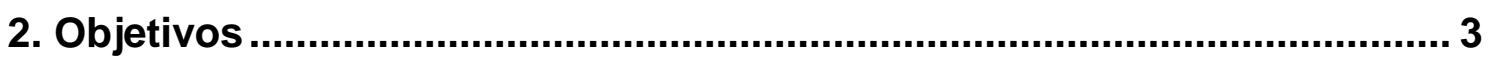

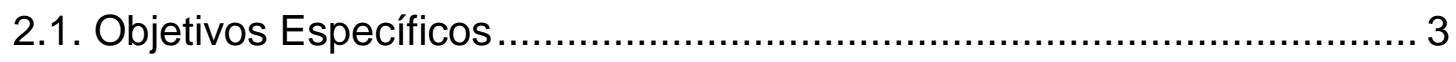

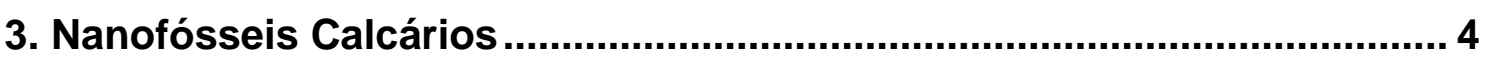

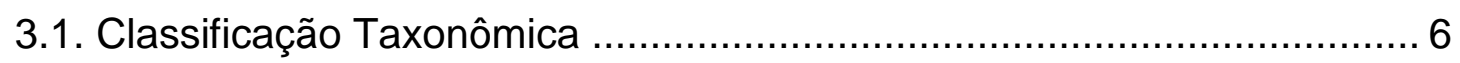

3.2. Principais espécies do oeste do Oceano Atlântico Sul ............................. 8

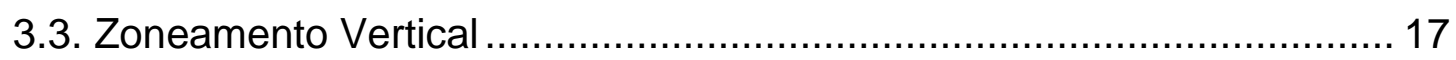

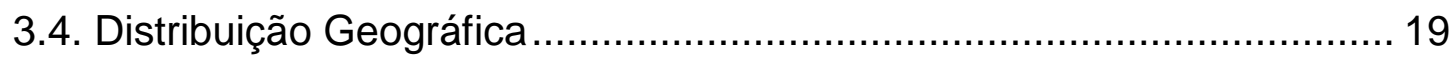

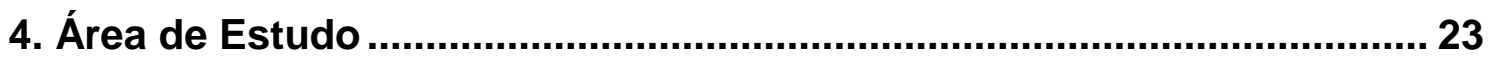

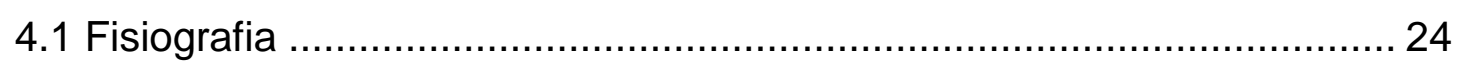

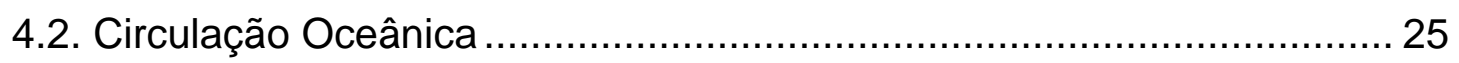

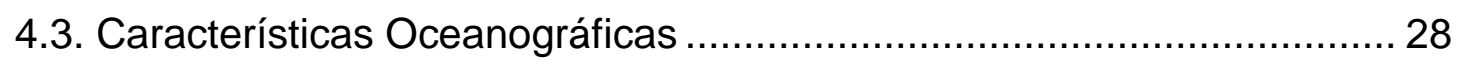

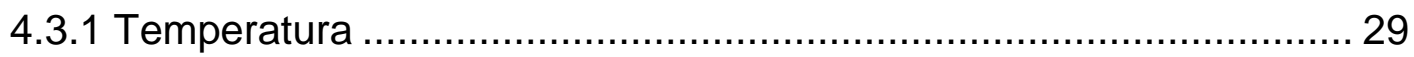

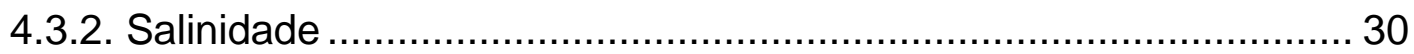

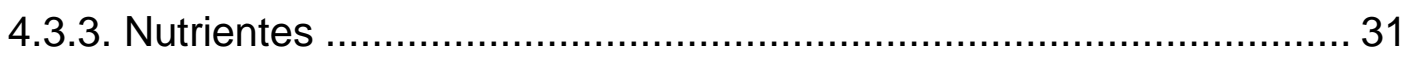

4.3.4. Camada de Mistura.................................................................... 33

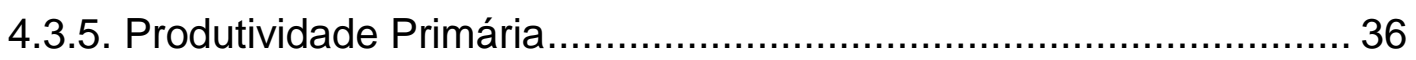

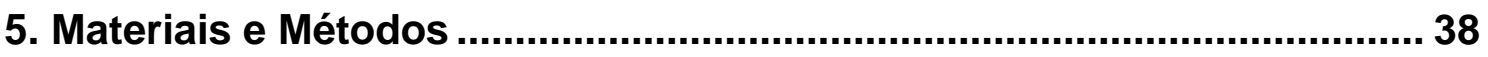

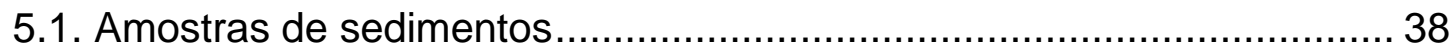

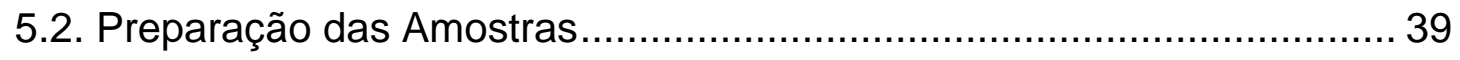

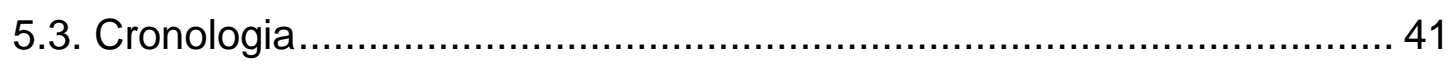

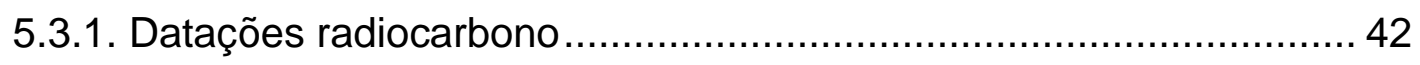

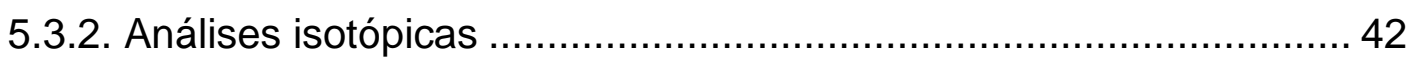

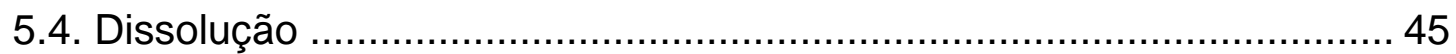




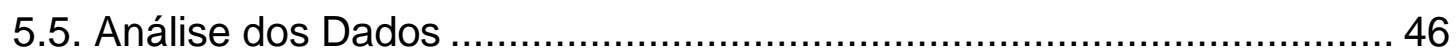

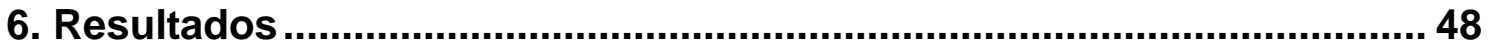

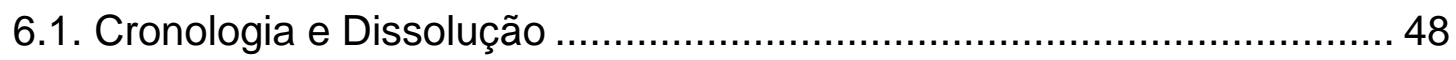

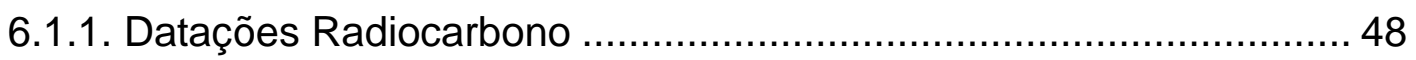

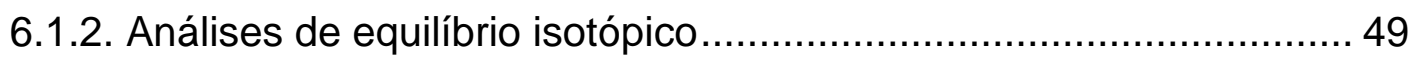

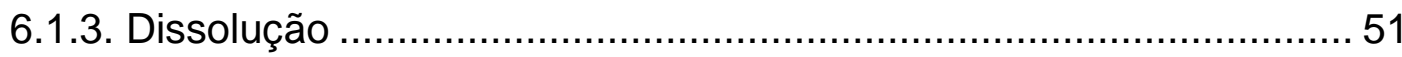

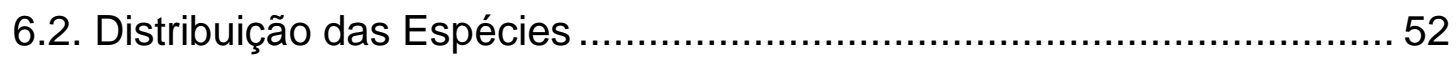

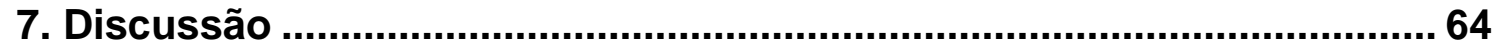

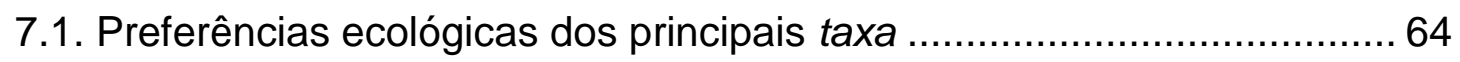

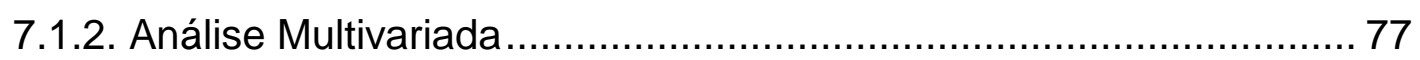

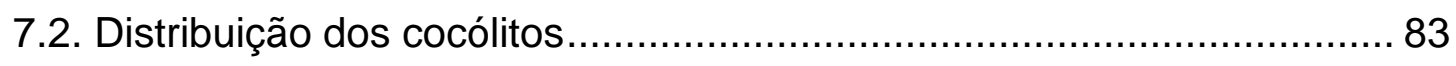

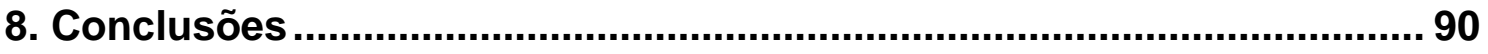

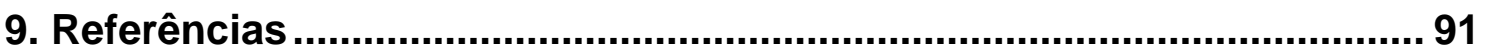




\section{Agradecimentos}

Agradeço a Deus por me guiar e colocar neste caminho, pelos obstáculos colocados a minha frente e pela determinação de superá-los.

A minha namorada, melhor amiga, maior revisora e maior leitora deste trabalho, Mariana Tomazella, sem seus "puxões de orelha" e seus conselhos talvez esse trabalho nem tivesse saído.

Aos meus pais e meu irmão por serem a minha base e minha raiz, sem as quais nada disso poderia ter sido feito.

Aos Prof. Dr. Felipe Toledo e a Prof. ${ }^{a}$ Dr. ${ }^{a}$ Karen Costa pela orientação, pela dedicação e pela amizade. Sem contar pelos inúmeros auxílios na parte de escrita. Vocês foram sensacionais!

Agradeço a CNPq pelo apoio financeiro através da Bolsa de Mestrado.

Ao Prof. Dr. Christian Millo pela ajuda na parte metodológica com os isótopos estáveis.

Agradeço também a toda equipe do LaPAS, tanto pela ajuda durante a elaboração da tese, quanto pela descontração e pelas conversas. Em especial um agradecimento ao pessoal da equipe de nanofósseis calcários, Heliane, Marcus e a Juliana. Muito obrigado pela atenção, por me apresentar a esse mundo e responder todas as minhas perguntas, mesmo as mais bizarras. Obrigado, sério mesmo. Não tem como não agradecer também o Eloy Cabarcos pela ajuda na elaboração do projeto e no início do trabalho.

Agradecer também o pessoal MUQATX esse grupo de pessoas singulares, extraordinárias e excelentes, só que não. Agora sério, obrigado mesmo, galera. Vocês foram mais do que sensacionais, não só para minha graduação ou pós, mas durante todo o período no qual estive em sua companhia. 


\section{Resumo}

Neste estudo a assembleia de cocolitoforídeos de 44 amostras de sedimentos marinhos de superfície da Margem Continental Brasileira foram analisados e comparados com os parâmetros oceanográficos locais. Com o intuito de obter um melhor entendimento da área de estudo, foram incluídas as análises de 36 amostras do estudo de Boeckel et al. (2006). A partir destes dados, os padrões de abundância das principais espécies e suas afinidades ecológicas foram verificadas. E. huxleyi, F. profunda e Gephyrocapsa spp. são as espécies mais abundantes. E. huxleyi dominou as assembleias características de águas mais frias e ricas em nutrientes, Gephyrocapsa spp. as regiões com menores profundidades da camada de mistura, ou seja, estas espécies demonstram uma preferência por uma nutriclina mais rasa. Por outro lado, F. profunda, foi mais abundante nas águas quentes e oligotróficas das regiões subtropicais, revelando sua preferência por uma nutriclina mais profunda. Além disso, os resultados da Análise de Correspondência Canônica revelaram uma afinidade de $C$. leptoporus, E. huxleyi, C. pelagicus e G ericsonii com águas mais enriquecidas em nutrientes. Em contraste, Gephyrocapsa spp. e Helicosphaera spp. foram associadas a regiões mesotróficas. Uma vez que G. flabellatus e $D$. tubifera parecem estar associadas a águas com camadas de mistura mais profundas, elas podem ser utilizadas, juntamente com $F$. profunda, como indicadoras de uma termo/nutriclina mais profunda. A partir de análise de clusters e análise por componentes principais, 4 províncias foram identificadas e parecem refletir as características oceanográficas da zona fótica.

Palavras-chave: cocolitoforídeos, biogeografia, Atlântico Sul, nutriclina. 


\section{Abstract}

In this study the coccolitophore assemblages of 44 samples of marine surface sediments from the Brazilian Continental Margin were analyzed and compared with the local oceanographic parameters. In order to obtain a better understanding of the study area, were included the analysis of 36 samples from the study by Boeckel et al. (2006). From these data, the abundance patterns of the main species and their ecological affinities were verified. E. huxleyi, F. profunda and Gephyrocapsa spp. are the most abundant species. E. huxleyi dominated the assemblages characteristic of colder and nutrient-rich waters, Gephyrocapsa spp. the regions with lower mixed layer depths, in other words, these species demonstrate a preference for a shallower nutricline. On the other hand, F. profunda, was more abundant in the warm and oligotrophic waters of the subtropical regions, revealing its preference for a deeper nutricline. In addition, the results of the Canonical Correspondence Analysis revealed an affinity of C. leptoporus, E. huxleyi, C. pelagicus and $G$ ericsonii for waters enriched in nutrients. In contrast, Gephyrocapsa spp. and Helicosphaera spp. were associated with mesotrophic regions. Since G. Flabellatus and D. tubifera appear to be associated with waters that have deeper mixed layers, they may be used, along with $F$. profunda, as indicators of a deeper nutricline. From the cluster analysis and by the principal components analysis, 4 provinces were identified and seems to reflect the oceanographic characteristics of the photic zone.

Keywords: cocolithophores, biogeography, South Atlantic, nutricline 


\section{Lista de Siglas e Abreviaturas}

ACAS - Água Central do Atlântico Sul

ACC - Análise de Correspondência Canônica

ACP - Análise de Componentes Principais

ACS - Água Circumpolar Superior

AFA - Água de Fundo Antártica

AIA - Água Intermediaria Antártica

APAN - Água Profunda do Atlântico Norte

AT - Água Tropical

CAS - Corrente do Atlântico Sul

CB - Corrente do Brasil

$\mathrm{CBe}$ - Corrente de Benguela

CEX’ - Índice de Dissolução de Cocólitos

Chl 0m - Concentração de Clorofila em superfície

Chl 0-100m - Média da concentração de Clorofila nos primeiros $100 \mathrm{~m}$ de profundidade

CNB - Corrente Norte do Brasil

CNE - Corrente Norte Equatorial

$\mathrm{CP}$ - Componente Principal

CSE - Corrente Sul Equatorial

DMS - Dimetilsulfeto

Fosf Om - Concentração de Fosfato na Superfície do Mar 
Fosf $0-150 m$ - Média da concentração de Fosfato nos primeiros $150 \mathrm{~m}$ de profundidade

LaPAS - Laboratório de Paleoceanografia do Atlântico Sul

MEV - Microscopio Eletrônico de Varredura

Nit 0m - Concentração de Nitrato na Superfície do Mar

Nit 0-150m - Média da concentração de Nitrato nos primeiros $150 \mathrm{~m}$ de profundidade

NOSAMS - National Ocean Science Accelerator Mass Spectrometrer Facility

NPP - Produção Primária Líquida

PAST - Paleontological Statistics

Prof. CDM - Profundidade da Camada de Mistura

SeaWiFS - Sea Viewing Wide Field of View Sensor

Sil 0m - Concentração de Silicato na superfície do mar

Sil 0-150m - Média da concentração de Silicato nos primeiros 150m de profundidade

SSS - Salinidade da Superfície do Mar

SSS 0m - Salinidade da Superfície do Mar

SSS 0-150m - Média da Salinidade nos primeiros 150m de profundidade

SST - Temperatura da Superfície do Mar

SST 0m - Temperatura da Superfície do Mar

SST 0-150m - Média da Temperatura nos primeiros 150m de profundidade

VGPM - Modelo de Profundidade Genericamente Vertical

WHOI - Woods Hole Oceanographic Institution

WOA - World Ocean Atlas 
WOA01 - World Ocean Atlas 2001

WOA13 - World Ocean Atlas 2013 


\section{Lista de Tabelas}

Tabela 1 - Zonas fóticas subtropicais. Modificado de Winter et al. $1994 \ldots \ldots \ldots . .18$

Tabela 2 - Amostras analisadas quanto a isótopos estáveis, assim como a espécie de foraminífero e o número de indivíduos utilizados em cada amostra.

Tabela 3 - Datações pelo método rabiocarbono considerando uma idade reservatório global de 400 anos.

Tabela 4 - Resultados da análise de equilíbrio isotópico para foraminíferos bentônicos. Em vermelho estão as amostras que não foram consideradas representativas do oceano atual.

Tabela 5 - Resultados da análise de equilíbrio isotópico para foraminíferos planctônicos. Em vermelho estão as amostras que não foram consideradas representativas do oceano atual.

Tabela 6 - Valores de $r$ e intensidade da correlação considerada. Modificado de Callegari-Jacques (2003)

Tabela 7 - Matriz de correlação entre os parâmetros ambientais e as espécies de cocolitoforídeos. Em negrito estão as espécies com correlações significativas, ou seja, as que obtiveram um $p$-valor menor do que $0,05 \ldots \ldots \ldots .75$

Tabela 8 - Porcentagem da variância explicada por cada eixo da Análise de Correspondência Canônica.

Tabela 9 - Correlação entre cada eixo da Análise de Correspondência Canônica e os parâmetros ambientais. Em negrito estão os valores significativos.

Tabela 10 - Porcentagem da variância explicada por cada componente

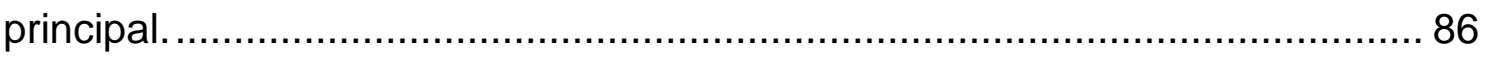

Tabela 11 - Matriz de Correlação entre as componentes principais e os parâmetros ambientais. Em negrito estão os valores de $r$ considerados significativos com um $p$-valor menor do que 0,05 . 86

Tabela 12 - Loadings de todas as espécie em cada componente principal, demonstrando qual espécie é mais representativa em cada componente principal. Em negrito estão os principais valores. 87 


\section{Lista de Figuras}

Figura 1 - Estrutura celular de um cocolitoforídeo. A imagem mostra diversas morfologias de cocólitos, sendo os cocólitos gradeados holococólitos e os coloridos em preto heterococólitos. P1 e P2 são dois tipos de pirenóides distintos, sendo, respectivamente, o primeiro típico nos cocolitoforídeos e o segundo nos gêneros Emiliania e Gephyrocapsa. As abreviações significam: ES: escamas orgânicas não mineralizadas, $\mathrm{F}$ : flagelo, $\mathrm{H}$ : haptonema, $\mathrm{M}$ : mitocôndrias, VC: vesícula formadora de cocólitos, N: núcleo. Modificado de Billard \& Inoue, 2004.

Figura 2 - Cocosferas dos morfotipos da espécie $C$. leptoporus por fotos de MEV. Da esquerda para a direita, C. quadriperforatus, C. leptoporus e $C$. leptoporus pequeno. Retirado do web site Nannotax3 (Young et al., 2014) de autoria de Jeremy Young. 9

Figura 3 - Cocosfera de Calciosolenia brasiliensis retratada pelo MEV. Retirado do web site Nannotax3 (Young et al., 2014) de autoria de Jeremy Young....... 10

Figura 4 - Cocosfera de Coccolithus pelagicus retratada pelo MEV. Retirado do web site Nannotax3 (Young et al., 2014) de autoria de Jeremy Young............ 10

Figura 5 - Cocosfera de Discosphaera tubifera retratada pelo MEV. Retirado do web site Nannotax3 (Young et al., 2014) de autoria de Jeremy Young............ 10

Figura 6 - Cocosferas dos morfotipos da espécie E. huxleyi retratadas pelo MEV. Retirado do web site Nannotax3 (Young et al., 2014) de autoria de Jeremy Young.

Figura 7 - Cocosfera de Florisphaera profunda retratada pelo MEV. Retirado do web site Nannotax3 (Young et al., 2014) de autoria de Jeremy Young............ 12

Figura 8 - Cocosfera de Gephyrocapsa oceanica retratada pelo MEV. Retirado do web site Nannotax3 (Young et al., 2014) de autoria de Jeremy Young....... 13

Figura 9 - Cocosfera de Gephyrocapsa ericsonii retratada pelo MEV. Retirado do web site Nannotax3 (Young et al., 2014) de autoria de Jeremy Young....... 13

Figura 10 - Cocosfera de Gladiolithus flabellatus retratada pelo MEV. Retirado do web site Nannotax3 (Young et al., 2014) de autoria de Jeremy Young...... 14

Figura 11 - Cocosfera de Helicosphaera carteri retratada pelo MEV. Retirado do web site Nannotax3 (Young et al., 2014) de autoria de Jeremy Young............ 14

Figura 12 - Cocosfera de Oolithotus fragilis retratada pelo MEV. Retirado do web site Nannotax3 (Young et al., 2014) de autoria de Jeremy Young............ 15

Figura 13 - Cocosfera de Rhabdosphaera clavigera var. clavigera retratada pelo MEV. Retirado do web site Nannotax3 (Young et al., 2014) de autoria de Jeremy Young. 15 
Figura 14 - Cocosfera de Rhabdosphaera clavigera var. stylifera retratada pelo MEV. Retirado do web site Nannotax3 (Young et al., 2014) de autoria de Jeremy Young. 15

Figura 15 - Cocosfera de Syracosphaera pulchra retratada pelo MEV. Retirado do web site Nannotax3 (Young et al., 2014) de autoria de Jeremy Young....... 16

Figura 16 - Cocosferas dos morfotipos da espécie Umbellosphaera tenuis retratadas pelo MEV. Retirado do web site Nannotax3 (Young et al., 2014) de autoria de Jeremy Young. 16

Figura 17 - Cocosfera de Umbellosphaera irregularis retratada pelo MEV. Retirado do web site Nannotax3 (Young et al., 2014) de autoria de Jeremy Young. 17

Figura 18 - Cocosfera de Umbilicosphaera sibogae retratada pelo MEV. Retirado do web site Nannotax3 (Young et al., 2014) de autoria de Jeremy Young.

Figura 19 - Cocosfera de Umbilicosphaera foliosa retratada pelo MEV. Retirado do web site Nannotax3 (Young et al., 2014) de autoria de Jeremy Young...... 17 Figura 20 - Zonas biogeográficas do Oceano Atlântico baseadas nas assembleias de cocolitoforídeos. Modificado de McIntyre \& Bé (1967). .......... 20

Figura 21 - Área de estudo com as amostras utilizadas neste trabalho (em preto) e as amostras adicionais do estudo de Boeckel et al, (2006) (em vermelho). 24

Figura 22 - Circulação superficial do Atlântico Sul. Modificado de Peterson e Stramma, 1991.

Figura 23 - Perfis da média da temperatura anual no Atlântico Sul a 0m, 50m, $100 \mathrm{~m}$ e $150 \mathrm{~m}$ (Locarini et al. 2013). 29

Figura 24 - Salinidade média anual no Atlântico Sul a 0m, 50m, 100m e 150m (Zweng et al. 2013). 30

Figura 25 - Média anual de Fosfato no Atlântico Sul a 0m, 50m, 100m e 150m (Garcia et al. 2014). 31

Figura 26 - Média anual de nitrato a 0m, 50m, 150m e 200m (Garcia et al. 2014). 32

Figura 27 - Média anual de Silicato a 0m, 50m, 150m e 200m (Garcia et al. 2014). 33

Figura 28 - Profundidade da Camada de Mistura estimada pelo critério de densidade variável. Dados retirados de Monterey e Levitus (1997)................. 34

Figura 29 - Representação dos efeitos de um vórtice na coluna d'água e sua associação as espécies de cocolitoforídeos. Em verde as espécies da zona fótica superior, em azul as do tipo placolito e em vermelho as espécies da zona fótica inferior. Modificado de Jin et al., 2016. 36 
Figura 30-Média anual da Clorofila a ( $\mu \mathrm{g} / \mathrm{l})$ no Atlântico Sul a 0m, 20m, 50m e a 100m (Conkright \& Boyer, 2002).

Figura 31 - Média anual de Produtividade Primária Líquida baseada nos dados do SeaWiFS (Behrenfeld \& Falkoswski, 1997)...

Figura 32 - Índice CEX' calculado na amostras analisadas. Circuladas em vermelho estão as amostras excluídas das análises por apresentarem indícios de dissolução.

Figura 33 - À esquerda porcentagens da espécie $C$. leptoporus em relação à latitude. À direita mapa de distribuição de C. leptoporus ao longo da área de estudo. 53

Figura 34 - À esquerda porcentagens da espécie Calciosolenia spp em relação à latitude. À direita mapa de distribuição de Calciosolenia spp ao longo da área de estudo.

Figura 35 - À esquerda porcentagens da espécie $D$. tubifera em relação à latitude. À direita mapa de distribuição de $D$. tubifera ao longo da área de estudo.

Figura 36 - À esquerda porcentagens da espécie E. huxleyi em relação à latitude. À direita mapa de distribuição de E. huxleyi ao longo da área de estudo. 55

Figura 37 - À esquerda porcentagens da espécie $F$. profunda em relação à latitude. À direita mapa de distribuição de F. profunda ao longo da área de estudo. 56

Figura 38 - À esquerda porcentagens da espécie Gephyrocapsa spp. em relação à latitude. À direita mapa de distribuição de Gephyrocapsa spp. ao longo da área de estudo.

Figura 39 - À esquerda porcentagens da espécie $G$. oceanica em relação à latitude. À direita mapa de distribuição de G. oceanica ao longo da área de estudo.

Figura 40 - À esquerda porcentagens da espécie G. ericsonii em relação à latitude. À direita mapa de distribuição de $G$. ericsonii ao longo da área de estudo. 58

Figura 41 - À esquerda porcentagens da espécie G. flabellatus em relação à latitude. À direita mapa de distribuição de G. flabellatus ao longo da área de estudo. 59

Figura 42 - À esquerda porcentagens da espécie Helicosphaera spp. em relação à latitude. À direita mapa de distribuição de Helicosphaera spp. ao longo da área de estudo. 59

Figura 43 - À esquerda porcentagens da espécie $O$. fragilis em relação à latitude. À direita mapa de distribuição de $O$. fragilis ao longo da área de estudo. 60 
Figura 44 - À esquerda porcentagens da espécie Rhabdosphaera spp. em relação à latitude. À direita mapa de distribuição de Rhabdosphaera spp. ao longo da área de estudo. 61

Figura 45 - À esquerda porcentagens da espécie Syracosphaera spp. em relação à latitude. À direita mapa de distribuição de Syracosphaera spp. ao longo da área de estudo. 61

Figura 46 - À esquerda porcentagens da espécie Umbellosphaera spp. em relação à latitude. À direita mapa de distribuição de Umbellosphaera spp. ao longo da área de estudo. 62

Figura 47 - À esquerda porcentagens da espécie Umbilicosphaera spp. em relação à latitude. À direita mapa de distribuição de Umbilicosphaera spp. ao longo da área de estudo. 63

Figura 48 - À esquerda porcentagens das espécies do grupo Subtropical em relação à latitude. À direita mapa de distribuição do grupo Subtropical ao longo da área de estudo. 63

Figura 49 - Biplot da Análise de Correspondência Canônica com as setas verdes indicando as variaiveis ambientais e os pontos em azul as espécies de cocolitoforídeos. As localizações dos scores das espécies representam a relação entre elas e as variáveis que representam cada eixo, destacadas nas setas nas margens da figura. 81

Figura 50 - Análise de Clusters realizada pelo método da Similaridade determinando 4 grupos entre as espécies de cocolitoforídeos com um grau de Coeficiente de Correlação de 0,707. 83

Figura 51- Mapa demonstrando a separação das amostras pelo critério

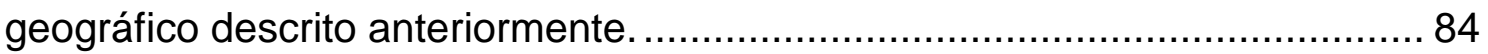

Figura 52 - Coeficiente de correlação 0,80. Utilizando distância euclideana ... 85 Figura 53 - Biplot da Análise por Componentes Principais. Em verde estão os eixos representando cada espécies selecionada para a análise. Os círculos coloridos são as estações, estas que foram separadas na análise de cluster anterior, podemos notar que o padrão foi mantido. 88 


\section{Introdução}

Os oceanos são um dos principais agentes climáticos do planeta Terra, uma vez que são grandes transportadores de calor ao longo de todo o globo, possuindo relação com a circulação e com os processos atmosféricos. Sendo assim estão relacionados a muitos dos processos climáticos atuais, como a precipitação nos continentes, atuando como reservatório de carbono e sendo importante até mesmo na troca de gases com a atmosfera, entre eles o gás carbônico $\left(\mathrm{CO}_{2}\right)$, gás de grande importância nas relações climáticas globais. Deste modo um objetivo central da paleoceanografia é elucidar o papel dos processos oceânicos nas mudanças climáticas e no ambiente global em geral (Wefer et al., 1999).

Estudar as variações dos parâmetros oceanográficos ao longo do tempo é de extrema importância para desenvolver o conhecimento sobre sua influência no clima. Tendo em vista que o oceano é um dos maiores reservatórios de carbono do planeta, ficando atrás apenas das rochas. 0 fitoplâncton marinho utiliza o gás carbônico e a luminosidade da superfície para criar matéria orgânica através da fotossíntese. Uma pequena fração desse carbono orgânico afunda para regiões mais profundas antes de ser integrado na cadeia trófica, retornando para forma inorgânica através da ação de bactérias, aumentando o carbono inorgânico dissolvido nas regiões mais profundas. Este carbono então é armazenado no oceano profundo, sendo o processo que finalmente causa esse armazenamento do carbono denominado de bomba biológica.

Informações essenciais para reconstruir a história dos oceanos estão preservadas nos sedimentos de muitas maneiras, uma dessas dá-se pelo estudo das assembleias de nanofósseis calcários (Wefer et al., 1999), formas fósseis do nanoplâncton calcário, sendo os cocolitoforídeos seus maiores representantes atuais. No Atlântico Sul, assim como em grande parte do mundo, os principais parâmetros oceanográficos foram preservados nas assembleias de cocolitoforídeos presentes no sedimento (Baumann et al. 1999). 
Cocolitoforídeos são microalgas unicelulares pertencentes à divisão Haptophyta que possuem um envoltório inorgânico de calcita ou aragonita, sendo principalmente de calcita, conhecido como cocosfera, esta é formada por uma série de pequenas placas que recebem o nome de cocólitos. Estes organismos unicelulares são um dos maiores componentes do fitoplâncton marinho e o único produtor primário que apresenta uma preservação fóssil geograficamente ampla (Stoll \& Ziveri, 2002). Somado a isso, sua grande abundância em rochas e sedimentos marinhos, bem como sua ampla distribuição geográfica, fazem com que estes fósseis sejam de extrema importância e com grande utilização em estudos bioestratigráficos e paleoceanográficos.

Estes produtores primários unicelulares possuem a capacidade de converter o gás carbônico $\left(\mathrm{CO}_{2}\right)$ dissolvido na água no carbonato de cálcio $\left(\mathrm{CaCO}_{3}\right)$ que compõe seu envoltório, esse processo de mineralização é parte essencial do ciclo do carbono (Steinmetz, 1994). É estimado que eles sejam responsáveis por cerca de metade de toda precipitação moderna de carbonato de cálcio nos oceanos (Milliman, 1993), com isso eles são parte fundamental no ciclo do carbono global. Atuando de forma dobrada no ciclo do carbono, sendo tanto organismos fotossintetizantes quanto conversores de carbono orgânico em carbono inorgânico (Saavedra-Pellitero et. al. 2010).

Os cocolitoforídeos não só afetam o sistema climático por meio das bombas biológica e de carbonato, como também pelas emissões de dimetilsulfeto (DMS). O DMS liberado para a atmosfera é importante para a formação de núcleos de condensação de nuvens (Charlson et al., 1987).

Devido ao rápido transporte dos cocólitos para o fundo via pellets fecais e neve marinha (Honjo, 1976), as informações preservadas no fundo marinho pelas assembleias desses organismos, embora reduzidas por uma destruição seletiva ou dissolução, podem ser relacionadas com as condições atuais na superfície da coluna d'água (Mclntyre \& Bé, 1967; Kinkel et al., 2000). Os cocolitoforídeos respondem as menores variações dos parâmetros ambientais dentro da zona fótica, como disponibilidade de nutrientes, temperatura, salinidade e estabilidade da coluna d'água (Winter et al.,1994), tornando-os ótimos indicadores destes parâmetros em tempos passados, mediante 0 estudo dos cocólitos preservados nos sedimentos marinhos. 
Embora existam muitas informações disponíveis em escala oceânica da distribuição geográfica dos cocolitoforídeos (Young, 1994), tanto em comunidades vivas utilizando amostras de água (McIntyre \& Bé, 1967; Okada \& Honjo, 1973; Nishida, 1979) quanto em amostras superficiais de sedimentos (Okada, 1983; Boeckel et al., 2006; Saavedra-Pellitero et al., 2010), os parâmetros ambientais que controlam esta distribuição ainda são pouco entendidos (Winter et al., 1994; Kinkel et al., 2000). A compreensão da relação entre a biogeografia destes organismos e os parâmetros ambientais nos quais eles são encontrados é crucial para entender suas preferências ambientais.

\section{Objetivos}

O objetivo deste estudo é avaliar os padrões de distribuição das assembleias de cocolitoforídeos em sedimentos marinhos de superfície e estabelecer uma distribuição biogeográfica destes organismos na porção oeste do oceano Atlântico Sul, mais precisamente na margem continental brasileira e comparar esta distribuição com os parâmetros oceanográficos da área de estudo.

Sendo assim, o presente estudo poderá auxiliar em uma maior compreensão de como os parâmetros ambientais controlam ou influenciam a ecologia e biogeografia dos cocolitoforídeos, organismos extremamente importantes nos estudos paleoclimáticos e paleoceanográficos, além de fortalecer o uso de algumas espécies como proxies.

\subsection{Objetivos Específicos}

Os objetivos específicos do presente estudo visam, a partir das amostras de sedimentos de superfície, realizar uma análise quantitativa das assembleias de cocolitoforídeos e responder as seguintes questões:

- Os parâmetros oceanográficos influenciam a distribuição dos cocolitoforídeos?

- Existem correlações entre cada espécie com os parâmetros oceanográficos da região de estudo? 
- É possível estabelecer diferentes províncias a partir das assembleias de cocolitoforídeos?

- Há espécies dominantes em cada província?

- As assembleias de cocolitoforídeos nos sedimentos de superfície refletem os parâmetros oceanográficos das águas sobrejacentes?

\section{Nanofósseis Calcários}

Os nanofósseis calcários são partículas fósseis com tamanhos inferiores a $63 \mu \mathrm{m}$ de diâmetro, excluindo fragmentos e juvenis de fósseis maiores, compostos principalmente de carbonato de cálcio $\left(\mathrm{CaCO}_{3}\right)$ precipitado na maioria das vezes sob a forma de calcita (Siesser \& Winter, 1994). Essas partículas são predominantemente constituídas de produtores primários planctônicos, no entanto podem ocorrer outros tipos de organismos como espículas de ascídias e dinoflagelados calcários.

Os cocolitoforídeos, por sua vez, são os organismos exclusivamente marinhos cobertos por um envoltório inorgânico formado por cocólitos, denominado cocosfera (Figura 1). Estes cocólitos são pequenas placas, geralmente discóides e de carbonato de cálcio podendo ser classificadas estruturalmente em dois grandes grupos, os heterococólitos e os holococólitos (Braruud et.at, 1955). Os heterococólitos possuem os cocólitos formados por unidades cristalinas de formato e tamanho variáveis, com as unidades cristalinas tipicamente dispostas em simetria radial (Braarud et al. 1955). Os holococólitos possuem os cocólitos formados por minúsculos cristais $(<0,1 \mu \mathrm{m})$, sendo todos de mesmo formato e tamanho (Braarud et al. 1955).

Além dos cocólitos podem ocorrer também formas não discóides de formatos variados chamadas de nanólitos, sendo que boa parte das espécies deste grupo estão extintas, dificultando a compreensão das afinidades biológicas necessárias para a definição taxonômica destas espécies (Bown \& Young, 1998).

A função dos cocólitos ainda é questão de debate, no entanto as duas principais hipóteses são as de que estas estruturas funcionam como proteção da membrana celular e contra predadores, além de auxiliarem na flutuabilidade 
dos organismos (Young, 1994). Outras funções sugeridas são as de que os cocólitos podem ser armazenadores de substâncias químicas, reguladores da concentração de luz e a calcificação pode ser também um meio de auxiliar na fotossíntese (Young, 1994).

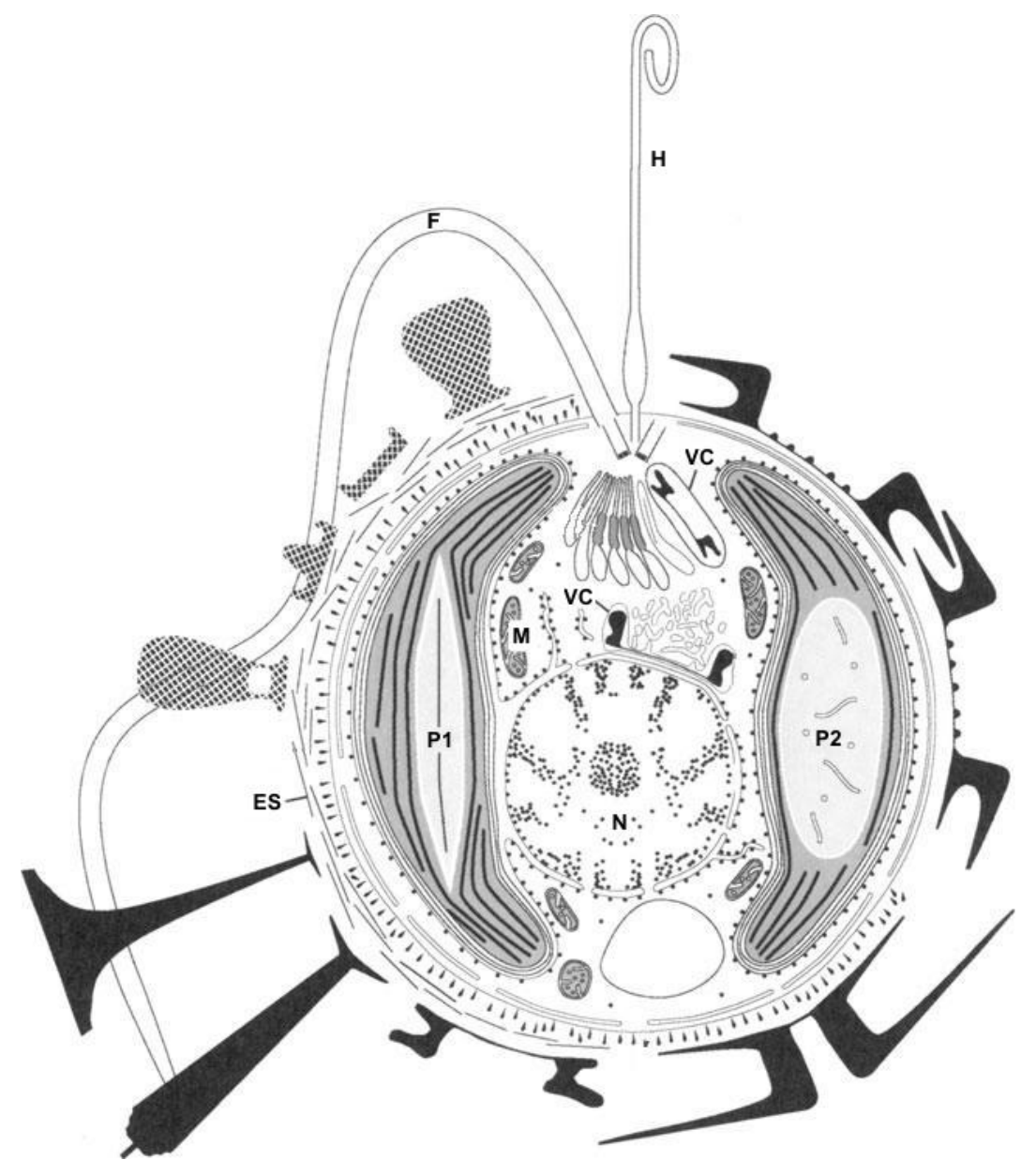

Figura 1 - Estrutura celular de um cocolitoforídeo. A imagem mostra diversas morfologias de cocólitos, sendo os cocólitos gradeados holococólitos e os coloridos em preto heterococólitos. P1 e P2 são dois tipos de pirenóides distintos, sendo, respectivamente, o primeiro típico nos cocolitoforídeos e o segundo nos gêneros Emiliania e Gephyrocapsa. As abreviações significam: ES: escamas orgânicas não mineralizadas, $F$ : flagelo, $H$ : haptonema, $M$ : mitocôndrias, VC: vesícula formadora de cocólitos, N: núcleo. Modificado de Billard \& Inoue, 2004.

Os cocólitos constituem um dos componentes mais importantes dos sedimentos de mar profundo, sendo um dos maiores integrantes das vazas carbonáticas pelágicas, chegando a cobrir aproximadamente metade do assoalho oceânico (Berger, 1976), e promovem importantes sinais da flora, tornando-se biomarcadores para interpretações de mudanças climáticas ao longo do tempo geológico (Kinkel et al., 2000). 
As diferentes espécies dessas nanoalgas possuem diferentes distribuições verticais devido à dependência da estratificação da coluna d'água e da luz. Estes organismos habitam a zona fótica dos oceanos, e a sua distribuição na coluna d'água superior é influenciada pela circulação oceânica superficial e outros parâmetros como temperatura, salinidade e disponibilidade de nutrientes (Kinkel et al., 2000; Boeckel et al., 2006; Saavedra-Pellitero et al., 2010).

Para facilitar a compreensão durante o texto a partir de agora apenas o termo cocolitoforídeo será utilizado, mesmo que em referência a todos os nanofósseis calcários ou a organismos incertae sedis.

\subsection{Classificação Taxonômica}

A divisão Haptophyta, na qual estão inseridos os cocolitoforídeos, é representada por algas unicelulares que possuem as clorofilas "a" e "c" e pigmentos como a fucoxantina. Esta divisão é caracterizada pela presença de um haptonema (Figura 1), uma organela similar a um flagelo, porém diferindo na disposição de seus micro túbulos e na sua utilização para captura de presas e anexo a substratos (de Vargas et al., 2007).

Atualmente existem aproximadamente 200 espécies de cocolitoforídeos morfologicamente definidas (Young et al., 2003), devido a esta diversidade somente as ordens com espécies que são relevantes a este estudo foram relacionadas neste item.

A classificação taxonômica utilizada é apresentada abaixo e seguiu a classificação adotada em Young et al. (2003) e Antunes (2007), utilizando como material de apoio o website Nannotax3 (Young et al.,2014).

Reino CHOROMISTA Cavalier-Smith, 1981

Divisão (Filo) HAPTOPHYTA Hibberd ex Cavalier-Smith, 1986

Classe PRYMNESIOPHYCEAE Hibberd, 1976

Subclasse PRYMNESIOPHYCIDAE Cavalier-Smith, 1986

Ordem ISOCHRYSIDALES (Pascher 1910) 
Família NOELAERHABDACEAE (Jerkovic 1970 emend. Young \& Brown 1997) Gênero/Espécie Emiliana huxleyi (Lohmann 1902) Hay \& Mohler, in Hay et al. 1967

Gephyrocapsaspp. (Kamptner 1943)

Gephyrocapsa oceanica (Kamptner 1943)

Gephyrocapsa muellerae (Bréhéret 1978)

Gephyrocapsa ericsonii (McIntyre \& Bé 1967)

Gephyrocapsa caribbeanica (Boudreaux \& Hay, in Hay et

al. 1967)

Ordem COCCOSPHAERALES (Haeckel 1894 emend. Young \& Bown 1997)

Família COCCOLITHACEAE (Poche 1913 emend.Young \& Bown 1997) Gênero/Espécie Coccolithus pelagicus (Wallich 1877) Schiller 1930

Família CALCIDISCACEAE Young \& Bown 1997

Gênero/Espécie Calcidiscus leptoporus (Murray \& Blackman 1898) Loeblich \& Tappan 1978

Oolithotus fragilis (Lohmann 1912) Martini \& Müller 1972

Umbilicosphaera spp. (Lohmann 1902)

Umbilicosphaera sibogae (Weber-van Bosse 1901) Gaarder 1970

Umbilicosphaera foliosa (Kamptner 1963, ex Kleijne 1993)

Geisen in Sáez et al. (2003).

Ordem ZIGODISCALES (Young \& Bown 1997)

Família HELICOSPHAERACEAE (Black 1971)

Gênero/Espécie Helicosphaera spp. (Kamptner 1954)

Helicosphaera carteri (Wallich 1877) Kamptner 1954

Família PONTOSPHAERACEAE (Lemmerman 1908) 
Ordem SYRACOSPHAERALES (Hay 1977 emend.)

Família SYRACOSPHAERACEAE (Lohmann 1902) Lemmerman 1903

Gênero/Espécie Syracosphaera spp. (Lohmann 1902)

Família CALCIOSOLENIACEAE (Kamptner 1927)

Gênero/Espécie Calciosolenia murrayi (Gran 1912)

Calciosolenia brasiliensis (Lohmann 1919) Young $\mathrm{n}$.

comb.

Família RHABDOSPHAERACEAE (Hackel 1984)

Gênero/Espécie Rhabdosphaera clavigera (Murray \& Blackman 1898)

Discosphaera tubifera (Murray \& Blackman 1898)

Ostenfeld 1900

Incertae sedis (Young et al. 2003)

Família UMBELLOSPHAERACEAE (Paasche in Markali \& Paasche 1955) Gênero/Espécie Umbellosphaera spp. (Paasche in Markali \& Paasche 1955)

Paasche 1955)

Umbellosphaera irregularis (Paasche in Markali \&

Umbellosphaera tenuis (Kamptner 1937) Paasche in

Markali \& Paasche 1955

Nanolito incertae sedis

Gênero/Espécie Florisphaera profunda (Okada \& Honjo 1973)

Gladiolithus flabellatus (Halldal \& Markali 1955) Jordan \&

Chamberlain 1993

\subsection{Principais espécies do oeste do Oceano Atlântico Sul}


Neste tópico será efetuada uma breve descrição sobre cada espécie de cocolitoforídeo e seus eventuais morfotipos, além da descrição de suas preferências ecológicas. As figuras das espécies apresentadas de microscópio eletrônico de varredura (MEV) são pertencentes ao web site Nannotax3 (Young et al., 2014) e de autoria de Jeremy Young.

\section{Calcidiscus leptoporus}

A espécie $C$. leptoporus exibe uma ampla tolerância para diferentes condições ambientais (Boeckel et al. , 2006; Baumann et al., 2016), porém é uma espécie rara em águas subtropicais e equatoriais, sendo mais abundante no lado leste do Atlântico (Boeckel et al., 2006).

Em um estudo realizado por Boeckel et al. (2006) no Atlântico Sul esta espécie foi correlacionada com ambientes eutróficos e obteve uma correlação negativa com temperatura e salinidade, o que a determinou como uma espécie de clima temperado a subpolar. A mesma correlação foi encontrada posteriormente por Baumann et al. (2016).

A espécie era subdividida em três morfotipos bem conhecidos separados pelo tamanho dos cocólitos: pequeno (3-5 um), intermediário (5-8um) e grande (8-10 um). Porém através de estudos genéticos percebeu-se que na verdade se tratavam de três espécies diferentes (Quinn et al., 2004). Com isso as espécies foram separadas em $C$. quadriperforatus (Figura 2), o que se acreditava ser o morfotipo grande (Quinn et al.,2004), enquanto o intermediário é considerado $C$. leptoporus (Figura 2) e o morfotipo pequeno ainda não foi descrito, e portanto é considerado C. leptoporus pequeno (Figura 2).

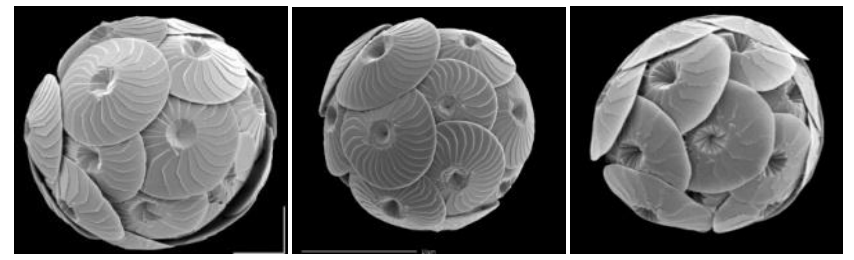

Figura 2 - Cocosferas dos morfotipos da espécie $C$. leptoporus por fotos de MEV. Da esquerda para a direita, $C$. quadriperforatus, $C$. leptoporus e $C$. leptoporus pequeno. Retirado do web site Nannotax3 (Young et al., 2014) de autoria de Jeremy Young.

\section{Calciosolenia spp.}

Sendo composta neste estudo pela associação entre as espécies $C$. brasiliensis e C. murrayi (Figura 3) este gênero esta associado principalmente a 
ambientes quentes e de pouca produtividade, particularmente a áreas costeiras e da plataforma continental (Andruleit \& Rogalla 2002).

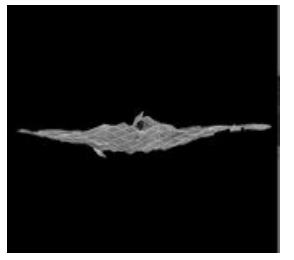

Figura 3 - Cocosfera de Calciosolenia brasiliensis retratada pelo MEV. Retirado do web site Nannotax3 (Young et al., 2014) de autoria de Jeremy Young.

\section{Coccolithus pelagicus}

C. pelagicus (Figura 4) é uma espécie considerada de ambientes frios e com muitos nutrientes (Roth, 1994; Winter et al., 1994, Boeckel et al., 2006). Cachão \& Moita (2000) sugerem que esta espécie está associada a ambientes mais dinâmicos e turbulentos, ou seja, em frentes oceânicas das mais diversas formas, como frentes termais e salinas.

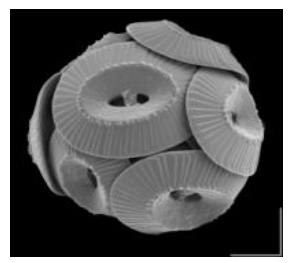

Figura 4 - Cocosfera de Coccolithus pelagicus retratada pelo MEV. Retirado do web site Nannotax3 (Young et al., 2014) de autoria de Jeremy Young.

\section{Discosphaera tubifera}

D. tubifera (Figura 5) é uma espécie considerada K-estrategista, pois sua abundância não aumenta com o aumento da quantidade de nutrientes (Brand, 1994). É considerada de regiões tropicais, pois tolera apenas temperaturas entre $20^{\circ} \mathrm{C}$ e $30^{\circ} \mathrm{C}$, sendo característica dos giros subtropicais oligotróficos.

Sendo assim $D$. tubifera exibe uma relação inversa com os nutrientes e direta em relação à temperatura e salinidade no Atlântico Sul (Boeckel et al., 2006).

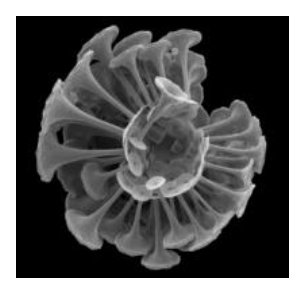

Figura 5 - Cocosfera de Discosphaera tubifera retratada pelo MEV. Retirado do web site Nannotax3 (Young et al., 2014) de autoria de Jeremy Young. 


\section{Emiliania huxleyi}

Espécie mais cosmopolita do oceano atual, estando representada em todas as bacias oceânicas (Mclntyre \& Bé, 1967; Geitznauer et al., 1977; Okada \& Mclntyre, 1979), é uma espécie do tipo placólito (Young, 1994), r estrategista e possui cerca de 4 morfotipos dependendo da calcificação de seus cocólitos (Figura 6).

E. huxleyi é a espécie mais abundante dos oceanos (Winter et al., 1994) e consegue viver em grandes amplitudes de temperatura e salinidade obtendo grandes abundâncias em diversas regiões, como regiões subpolares, nas bordas dos giros subtropicais e regiões de ressurgência (Mclntyre \& Bé, 1967; Brand, 1994; Baumann et al., 2000). No Atlântico Sul é geralmente associada à ambientes ricos em nutrientes e com uma correlação inversa a temperatura e salinidade (Boeckel et al., 2006).
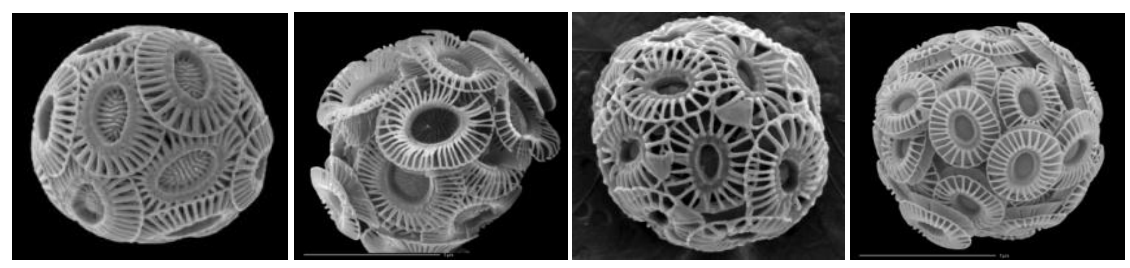

Figura 6 - Cocosferas dos morfotipos da espécie E. huxleyi retratadas pelo MEV. Retirado do web site Nannotax3 (Young et al., 2014) de autoria de Jeremy Young.

\section{Florisphaera profunda}

F. profunda (Figura 7) é uma espécie floriforme que é caracterizada principalmente por viver nas mais altas profundidades da zona fótica, habitando a região abaixo da termoclina em condições nas quais há pouca quantidade de luz (Young, 1994; Winter et al., 1994;), por este e outros fatores é sugerida por Poulton et al. (2017) como uma espécie mixotrófica. Okada \& Honjo (1973) também descrevem esta espécie como restrita a zona fótica inferior, sendo que dentro desta zona é amplamente distribuída ao longo das regiões tropicais e subtropicais.

Por estar em profundidades abaixo da termoclina esta espécie é correlacionada a ambientes mais estratificados, sendo em muitos estudos paleoceanográficos utilizada em índices para estimar a posição relativa da nutriclina ou da termoclina (Molfino \& McIntyre, 1990a; Molfino \& McIntyre, 1990b). Por isso F. profunda também é diretamente utilizada como indicador de 
paleoprodutividade incluindo o índice de Paleoprodutividade de Beaufort et al. (1997) e na razão N proposta por Flores et al. (2000).

No Atlântico Sul recente a abundância relativa de $F$. profunda está relacionada a águas superficiais quentes e estratificadas com uma nutriclina profunda (Boeckel et al., 2006).

Ahagon et al. (1993) relacionam a distribuição de F. profunda com a turbidez da água superficial, com isso esta espécie é correlacionada com ambientes oligotróficos e estratificados, sendo rara ou ausente em ambientes mais turbulentos como zonas costeiras e de ressurgência.

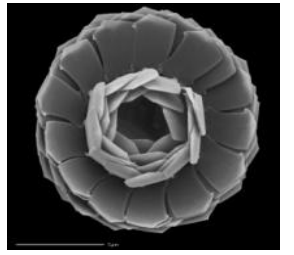

Figura 7 - Cocosfera de Florisphaera profunda retratada pelo MEV. Retirado do web site Nannotax3 (Young et al., 2014) de autoria de Jeremy Young.

\section{Gênero Gephyrocapsa}

As espécies do gênero Gephyrocapsa estão presentes em todas as bacias oceânicas, podendo até mesmo serem espécies dominantes de assembleias, tanto de comunidades vivas quanto fósseis (Roth, 1994; Bollmann, 1997; Geitzenauer, 1977;).

As espécies deste gênero são separadas por diferenças no ângulo da ponte dos cocólitos e por diferenças morfométricas, principalmente da espécie G. oceanica (Bollmann, 1997; Bollmann \& Klaas, 2008). Diversos trabalhos estabelecem diferentes preferências ecológicas para cada espécie ou morfotipo (Boeckel et al., 2006; Hagino et al., 2000; Saavedra-Pellitero et al., 2010).

\section{G. oceanica}

Esta espécie é considerada uma espécie abundante ou dominante tanto em amostras de água quanto de sedimentos de mares marginais, ambientes neríticos e áreas de ressurgência, podendo até ser formadora de florações oceânicas (Brand, 1994).

G. oceanica (Figura 8) possui uma grande tolerância a salinidade, preferindo águas oceânicas menos salinas, porém com alto teor de nutrientes (Bollmann, 1997), sendo assim esta espécie pode ser considerada mais costeira do que E. huxleyi. Boeckel et al. (2006) também observaram uma 
correlação positiva entre G. oceanica e nutrientes, também sugerindo que esta espécie está mais correlacionada a ambientes turbulentos.

Hagino et al. (2000) sugeriram três tipos de G. oceanica no Pacifico, sendo dois tipos mais abundantes em águas com uma grande variedade de níveis de nutrientes, enquanto um tipo seria exclusivo de águas frias e eutróficas. Hagino et al (2000) também sugeriu uma que G. oceanica é abundante na zona fótica superior e comum na zona fótica inferior.

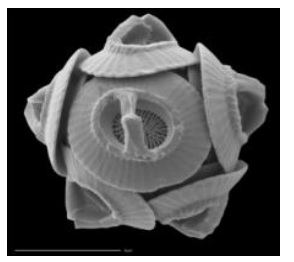

Figura 8 - Cocosfera de Gephyrocapsa oceanica retratada pelo MEV. Retirado do web site Nannotax3 (Young et al., 2014) de autoria de Jeremy Young.

\section{G. ericsonii}

Esta espécie do gênero Gephyrocapsa está presente em regiões de águas quentes dos oceanos temperados e tropicais.

Nos sedimentos superficiais do Atlântico Sul, G. ericsonii (Figura 9) foi correlacionada a ambientes turbulentos e a concentração de nutrientes na água (Boeckel et al., 2006), sendo também correlacionada inversamente a temperatura e salinidade.

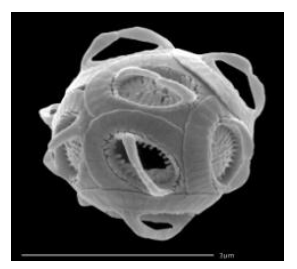

Figura 9 - Cocosfera de Gephyrocapsa ericsonii retratada pelo MEV. Retirado do web site Nannotax3 (Young et al., 2014) de autoria de Jeremy Young.

\section{Gladiolithus flabellatus}

Espécie da nanoflora tropical do Atlântico Sul encontrada em grande número no equador (Boeckel et al., 2006). G. flabellatus (Figura 10) também está presente nos centros dos giros subtropicais oligotróficos na zona fótica inferior, habitando a zona abaixo da termoclina até a base da zona fótica com uma distribuição similar a de F. profunda, porém em profundidades maiores (Poulton et al., 2017). 


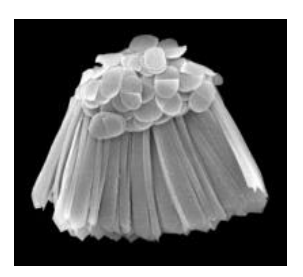

Figura 10 - Cocosfera de Gladiolithus flabellatus retratada pelo MEV. Retirado do web site Nannotax3 (Young et al., 2014) de autoria de Jeremy Young.

\section{Helicosphaera spp.}

Sendo principalmente representado por $H$. carteri (Figura 11) neste estudo, este grupo, segundo Brand (1994), não aumenta em abundância em áreas de ressurgência ou em regiões de altas concentrações de nutrientes no oceano, o que seria um indicador de um extremo K-estrategismo em condições oligotróficas. Okada (1992) destacou o grupo Helicosphaera spp. como uma espécie nerítica.

Por outro lado outros estudos apontam que $H$. carteri seria uma espécie de águas mais frias e eutróficas, devido a sua correlação inversa com a temperatura e salinidade aliada à correlação direta com os nutrientes (Baumann et al., 2000; Boeckel et al., 2006).

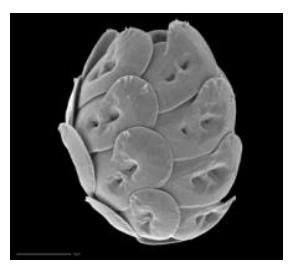

Figura 11 - Cocosfera de Helicosphaera carteri retratada pelo MEV. Retirado do web site Nannotax3 (Young et al., 2014) de autoria de Jeremy Young.

\section{Oolithotus fragilis}

No Atlântico Sul as maiores abundâncias de O. fragilis (Figura 12) em sedimentos superficiais são encontradas na região equatorial, sendo sua principal preferência ecológica relacionada diretamente com a estratificação das águas superiores (Boeckel et al., 2006).

Entretanto no Pacifico Tanaka \& Kawahata (2001) relatam, a partir de amostras de armadilhas de sedimento, um possível aumento nas abundâncias relativas de $O$. fragilis com o aumento da concentração de nutrientes. 


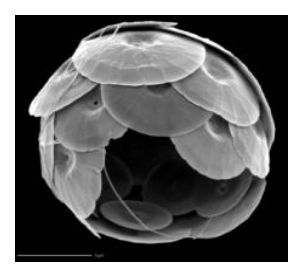

Figura 12 - Cocosfera de Oolithotus fragilis retratada pelo MEV. Retirado do web site Nannotax3 (Young et al., 2014) de autoria de Jeremy Young.

\section{Rhabdosphaera clavigera}

No Atlântico Sul, $R$. clavigera é considerada uma espécie de águas quentes e oligotróficas (Boeckel et al., 2006) e de acordo com Brand (1994) esta espécie cresce mesmo com baixos níveis de nutrientes e não aumenta sua taxa de crescimento como uma resposta ao aumento de nutrientes. Podendo ser subdividida em $R$. clavigera var. clavigera (Figura 13) e $R$. clavigera var. stylifera (Figura 14).

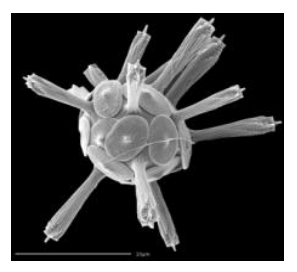

Figura 13 - Cocosfera de Rhabdosphaera clavigera var. clavigera retratada pelo MEV. Retirado do web site Nannotax3 (Young et al., 2014) de autoria de Jeremy Young.

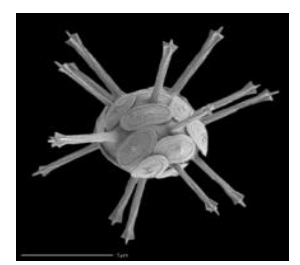

Figura 14 - Cocosfera de Rhabdosphaera clavigera var. stylifera retratada pelo MEV. Retirado do web site Nannotax3 (Young et al., 2014) de autoria de Jeremy Young.

\section{Syracosphaera spp.}

No presente estudo o grupo Syracosphaera spp. é representado principalmente pela espécie Syracosphaera pulchra. Este grupo não possui uma biogeografia muito clara, mas preferencialmente tende a ser mais importante em ambientes intermediários do que em ambientes mais extremos, tanto para regiões eutróficas quanto oligotróficas, demonstrando uma leve tendência a ser uma espécie K-estrategista (Brand, 1994; Young, 1994; Baumann et al., 2005). 
Por outro lado, Syracosphaera spp. (Figura 15) mostra uma distribuição oceânica mais ampla (Boeckel et al., 2006), embora alguns autores (Young, 1994; Andruleit \& Rogalla, 2002) consideram este táxon como um indicador de condições oligotróficas.

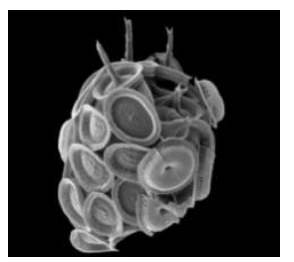

Figura 15 - Cocosfera de Syracosphaera pulchra retratada pelo MEV. Retirado do web site Nannotax3 (Young et al., 2014) de autoria de Jeremy Young.

\section{Umbellosphaera spp.}

O gênero Umbellosphaera spp., juntamente com D. tubifera, $R$. clavigera e Syracosphaera spp., formam o grupo de espécies subtropicais, tendo distribuições ligeiramente similares. No presente estudo as espécies que compõe esse gênero são as espécies $U$. tenuis (Figura 16) e $U$. irregularis (Figura 17), sendo que a primeira possui 5 morfotipos diferentes (Figura 16), podendo ser distintos apenas com a utilização de microscópio eletrônico de varredura.

Segundo Kinkel et al. (2000) este grupo domina as massas de água quentes e oligotróficas do Atlântico Equatorial. Assim como a maioria das espécies subtropicais estas espécies possuem uma correlação inversa com nutrientes e uma relação direta com temperatura e salinidade (Boeckel et al., 2006).

Umbellosphaera tenuis

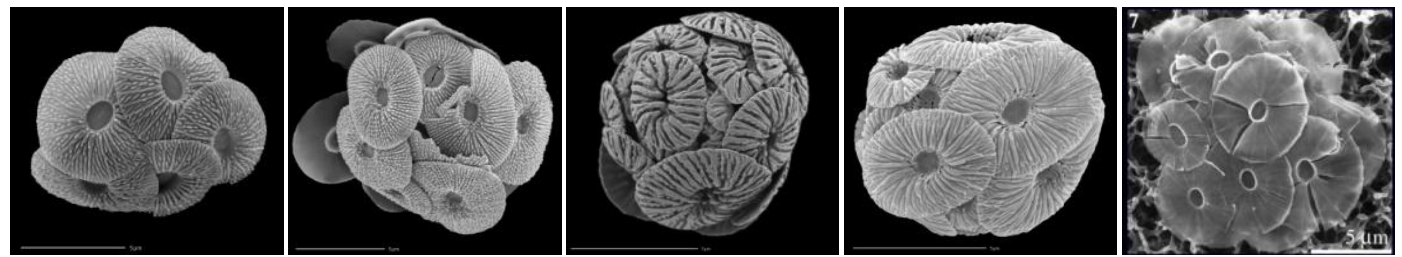

Figura 16 - Cocosferas dos morfotipos da espécie Umbellosphaera tenuis retratadas pelo MEV. Retirado do web site Nannotax3 (Young et al., 2014) de autoria de Jeremy Young.

Umbellosphaera irregularis 


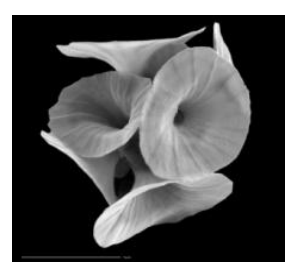

Figura 17 - Cocosfera de Umbellosphaera irregularis retratada pelo MEV. Retirado do web site Nannotax3 (Young et al., 2014) de autoria de Jeremy Young.

\section{Umbilicosphaera spp.}

O gênero Umbilicosphaera spp. neste trabalho é composto principalmente pelas espécies U. sibogae (Figura 18) e U. foliosa (Figura 19), sendo ambas caracterizadas como espécies de águas quentes, tolerando temperaturas entre $20^{\circ} \mathrm{C}$ e $30^{\circ} \mathrm{C}$ (Aizawa et al., 2004), com preferência por regiões com poucos nutrientes (Baumann et al., 2016; Boeckel et al., 2006).

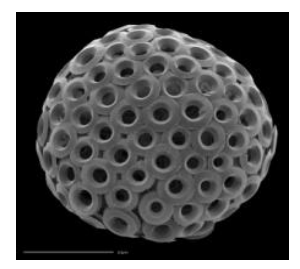

Figura 18 - Cocosfera de Umbilicosphaera sibogae retratada pelo MEV. Retirado do web site Nannotax3 (Young et al., 2014) de autoria de Jeremy Young.

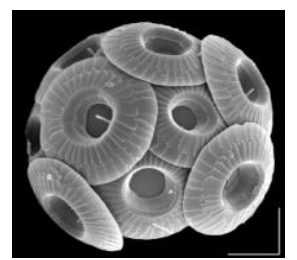

Figura 19 - Cocosfera de Umbilicosphaera foliosa retratada pelo MEV. Retirado do web site Nannotax3 (Young et al., 2014) de autoria de Jeremy Young.

\subsection{Zoneamento Vertical}

Os cocolitoforídeos são capazes de exercer sua motilidade através de dois flagelos e com seu comportamento fototático (Mjaaland, 1956) eles podem manter distribuições verticais distintas, presumidamente para ótimas combinações de intensidade luminosa e conteúdo de nutrientes (Brand 1994).

De acordo com Winter et al. (1994), as espécies se distribuem seguindo uma estratificação vertical da coluna d'água, em função da distribuição de luz. Estas zonas estão mais definidas nas águas subtropicais e na Zona Tropical (Tabela1). 
Tabela 1 - Zonas fóticas subtropicais. Modificado de Winter et al. 1994

Zona Fótica Superior $(0-80 \mathrm{~m})$

Holococolitoforídeos

Rhabdosphaera clavigera

Discosphaera tubifera

Neosphaera coccolithomorpha

Umbellosphaera spp.

Acanthoica quatrospina

Ceratolithus cristatus

Zona Fótica Média - Transição (80-120m)

Umbellosphaera tenuis

Syracosphaera spp.

Gephyrocapsa spp.

Emiliania huxleyi

Calcidiscus leptoporus

Zona fótica Inferior (120-220m)

Florispahaera profunda

Thoracosphaera flabellata

Hayater perplexus

Algirosphaera quadricornu

Turrilithus latericioides

Syracosphaera anthos.

Espécies sem preferência por profundidades

A maioria das espécies do tipo placólito

Helicosphaera spp

Syracosphaera spp

Baumann et al. (2008) realizando um transecto leste-oeste no Atlântico Sul subtropical com base em cocolitoforídeos caracterizaram a zona fótica em duas assembleias, a zona fótica superior e a zona fótica inferior e concluíram que a distribuição vertical da maioria dos cocolitoforídeos nesta região, exceto pelas espécies do tipo placólito que se distribuem ao longo de toda a coluna fótica, é controlada pela temperatura da camada fótica superior e pela estratificação da água, sendo a ultima provavelmente relacionada a presença de nutrientes. Segundo estes autores, a assembléia da zona fótica superior pode ser reconhecida até aproximadamente $80 \mathrm{~m}$, podendo chegar a um máximo de $100 \mathrm{~m}$ de profundidade. Os membros característicos desse grupo são Syracosphaerales, as Rhabdosphaeraceae, Umbellosphaeroidae e todos os holococolitoforídeos observados. A zona fótica inferior na região oeste do Atlântico Subtropical é representada principalmente pelas espécies Florisphaera profunda, Oolithotus fragilis e Umbilicosphaera sibogae. 
Poulton et al. (2017) analisaram a estrutura vertical dos cocolitoforídeos em relação a disponibilidade de luz e nutrientes ao longo de um transecto norte-sul no oceano Atlântico. No Atlântico equatorial e subtropical três grupos distintos foram observados com base na irradiação solar na superfície, sendo o primeiro o da zona eufótica superior, na qual a irradiação solar é maior do que $10 \%$, em relação à superficial, o segundo da zona eufótica inferior, com irradiação solar entre $10 \%$ e $1 \%$, e o terceiro da zona sub-eufótica com irradiação solar menor do que $1 \%$. Os autores denominaram a zona mais profunda de "sub-eufótica" pelo fato dela ser delimitada pelo máximo de clorofila profunda, ou seja, estar abaixo desta medida que delimita a zona eufótica.

O grupo da zona eufótica superior é caracterizado pelas espécies Umbellosphaera irregularis, Umbellosphaera tenuis, Syracosphaera pulchra, Discosphaera tubifera.

Por sua vez, a zona eufótica inferior é caracterizada pelas espécies que geralmente são mais abundantes nas regiões temperadas e de alta latitude, como Calciosolenia brasiliensis,Ceratolithus spp., Emiliania huxleyi, Gephyrocapsa ericsonii, Gephyrocapsa oceanica, Helicosphaera spp. e Umbilicosphaera spp.

Segundo Poulton et al. (2017), a zona sub-eufótica é a zona na qual a luz solar é considerada o limitante para a fotossíntese e não os nutrientes, o que seria um indicativo de que a maioria, se não todas, as espécies da zona sub-eufótica seriam mixotróficas ou fagotróficas. As espécies mais representativas desta zona são Florisphaera profunda e Gladiolithus flabellatus, sendo que G.flabellatus costuma ocorrer em maiores profundidades comparando-se com F. profunda.

\subsection{Distribuição Geográfica}

Mesmo que existam espécies de cocolitoforídeos em ambientes costeiros e estuarinos, a maioria vive hoje em águas quentes, estratificadas e com poucos nutrientes no oceano aberto (Brand, 1994). A maioria das espécies dos cocolitoforídeos é cosmopolita, porém algumas espécies apresentam 
padrões de distribuição com maiores ou menores limitações latitudinais (Kinkel et al. 2000).

O primeiro trabalho em larga escala para determinar a biogeografia dos cocolitoforídeos no oceano Atlântico foi conduzido por Mclntyre \& Bé (1967), utilizando amostras superficiais de água. Estes autores separam o Atlântico em 4 biozonas diferentes, sendo elas: transicional ou temperada, subtropical, tropical e subártica-subantártica (Figura 20). O mesmo estudo comparou seus resultados com a distribuição dos cocolitoforídeos em amostras de sedimento superficial, observando as mesmas biozonas, tanto nas amostras de água, quanto nas amostras de sedimento.

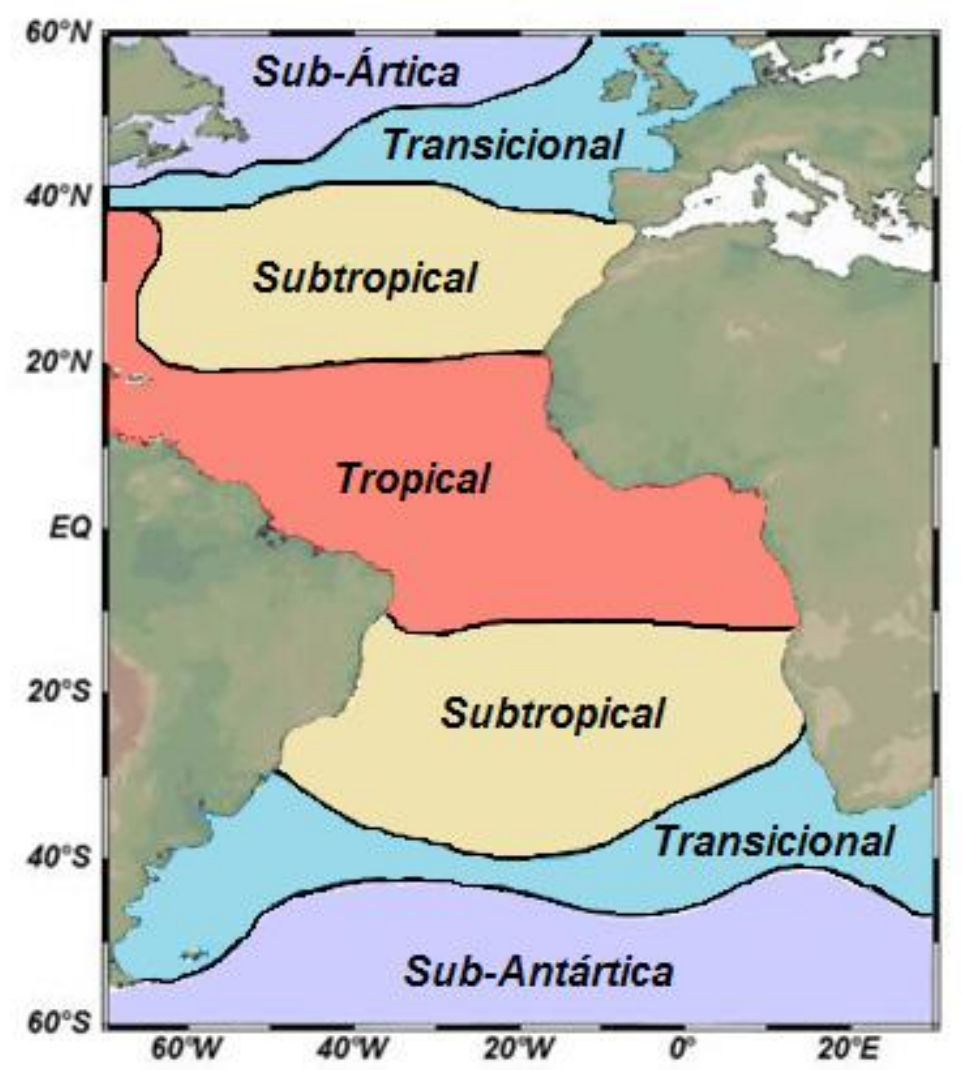

Figura 20 - Zonas biogeográficas do Oceano Atlântico baseadas nas assembleias de cocolitoforídeos. Modificado de Mclntyre \& Bé (1967).

Segundo Winter et al. (1994), as espécies podem ser divididas em cinco biozonas latitudinais, levando em consideração o controle da temperatura sobre esses organismos, sendo elas: subártica, transicional ou temperada, subtropical, tropical e sub-antártica. Os limites destas zonas foram determinados com base no estudo realizado por Mclntyre \& Bé (1967). Essas 
zonas foram interpretadas como sendo produto do movimento das principais massas de água no oceano. Portanto, os limites entre elas não são estáticos eles estão continuamente em movimento (Winter et al., 1994) e com isso, a biogeografia de espécies individuais muda ao longo do tempo devido a mudanças nos parâmetros ambientais (Brand, 1994).

Por sua vez, Young (1994) separou os cocolitoforídeos em três grupos gerais, descritos a seguir, definidos por critérios morfológicos e ecológicos similares ao zoneamento vertical proposto por Winter et al. (1994).

O primeiro foi definido como o grupo de espécies características de ambientes eutróficos. Estes ambientes em águas equatoriais, altas latitudes, assim como áreas de ressurgência, são dominados por espécies de tipo placolito. As espécies dentro deste grupo são chamadas de r-estrategistas, ou seja, elas respondem ao aumento de nutrientes com um aumento nas taxas de crescimento ou produtividade. Neste grupo estão incluídas predominantemente as espécies formadoras de blooms, com Emiliania huxleyi e Gephyrocapsa spp sendo as espécies dominantes.

O segundo, caracterizado por espécies que são adaptadas a zonas com baixo conteúdo de nutrientes, é dominado pelas espécies umbeliformes. Estas espécies são chamadas de K-estrategistas e foram relacionadas às águas superficiais de latitudes subtropicais, especialmente nos giros oceânicos oligotróficos. As espécies dominantes neste grupo são Umbilicosphaera spp., Umbellosphaera spp. e Rhabdosphaera spp.

O terceiro grupo é o das espécies floriformes. As assembleias de zonas fóticas profundas, em baixas e médias latitudes, são dominadas por este grupo. A ausência destes organismos em águas superficiais sugere que eles vivem abaixo da camada de mistura, onde o ambiente é caracterizado não só pela baixa intensidade luminosa, como também pela elevada quantidade de nutrientes. A espécie Florisphaera profunda é a principal representante deste grupo. Além disso, existem também as espécies miscelanaceas, que não têm um padrão de distribuição simples, entretanto algumas assembleias são dominadas por este grupo. As espécies características deste grupo são Helicosphaera spp., Calcidiscus leptoporus, Pontosphaera spp., Braarudosphaera spp. 
Diversos trabalhos sobre a biogeografia dos cocolitoforídeos foram realizados com enfoque para o Atlântico Norte (Geitzenauer et al., 1977;Okada \& McIntyre, 1979), para o leste do Atlântico Sul (Giraudeau,, 1992; Boeckel \& Baumann 2004) ou em larga escala considerando o Atlântico Sul como um todo (McIntyre \& Bé, 1967; Ziveri et al., 2004; Boeckel et al., 2006).

Kinkel et al. (2000) estudaram as assembleias de cocolitoforídeos em sedimentos superficiais no Atlântico equatorial, e com suas observações perceberam que estas assembleias refletem os parâmetros oceanográficos do padrão de circulação na camada de mistura superior, pois as assembleias se correlacionaram bem com a distribuição e composição das comunidades de cocolitoforídeos vivos nestas massas d'água. Além disso, um maior número de cocólitos, bem como maiores abundâncias de Emiliania huxleyi foram encontrados sob a área influenciada pela ressurgência equatorial.

Boeckel \& Baumann (2004) analisaram a distribuição de cocólitos em sedimentos superficiais no sudeste do oceano Atlântico Sul, encontrando quatro grupos de organismos delineados pelo seu conteúdo de cocólitos, caracterizando as regiões da Corrente de Benguela em porção norte e porção sul, Cordilheira de Walvis e água profunda. Para distinguir estas regiões, Boeckel \& Baumann (2004) realizaram uma análise estatística multivariada baseada em técnicas de agrupamento foi aplicada nas abundâncias relativas de Emiliania huxleyi, Calcidiscus leptoporus, Gephyrocapsa spp., Coccolithus pelagicus e espécies subtropicais a tropicais. Com isso, os autores relatam que a distribuição dos cocólitos parece ser controlada pela temperatura e pelo conteúdo de nutrientes.

Boeckel et al. (2006), analisando sedimentos superficiais do Atlântico Sul e do Oceano Antártico com relação as assembleias de cocolitoforídeos e aos parâmetros ambientais das águas superficiais sobrepostas, determinaram os padrões de abundância das principais espécies e suas afinidades ecológicas. Os autores observaram que Emiliania huxleyi é a espécie mais abundante das assembleias de cocolitoforídeos da região de estudo. No entanto, os táxons da zona fótica inferior, compostos por Florisphaera profunda e Gladiolithus flabellatus, dominam frequentemente as assembleias entre $20^{\circ} \mathrm{N}$ e $30^{\circ} \mathrm{S}$. Com base nas abundâncias relativas de $C$. leptoporus, F. profunda, G. flabellatus, Helicosphaera spp., U. foliosa, U. sibogae e um grupo de espécies 
subtropicais. Estes autores identificaram seis diferentes grupos de assembleias nos sedimentos de superfície, os quais refletem a distribuição e as características das águas superficiais sobrejacentes. Suas distribuições parecem ser principalmente função da posição relativa da nutriclina e da termoclina na zona fótica.

Mesmo que as assembleias de cocolitoforídeos possam ser modificadas por destruição seletiva ou dissolução e demonstrem uma imagem distorcida das comunidades vivas (Baumann et al., 1999), o conhecimentos sobre sua distribuição nos sedimentos de superfície é um pré-requisito para estudos paleoecológicos e paleoceanográficos de sedimentos quaternários (Baumann et al., 2000; Kinkel et al., 2000; Boeckel et al., 2006, Saavedra-Pellitero et al., 2010).

No estudo realizado por Kinkel et al. (2000), comparando as assembleias obtidas em amostras superficiais com amostras de plâncton, obtidas através de coletas de água nos primeiros $200 \mathrm{~m}$ de coluna d'água, embora tenha sido observada a degradação das espécies Umbellosphaera tenuis e Umbellosphaera irregularis, as mesmas características observadas nas amostras de água permaneceram visíveis nos sedimentos de superfície amostrados.

\section{4. Área de Estudo}

Para determinar as abundâncias das principais espécies de cocolitoforídeos, 44 amostras de sedimentos de superfície, localizados na Margem Continental Brasileira foram analisadas. Adicionalmente, foram inclusas neste trabalho o resultado das análises de 33 amostras do estudo realizado por Boeckel et al. (2006). Deste modo, as amostras se distribuem geograficamente entre aproximadamente $58^{\circ} \mathrm{W}$ e $22^{\circ} \mathrm{W}$ e $40^{\circ} \mathrm{S}$ e $5^{\circ} \mathrm{N}$ (Figura 21).

As amostras analisadas foram subamostradas tanto de topos de testemunhos coletados a pistão quanto de amostras superficiais de box-corer. Para ambos os tipos de coleta foram realizadas análises cronológicas para 
determinar se as amostras são recentes, ou seja, se elas possuem representatividade do oceano atual.

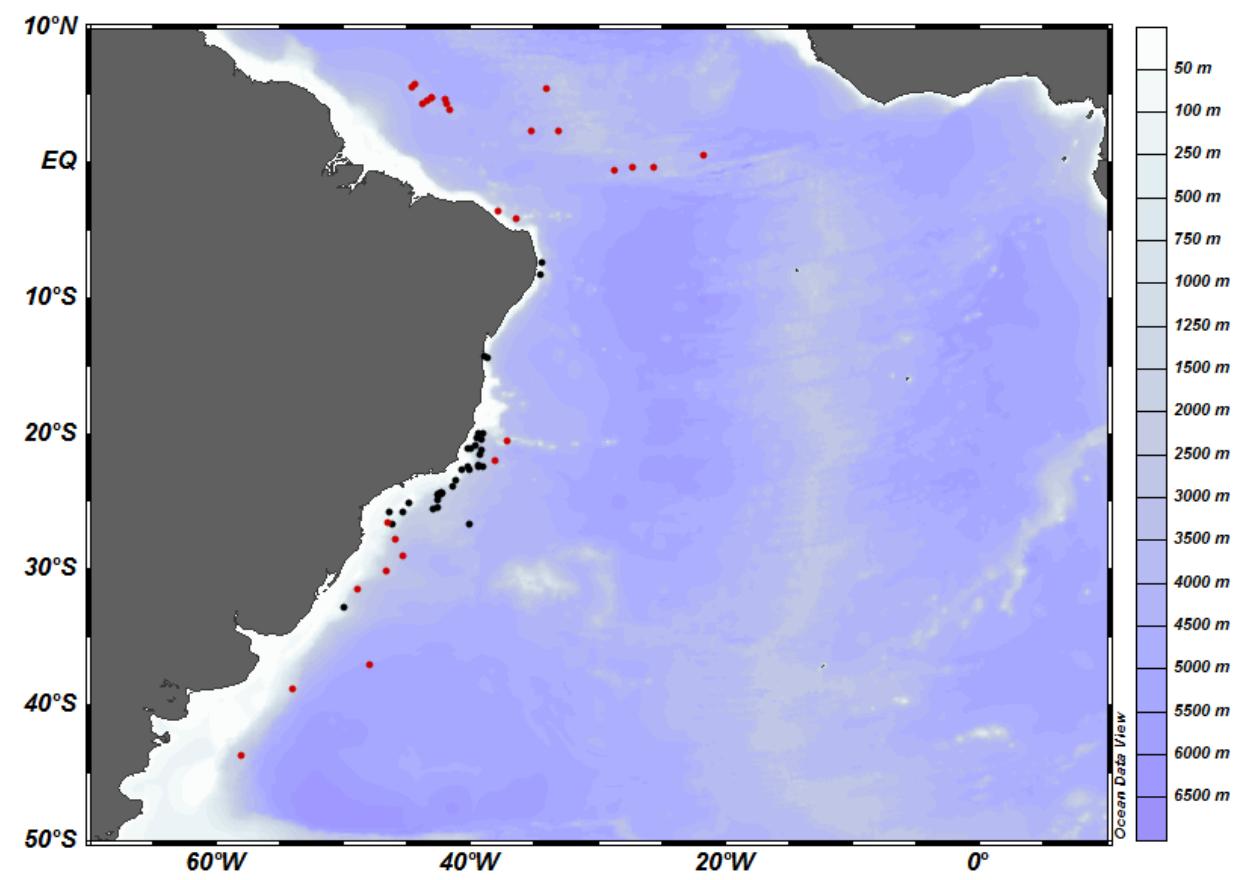

Figura 21 - Área de estudo com as amostras utilizadas neste trabalho (em preto) e as amostras adicionais do estudo de Boeckel et al, (2006) (em vermelho).

\subsection{Fisiografia}

A Margem Continental Brasileira é uma margem continental passiva dividida em três regiões, sendo elas: a Equatorial, Leste e a Sul.

O Atlântico Equatorial Oeste possui plataforma, talude e sopé continentais bem desenvolvidos. A continuidade do talude e do sopé é quebrada ao largo do rio Amazonas pelo cone do rio que é um enorme leque de mar profundo que avança mar adentro, por até $700 \mathrm{~km}$. O talude continental é recortado por numerosos e pouco espaçados cânions submarinos com profundidades de até $1000 \mathrm{~m}$. (Damuth \& Palma, 1979).

A região oceânica Leste, ao contrário do observado nas outras duas regiões, possui a plataforma continental caracterizada por uma largura reduzida, sendo o valor médio de $32 \mathrm{~km}$ eliminado o vulcanismo dos Abrolhos, e linha de quebra da plataforma rasa, predominantemente na isóbata de $60 \mathrm{~m}$, já o talude continental apresenta larguras praticamente uniformes por toda a área, com valores próximos aos $100 \mathrm{~km}$, sendo os valores mínimos 
encontrados nas faixas adjacentes as maiores larguras da plataforma dos Abrolhos (França, 1979).

A margem continental Sul brasileira está compreendida entre a Cadeia Vitória-Trindade e o limite geográfico com o Uruguai. Foi descrita por Zembruski (1979) como uma margem de tipo deposicional, sendo constituída de amplas províncias morfológicas de formas e formatos suavizados, declives minimizados, e com todos os compartimentos clássicos bem desenvolvidos, plataforma, talude e sopé continentais.

Adjacentes à margem Sul situam-se duas bacias oceânicas, a do Brasil e a da Argentina. A primeira constituída em grande parte por colinas abissais, em parte por grandes elevações oceânicas, em grande parte pela Elevação de Rio Grande, enquanto a segunda se adentra pela região Sul através de uma ponta da planície abissal de mesmo nome (Zembruski, 1979).

\subsection{Circulação Oceânica}

A circulação superficial do Atlântico Sul, controlada pelo vento, é dominada por um Giro Subtropical anticiclônico (Figura 22) que está sob a influencia de um sistema semi permanente de alta pressão atmosférica (Peterson \& Stramma, 1991).

O giro subtropical promove a troca de águas entre os oceanos Índico e Atlântico através da retroflexão/vazamento da Corrente das Agulhas transportando principalmente as águas mais quentes e salinas do Oceano Indico para o Atlântico através de vórtices.

Estas águas são então transportadas pela Corrente de Benguela $(\mathrm{CBe})$, corrente de borda leste do giro subtropical do Atlântico, que flui inicialmente para norte até aproximadamente $30^{\circ} \mathrm{S}$ onde passa a ir para noroeste, e é alimentada pela Corrente do Atlântico Sul (CAS). A CBe está associada a grande área de ressurgência costeira de águas frias e ricas em nutrientes na borda leste do Atlântico Sul, sendo a ressurgência causada pelos ventos que sopram de sul e sudeste nesta região.

A CBe então abastece a Corrente Sul Equatorial (CSE) que flui para oeste e possui dois ramos separados pela Contra-Corrente Sul Equatorial que flui no sentido oposto. O ramo norte da CSE está entre $2^{\circ}$ e $4^{\circ} \mathrm{S}$ e possui altas 
velocidades, enquanto o ramo sul chega a América do Sul em aproximadamente $10^{\circ} \mathrm{S}$ e bifurca-se em duas correntes que contornam a área de estudo. Portanto a região de estudo encontra-se banhada em superfície por duas principais correntes, a Corrente do Brasil (CB) e a Corrente Norte do Brasil (CNB) (Silveira et al., 2000). Após a bifurcação a maior parte das águas vindas da CSE flui para norte, através da CNB, enquanto uma a menor parte, a CB, flui para sul (Stramma et al.,1990).

A CB é a corrente de contorno oeste associada ao giro subtropical e origina-se ao sul de $10^{\circ} \mathrm{S}$, na região onde o ramo mais ao sul da Corrente Sul Equatorial (CSE) se bifurca formando também a CNB (Peterson \& Stramma, 1991; Silveira et al., 1994)., bordejando o continente sul-americano até a região da Convergência Subtropical (33-38 $\mathrm{S})$, onde conflui com a Corrente das Malvinas e se separa da costa (Silveira et al. 2000).

$A$ região da $\mathrm{CB}$ é formada pelo empilhamento das massas de água características do Atlântico Sul. Nos primeiros três quilômetros de coluna d'água encontram-se a Água Tropical (AT), Água Central do Atlântico Sul (ACAS), Água Intermediária Antártica (AIA), Água Circumpolar Superior (ACS) e Água Profunda do Atlântico Norte (APAN) (Silveira et al., 2000).

Meandramentos de mesoescala ciclônicos de larga amplitude são freqüentemente observados na região sudeste da costa brasileira, especialmente nas regiões de latitudes entre $20^{\circ} \mathrm{S}$ e $23^{\circ} \mathrm{S}$ (Calado et al., 2006), influenciando os processos oceanográficos. Estes vórtices de mesoescala podem se deslocar na direção do equador (Arruda et al., 2013). Soutelino et al. (2011) também sugerem que ao norte de $20^{\circ} \mathrm{S}$ a CB seja dominada por essas variabilidades de mesoescala, porem com maior domínio dos vórtices anticlônicos desprendidos do ramo sul da CSE.

A CNB flui em direção ao hemisfério norte e atravessa o Equador transportando águas da região tropical para este hemisfério. Ao norte do Equador parte dessas águas abandona a CNB e fluem para o interior da bacia oceânica, alimentando um sistema zonal de contracorrentes (Urbano et al., 2008).

A CNB desempenha duas funções importantes no oceano Atlântico. A primeira é fechar o Giro Equatorial, que é forçado pelo vento e limitado ao sul pela CSE e ao norte pela Corrente Norte Equatorial (CNE) e a segunda é 
propiciar um canal para o transporte das águas do Oceano Atlântico Sul para o norte, através do Equador, como parte da Célula de Revolvimento Meridional do Oceano Atlântico (Patti, 2001).

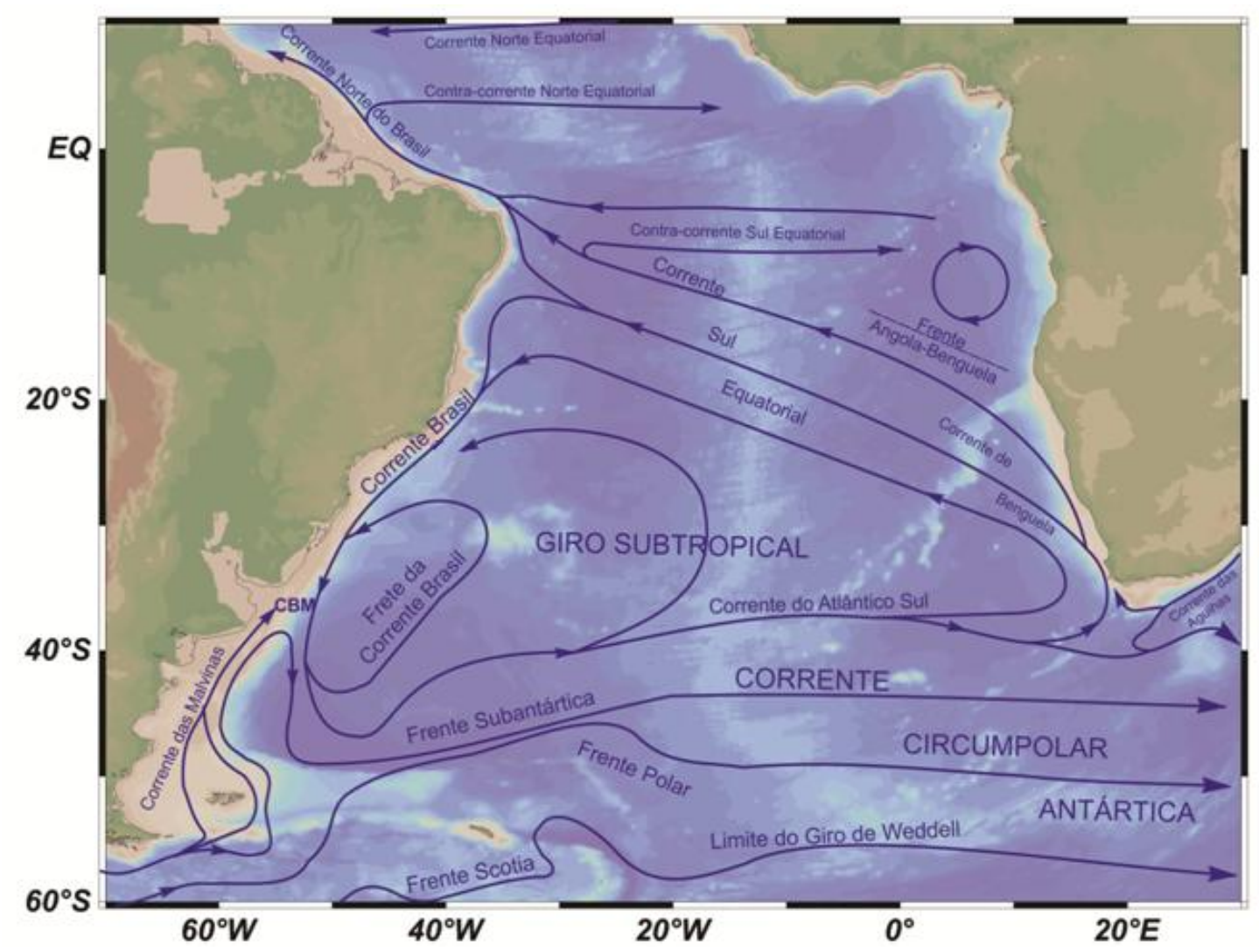

Figura 22 - Circulação superficial do Atlântico Sul. Modificado de Peterson e Stramma, 1991.

Na parte superior do oceano da região de estudo duas massas d'água se destacam. Em superfície a Água Tropical (AT), observada com temperaturas acima dos $20^{\circ} \mathrm{C}$ e salinidade acima dos $36 \mathrm{psu}$, é formada nas regiões tropicais devido à intensa radiação solar e ao típico excesso da precipitação em relação à evaporação na região do equador. Esta massa de água está presente como a camada de mistura superficial no Atlântico Tropical.

$\mathrm{Na}$ região de sub superfície nos trópicos e subtrópicos, no topo da termoclina, está presente a Água Central do Atlântico Sul (ACAS), observada com temperaturas entre 20 e $6^{\circ} \mathrm{C}$ e salinidades entre 36 e 34,6 psu, é formada pela subducção de águas na região da confluência entre a Corrente do Brasil (CB) e a Corrente das Malvinas. Na CNB essa massa de água pode ter origem diferente, ela pode ser reconhecida como uma água central vinda do oceano Índico Tropical via Corrente das Agulhas (Stramma \& England, 1999). 
$\mathrm{Na}$ camada profunda temos duas principais massas de água, a Água Profunda do Atlântico Norte (APAN) e a Água de Fundo Antártica (AFA). A APAN na região sudeste da margem brasileira é caracterizada por valores de temperatura entre $3^{\circ} \mathrm{C}$ e $4^{\circ} \mathrm{C}$ e salinidades entre 34,6 e 35 psu, ocorrendo majoritariamente nas profundidades entre $1500 \mathrm{~m}$ e $3000 \mathrm{~m}$ (Silveira et al., 2000)

\subsection{Características Oceanográficas}

Todos os dados desta sessão são do World Ocean Atlas 2013 (WOA13), com a exceção dos dados de clorofila "a", que são do World Ocean Atlas 2001 (WOA01). O World Ocean Atlas (WOA) é um conjunto de campos climatológicos analisados objetivamente, com dados de diversos parâmetros oceanográficos ao longo da coluna d'água. Os dados do WOA são obtidos nas profundidades padrão e em períodos distintos, com médias anuais, sazonais ou mensais. Como os cocolitoforídeos habitam apenas os primeiros metros da coluna de água, os parâmetros oceanográficos são apresentados apenas nas profundidades de 0,50,100 e 150m. Como a intenção deste estudo é comparar os parâmetros oceanográficos com amostras de sedimentos de topo, os valores apresentados são das médias anuais destes parâmetros.

O conjunto de dados oceanográficos pode ser analisado em grades de $1^{\circ}$ ou $5^{\circ}$. As figuras apresentadas nesta sessão estão em grades de $1^{\circ}$ para obter um detalhamento maior da área de estudo. O software Ocean Data View (Schlitzer, 2017) versão 4.7.10 foi utilizado para gerar os mapas nestas especificações.

Para as posteriores análises de correlação entre os parâmetros oceanográficos e as assembleias de cocolitoforídeos, os valores dos parâmetros foram interpolados para a localização das amostras. Os dados foram obtidos em superfície e em uma média dos primeiros $150 \mathrm{~m}$ de profundidade.

O software Matlab X foi utilizado para realizar a interpolação dos dados. No software foi utilizada a função griddata com a configuração 'cubic' que permite a interpolação pelo método da spline cúbica, quando isso não era possível pela falta de pontos próximos a amostra analisada, geralmente nas 
estações mais costeiras, a configuração 'nearest' foi utilizada, pois ela permite a interpolação pelo método da vizinhança.

\subsubsection{Temperatura}

De acordo com a Figura 23, elaborada com os dados do WOA13, a média anual da temperatura da superfície do mar (SST) no oceano Atlântico Sul tem os maiores valores na região do equador, com temperaturas por volta de $30^{\circ} \mathrm{C}$, e vai diminuindo na direção de maiores latitudes.
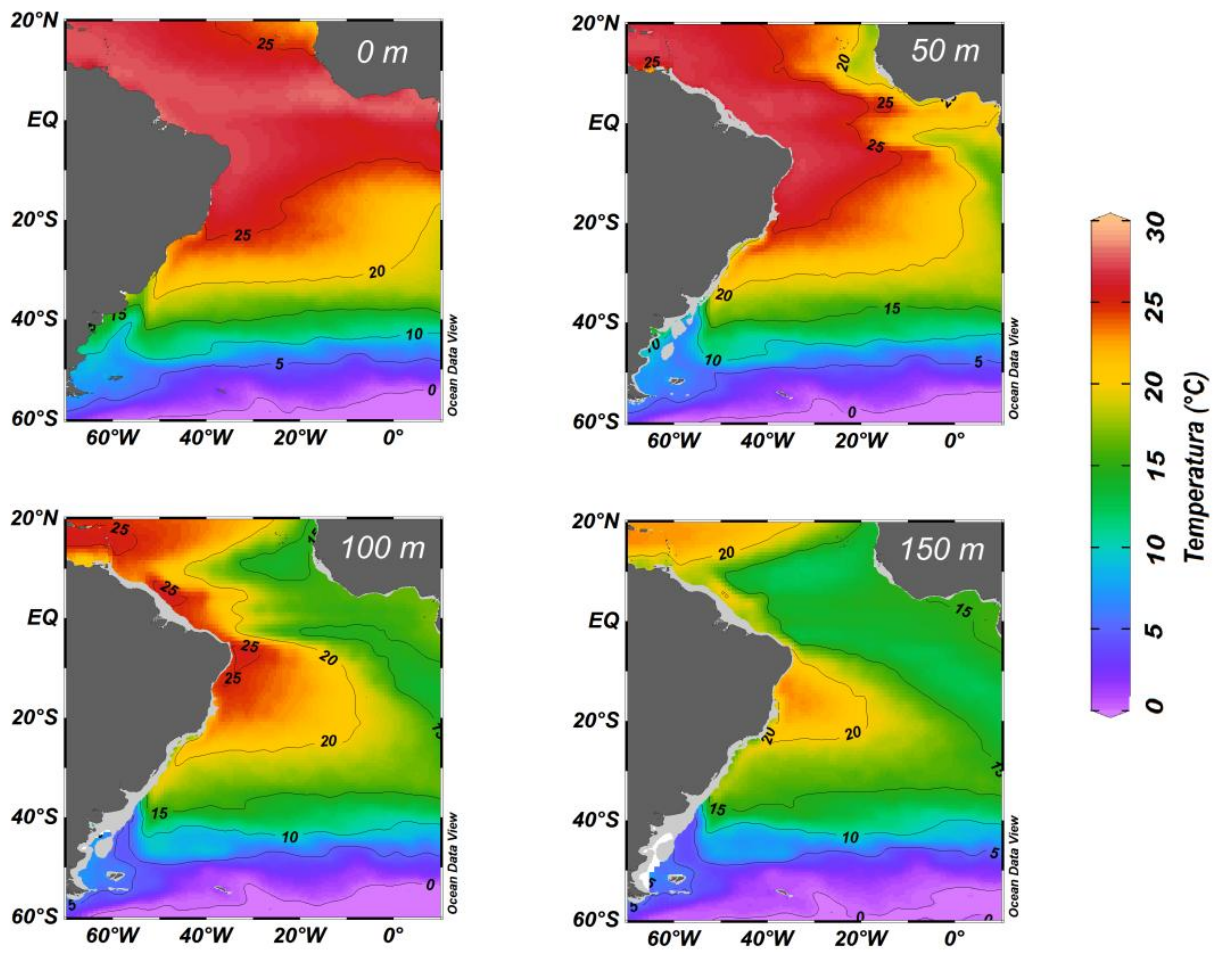

Figura 23 - Perfis da média da temperatura anual no Atlântico Sul a 0m, 50m, 100m e 150m (Locarini et al. 2013).

A temperatura também decresce de acordo com a profundidade. Nas maiores profundidades já podemos notar um perfil de temperatura bem distinto em relação ao observado na superfície. Podemos também identificar menores temperaturas e uma termoclina mais rasa na borda leste do oceano Atlântico, devido principalmente aos processos de ressurgência e circulação superficial ocorrendo na margem africana.

A temperatura, além de ser dependente da radiação solar, também é função da hidrografia (Figura 21). O giro subtropical é mais destacado nas 
imagens das maiores profundidades, nas quais podemos observar as águas mais frias vindas da costa africana chegando ao oeste do Atlântico próximo a $10^{\circ} \mathrm{S}$.

\subsubsection{Salinidade}

Os menores valores de salinidade encontrados no oeste do Atlântico Sul estão nas plumas provenientes dos rios Amazonas e da Prata (Figura 24).

A região equatorial apresenta menores valores de salinidade na superfície se comparada com a região do giro subtropical, este no qual estão localizados os maiores valores de salinidade, por volta de 38 unidades de salinidade. No oeste do oceano podemos perceber uma zona de maiores salinidades decorrentes do giro subtropical. Observa-se também o transporte destas maiores salinidades para sul pela $\mathrm{CB}$, fazendo com que a salinidade na quebra da plataforma desta região tenha altos valores de salinidade.

A salinidade diminui conforme a profundidade aumenta, somente na profundidade de $200 \mathrm{~m}$ podemos observar um padrão de salinidade distinto, em relação ao padrão observado na superfície.
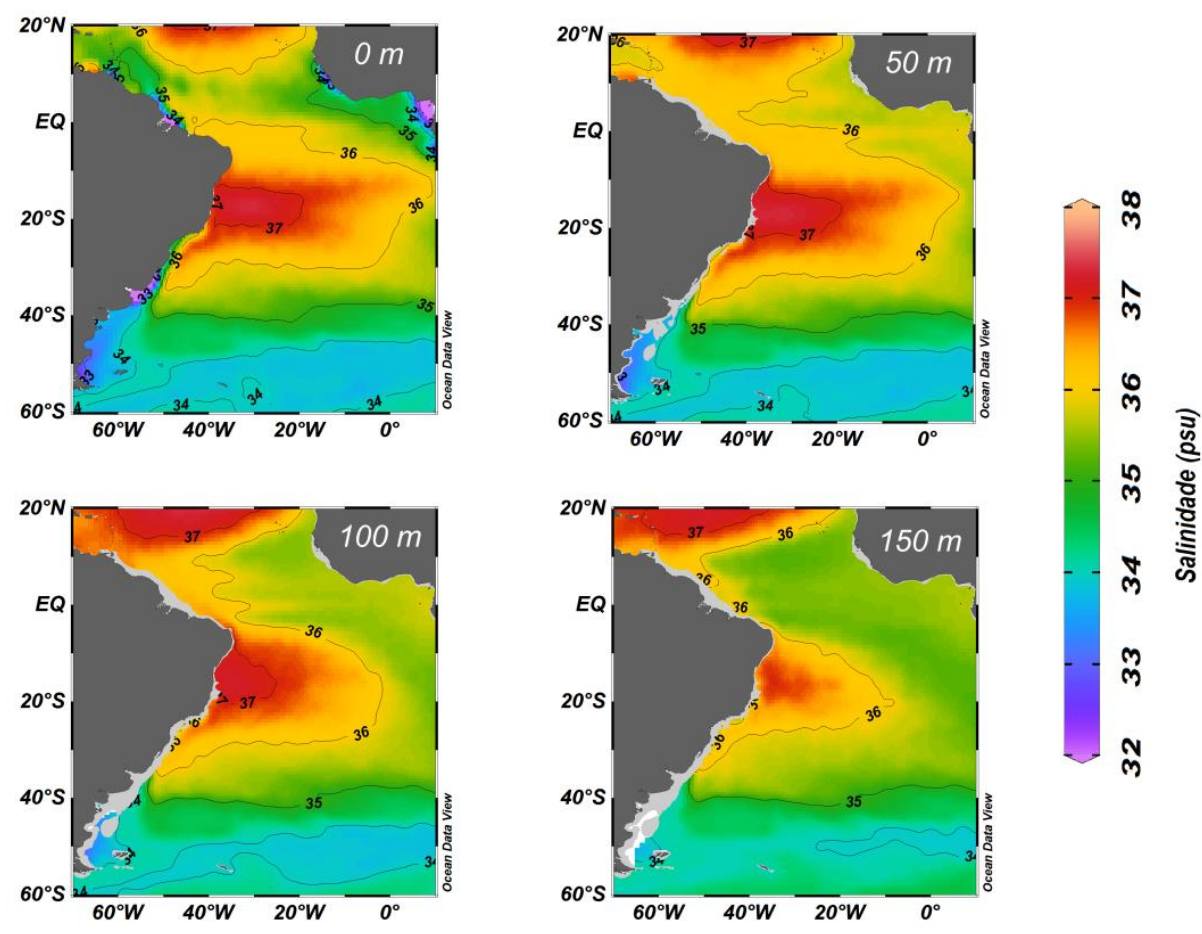

Figura 24 - Salinidade média anual no Atlântico Sul a 0m, 50m, 100m e 150m (Zweng et al. 2013). 


\subsubsection{Nutrientes}

Nas águas de oceano aberto do Atlântico Equatorial e Subtropical a luz não é um fator limitante para a produção primária. Em razão de sua posição latitudinal, as regiões recebem uma grande quantidade de luz. Sendo assim, os nutrientes são o principal fator limitante para a produção na área de estudo.

Os nutrientes são elementos essenciais para a vida do fitoplâncton marinho, sendo capazes de limitar o crescimento e a reprodução destes seres, bem como as taxas de fotossíntese. Os principais nutrientes inorgânicos no ambiente marinho são o nitrogênio e o fósforo, sendo o silício também um importante nutriente. Eles são encontrados nos oceanos geralmente na forma de nitrato, fosfato e silicato.

Segundo os dados de Garcia et al. (2006) da região equatorial até a região subtropical o Atlântico Sul é uma região oligotrófica (Figura 25, Figura 26 e Figura 27) para qualquer um dos nutrientes. É possível notar também os giros subtropicais oligotróficos em todas as distribuições.
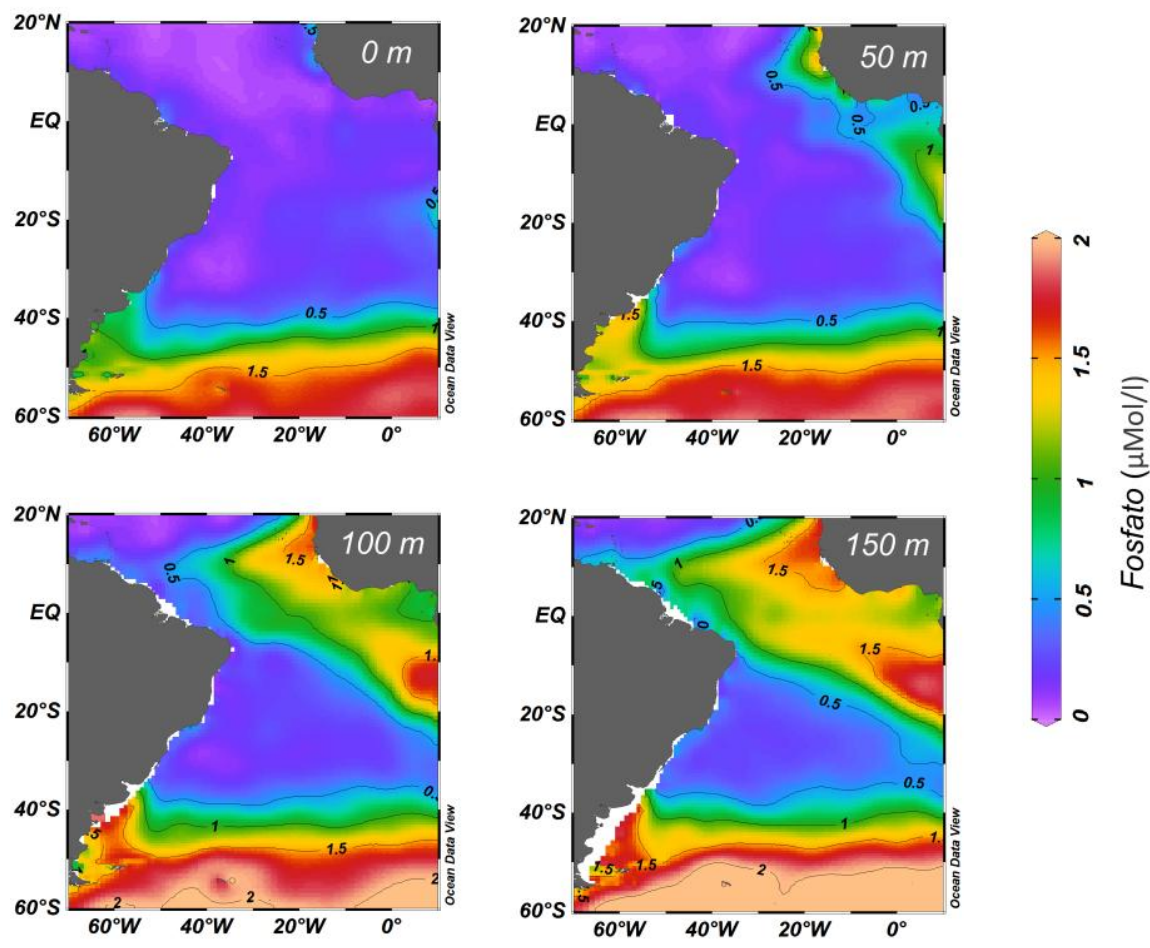

Figura 25 - Média anual de Fosfato no Atlântico Sul a 0m, 50m, 100m e 150m (Garcia et al. 2014). 
Os perfis de nutrientes se modificam conforme a profundidade da coluna de água aumenta, nas camadas mais profundas encontram-se águas mais frias e ricas em nutrientes, sendo mais clara a influência da hidrografia na distribuição destes nutrientes.

A região leste do Atlântico Sul possui uma maior quantidade de nutrientes devido à ressurgência costeira que ocorre no sul do continente Africano e é transportada pela CBe para norte e nordeste, podendo encontrarse com a área do Giro de Angola e juntas levarem nutrientes até o equador em sub-superfície.

Os dados de silicato no Atlântico Sul estão ligados principalmente a presença da costa dos continentes e do aporte fluvial que leva este nutriente para os oceanos.
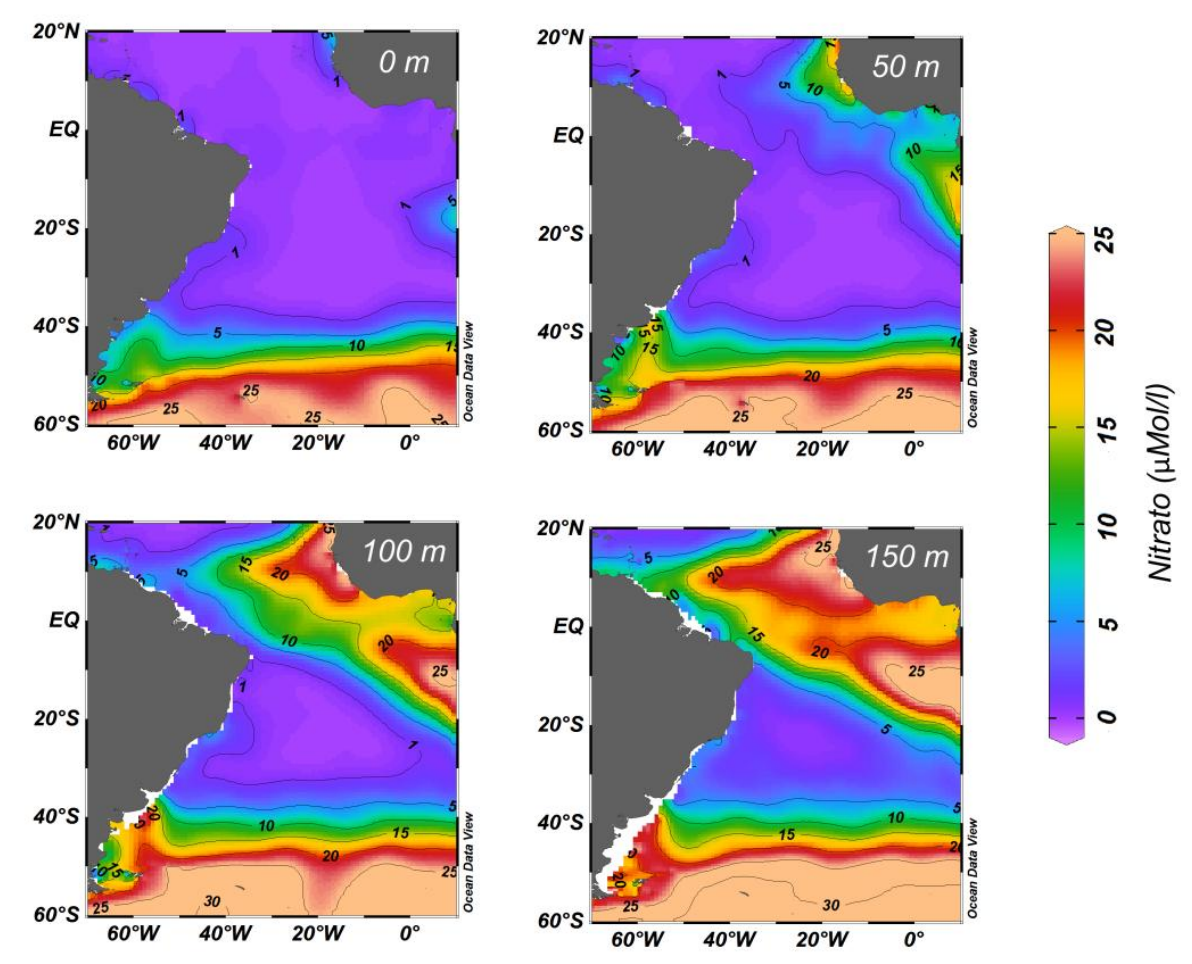

Figura 26 - Média anual de nitrato a 0m, 50m, 150m e 200m (Garcia et al. 2014).

$\mathrm{Na}$ região leste da área de estudo, estes nutrientes assim como os outros, é proveniente da área de ressurgência. Porém na parte oeste, os rios têm uma importante influência, principalmente o rio da Prata, que enriquece de nutrientes a região sudeste da América do Sul, podendo impactar áreas próximas a costa até aproximadamente $20^{\circ} \mathrm{S}$. Já na região noroeste do 
continente, o rio Amazonas exerce influência, porém de forma mais local e apenas em superfície (Figura 27).
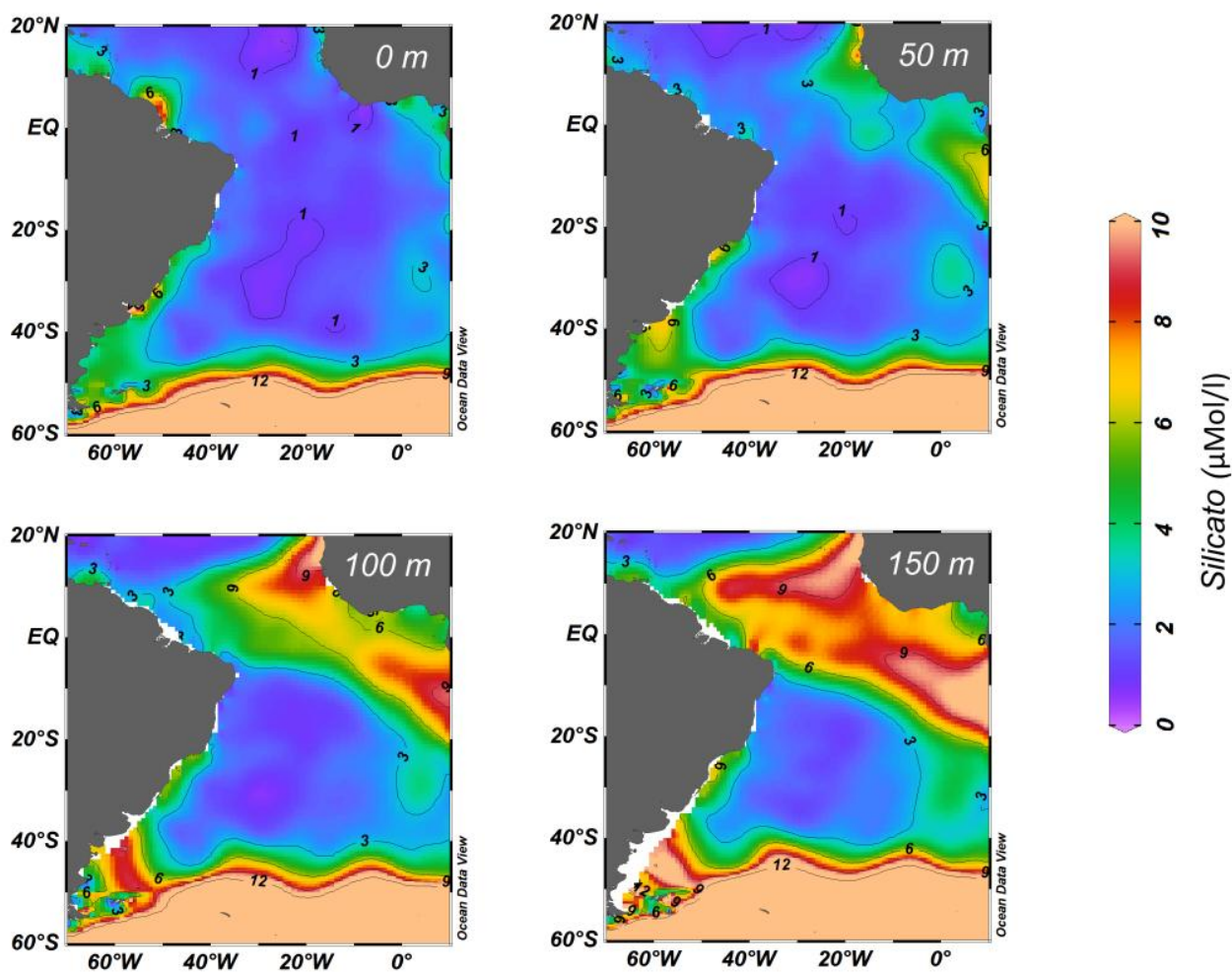

Figura 27 - Média anual de Silicato a 0m, 50m, 150m e 200m (Garcia et al. 2014).

\subsubsection{Camada de Mistura}

Camada de Mistura é a parte superficial do oceano na qual ocorre intensa mistura turbulenta devido à ação dos ventos, das ondas e da circulação convectiva. Portanto, é nessa região que ocorre a troca de calor entre oceano e atmosfera. Devido à mistura ocorrida nesta camada, a temperatura é praticamente igual ao longo de todo o seu perfil vertical.

A Camada de Mistura é definida hidrograficamente como a região na qual a diferença da temperatura ou da densidade é menor do que uma quantidade limite pré-determinada. No presente estudo, o critério utilizado para determinar a Camada de Mistura foi o de uma mudança de densidade variável da superfície do oceano correspondente a uma mudança de temperatura de $0,5^{\circ} \mathrm{C}$ (Levitus, 1982). A Camada de Mistura baseada no critério da densidade 
variável foi desenvolvida para levar em conta a grande variabilidade do coeficiente de expansão térmica que caracteriza a água do mar.

As superfícies de Camada de Mistura demonstradas neste estudo (Figura 28) foram calculadas por Monterey e Levitus (1997) a partir de perfis climatológicos de médias anuais de temperatura e densidade potenciais. Os dados utilizados neste estudo foram de médias anuais utilizando uma grade de $1^{\circ} \times 1^{\circ}$.

De acordo com a Figura 28 podemos observar maiores espessuras das camadas de mistura na porção central do giro subtropical. Na margem oeste do oceano observamos a presença da $\mathrm{CB}$ e menores espessuras das camadas de mistura entre a $\mathrm{CB}$ e a costa, provavelmente devido a processos costeiros e de mesoescala que ocorrem nesta região (Calado et al, 2006). Podemos notar também menores espessuras das camadas de mistura na região de desembocadura do rio Amazonas, bem como seu transporte para norte pela CNB.

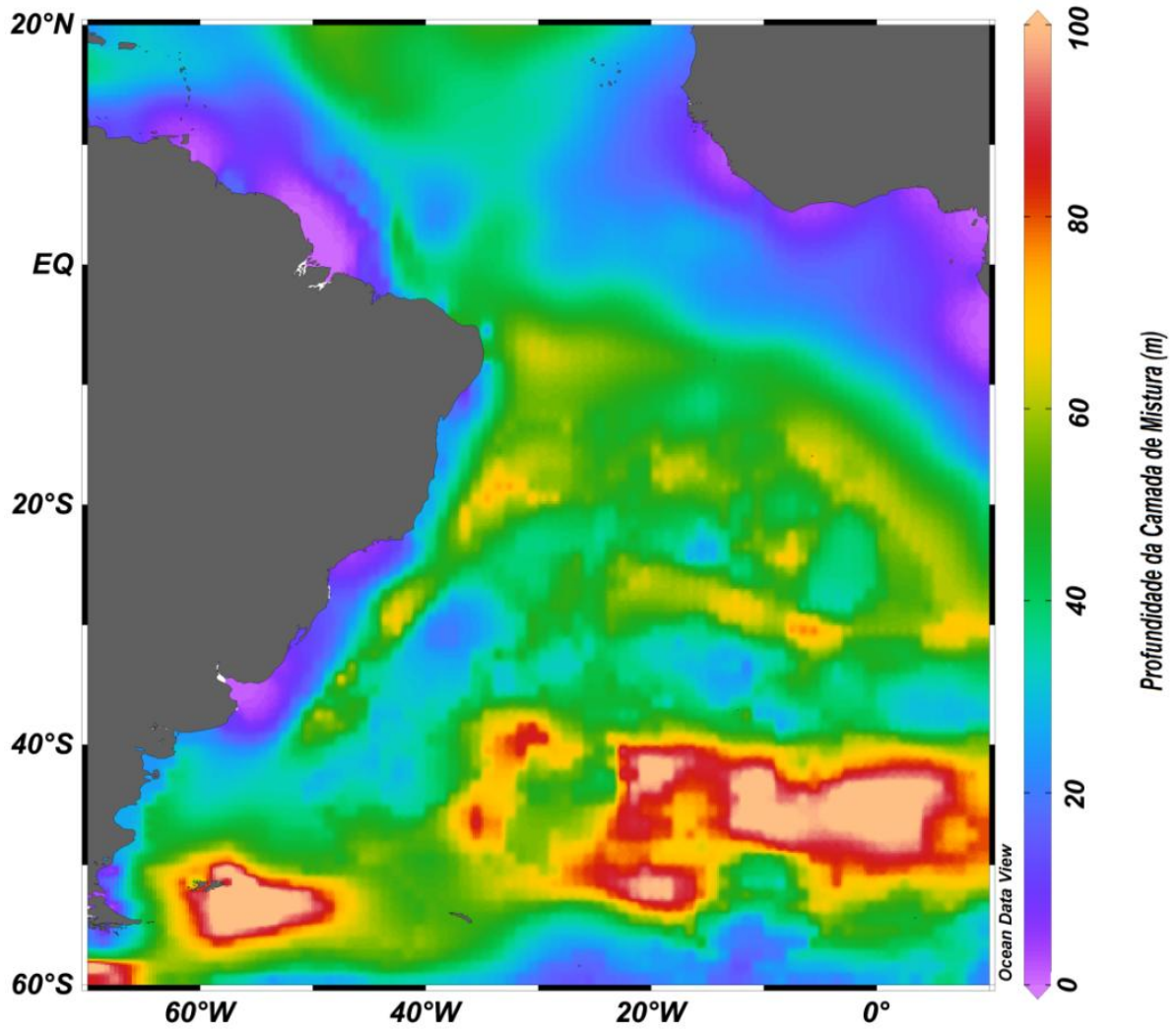

Figura 28 - Profundidade da Camada de Mistura estimada pelo critério de densidade variável. Dados retirados de Monterey e Levitus (1997). 
Como a base da Camada de Mistura é limitada por uma zona na qual a densidade aumenta muito em poucos metros (picnoclina), a Camada de Mistura é de grande importância para a distribuição do fitoplâncton. Isto porque, em altas latitudes, onde há uma grande quantidade de nutrientes e a luz é um fator limitante, é a profundidade da Camada de Mistura, geralmente profunda, que irá definir quanto tempo os produtores primários ficam na camada fótica, assim limitando a produção. No caso dos trópicos e subtrópicos, há uma grande quantidade de radiação solar, porém os nutrientes, localizados nas águas mais profundas abaixo da termoclina, são os limitantes da produção primária. Quando a profundidade da Camada de Mistura é baixa, esses nutrientes adentram a zona fótica, fazendo com que a produção aumente, ou seja, na área de estudo, quanto menor a profundidade da Camada de Mistura mais eficientemente os organismos fitoplanctônicos recebem e assimilam esses nutrientes.

Vórtices de mesoescala também podem modificar a estrutura da coluna de água. Dependendo do seu sentido de rotação eles podem gerar convergência ou divergência em seus núcleos, sendo os vórtices anticiclônicos responsáveis pela convergência e os ciclônicos pela divergência. Com isso, os vórtices ciclônicos promovem uma diminuição da profundidade da Camada de Mistura e também da profundidade da nutriclina, enquanto os anticiclônicos promovem o movimento inverso, causando um aprofundamento da profundidade da Camada de Mistura e da nutriclina (Jin et al., 2016; McGillicuddy, 2016). Portanto, os vórtices ciclônicos criam ambientes ligeiramente mais eutróficos, enquanto os anticiclônicos ambientes mais oligotróficos, sendo assim favorecendo espécies diferentes de cocolitoforídeos (Figura 29), separados principalmente pelas diferentes zonações verticais (Jin et al.,2016). 


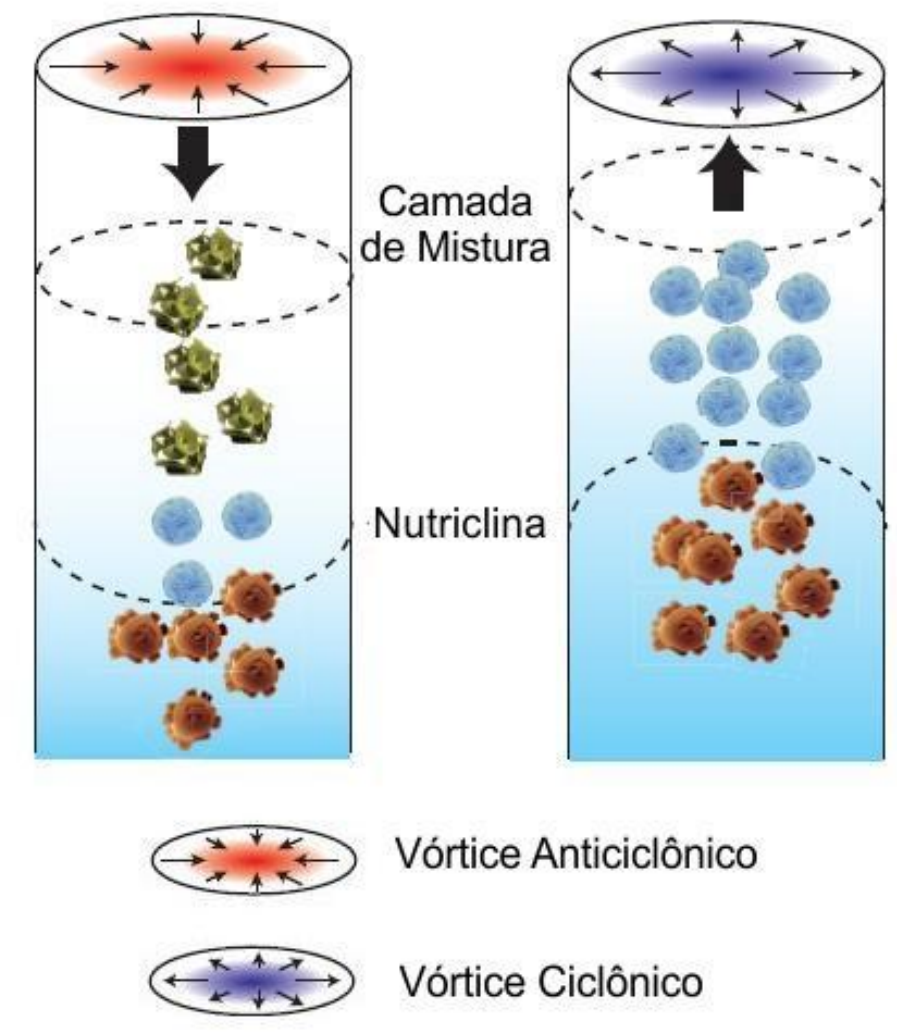

Figura 29 - Representação dos efeitos de um vórtice na coluna d'água e sua associação as espécies de cocolitoforídeos. Em verde as espécies da zona fótica superior, em azul as do tipo placolito e em vermelho as espécies da zona fótica inferior. Modificado de Jin et al., 2016.

\subsubsection{Produtividade Primária}

O fitoplâncton marinho utiliza a energia solar para converter matéria inorgânica, os nutrientes, em matéria orgânica, sustentando a vida marinha, portanto a produtividade primária é diretamente função da disponibilidade de nutrientes e da presença de luz, ou seja, a produtividade é função dos parâmetros descritos acima.

Produção primária consiste na fixação de carbono através da atividade biológica. Produtividade primária, portanto seria a taxa de fixação de carbono durante certo período de tempo. Diversos organismos são responsáveis por esta produção, como cianobactérias, o microfitobentos, as macroalgas, as plantas vasculares e o fitoplâncton, sendo o ultimo o principal contribuinte para a produtividade marinha (Lourenço \& Marques-Junior; 2002).

A produtividade primária pode ser dividida também em Produtividade Primária Bruta e Produtividade Primária Líquida (NPP), sendo a primeira calculada pela quantidade de matéria orgânica produzida em um ecossistema e 
a segunda sendo a produção primária bruta menos a matéria orgânica perdida pela respiração. A Produtividade Primária Líquida utilizada neste estudo é calculada pelo sensor SeaWiFS e os dados utilizados neste estudo são do banco de dados disponibilizado por Behrenfeld \& Falkowski (1997).

Para obter uma estimativa da produtividade primária do oceano Atlântico utilizamos dados de concentração de Clorofila "a" (Conkright \& Boyer, 2002), pois este é o principal pigmento associado a todos os produtores primários marinhos e a quantificação de sua biomassa, (Figura 30) e também os dados de NPP de Behrenfeld \& Falkowski (1997) que utilizam um Modelo de Profundidade Genericamente Vertical (VGPM) no qual a NPP é função da clorofila, da disponibilidade de luz e da eficiência fotossintética em uma determinada produndidade, a qual no caso é a zona eufótica (Figura 31).
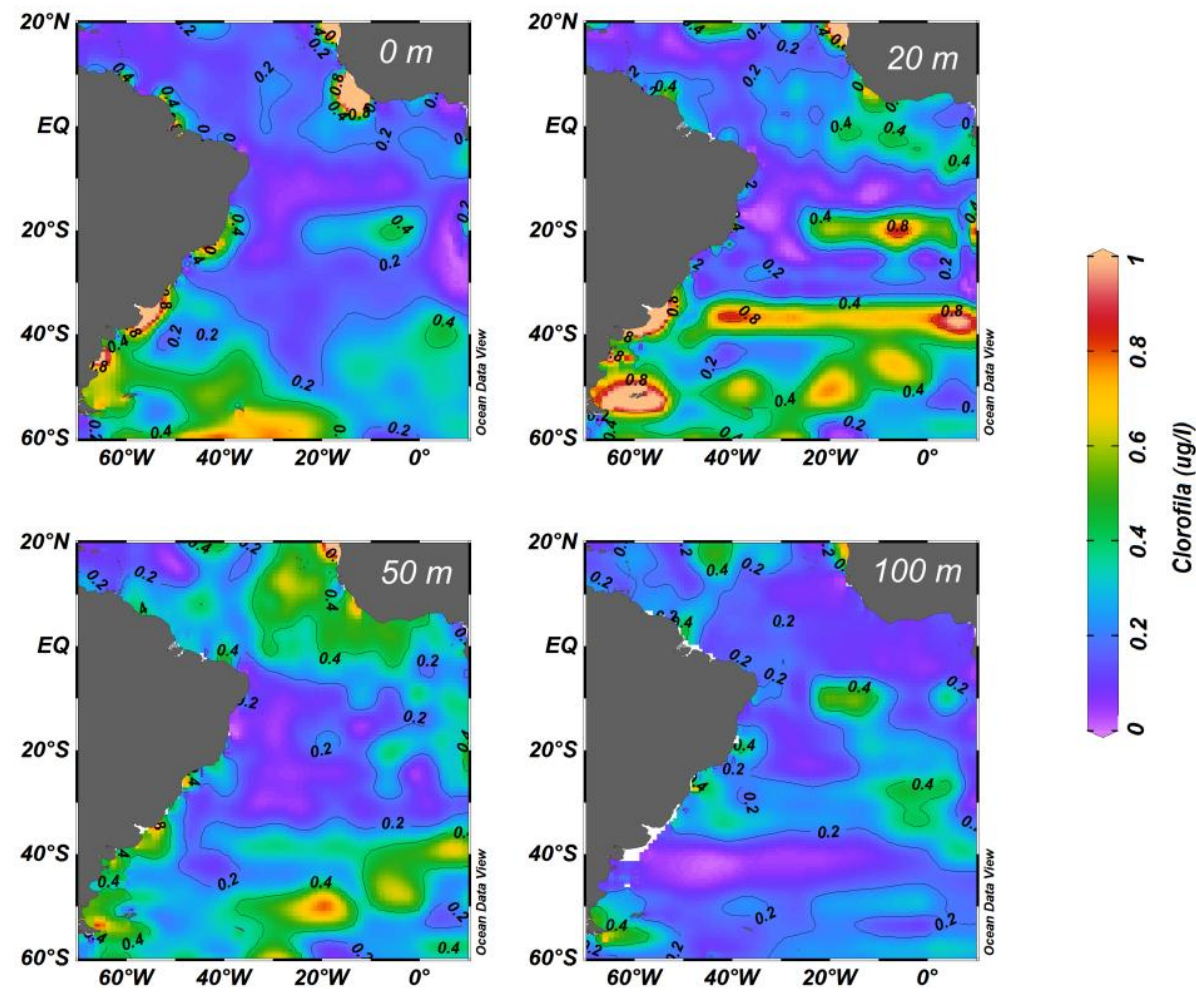

Figura 30-Média anual da Clorofila a $(\mu \mathrm{g} / \mathrm{l})$ no Atlântico Sul a $0 \mathrm{~m}, 20 \mathrm{~m}, 50 \mathrm{~m}$ e a $100 \mathrm{~m}$ (Conkright \& Boyer, 2002).

Os dados de Conkright \& Boyer (2002) acompanham os dados de nutrientes e da profundidade da Camada de Mistura, apresentando em geral uma região oligotrófica, com uma pequena produção primária, exceto pelas zonas de ressurgência na região leste do Atlântico Sul e pelas regiões 
próximas a descarga do rio da Prata, na região sudoeste, que fornece nutrientes para o oceano (Figura 30).

Nos dados de Behrenfeld \& Falkowski (1997) podemos observar maiores taxas de produtividade primária líquida nas regiões próximas a plataforma continental e a desembocaduras de rios. As taxas também foram elevadas em locais como nas regiões sul (latitudes acima de $40^{\circ} \mathrm{S}$ ) e norte (acima do equador), quando comparadas a região central, na qual podemos notar a influencia do Giro Subtropical do Atlântico Sul tornando a região menos produtiva (Figura 31).

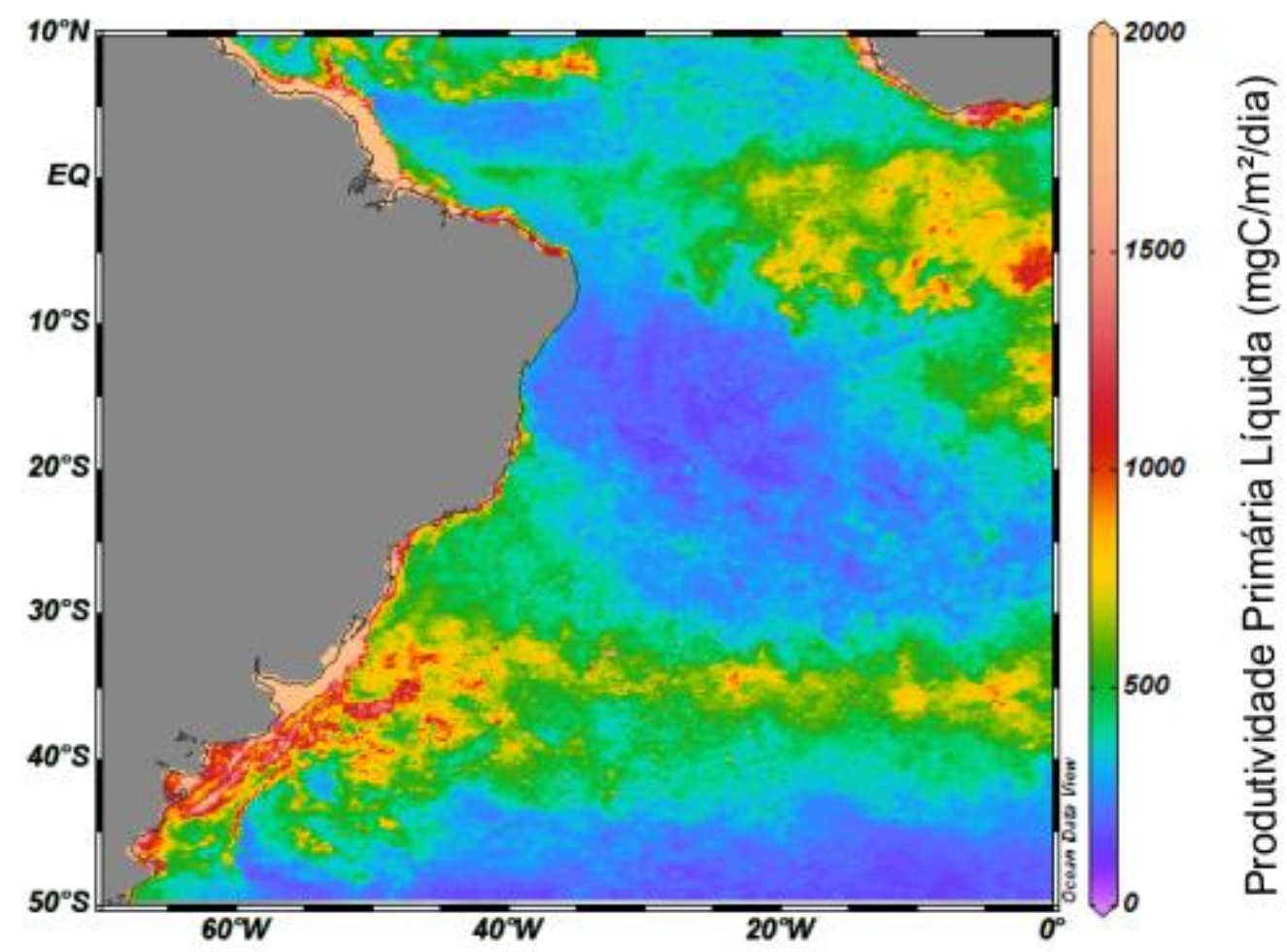

Figura 31 - Média anual de Produtividade Primária Líquida baseada nos dados do SeaWiFS (Behrenfeld \& Falkoswski, 1997)

\section{Materiais e Métodos}

\subsection{Amostras de sedimentos}

O material utilizado neste estudo são amostras de topo de testemunhadores a pistão e box corer disponíveis no Laboratório de Paleoceanografia do Atlântico Sul (LaPAS), com isso, 44 amostras de 
sedimentos de superfície foram analisadas para a identificação e quantificação de todas as espécies de cocolitoforídeos.

Algumas destas amostras já haviam sido analisados pela equipe do LaPAS e os dados já estavam disponíveis no banco de dados do laboratório. Para as outras amostras, os procedimentos descritos nas próximas seções foram executados no presente estudo.

Para aumentar a confiabilidade e o rigor sobre as análises estatísticas e nos permitir uma compreensão mais abrangente da área de estudo, foram incluídas as análises de 36 amostras do estudo realizado por Boeckel et al. (2006). Destas 15 amostras do oeste do oceano Atlântico Equatorial foram descritas quanto à sua composição de cocolitoforídeos por Kinkel et al. (2000). A preparação destas amostras seguiu a técnica de diluição/filtração combinada e as análises quantitativas foram realizadas no MEV.

Embora os números absolutos totais de cocolitoforídeos sejam mais elevados utilizando a técnica de filtração e a análise no MEV do que para a técnica de decantação, elas se correlacionam bem e são comparáveis. As abundâncias relativas das espécies também podem ser comparadas, com exceção a algumas espécies nas quais as metodologias podem tendenciar os resultados e não ser comparáveis, entre elas estão as Gephyrocapsas pequenas e algumas espécies consideradas raras no Atlântico Sul como Oolithotus spp., Umbellosphaera spp., Calciosolenia spp. (Saavedra-Pellitero et al., 2011). Para estes taxa, essas diferenças na distribuição em função da metodologia, foram levadas em consideração nas discussões e nos resultados apresentados a seguir.

\subsection{Preparação das Amostras}

Todas as amostras obtidas no LaPAS passaram pelo mesmo processo de preparação. Os primeiros passos após a amostragem foram: a pesagem do material ainda úmido, a secagem em uma estufa a aproximadamente $60^{\circ} \mathrm{C}$ e a pesagem do material seco. Posteriormente foi efetuado o peneiramento úmido dos sedimentos em peneiras de $63 \mu \mathrm{m}$, separando o material em uma fração grossa, com sedimentos $>63 \mu \mathrm{m}$, e uma fração fina, com sedimentos $<63 \mu \mathrm{m}$. A fração fina foi utilizada para a elaboração das lâminas para a análise de 
cocolitoforídeos, enquanto a fração grossa foi utilizada para as análises de foraminíferos.

Algumas das amostras foram previamente analisadas quanto ao conteúdo de cocolitoforídeos pela equipe do LaPAS, estas amostras foram preparadas segundo as metodologias descritas em Antunes (1997), Toledo (2000) e Flores \& Sierro (1997). As amostras preparadas e analisadas no presente estudo seguiram a técnica de decantação de Flores \& Sierro (1997) descrita abaixo.

Uma alíquota de 0,200 g de amostra é separada e colocada em tubos Falcon identificados, logo após adiciona-se $10 \mathrm{ml}$ de água tamponada medidos em proveta volumétrica. As amostras então são agitadas a $250 \mathrm{rpm}$ até sua homogeneização. No caso de as amostras não se desagregarem elas são submetidas à no máximo 10 segundos em ultrasom.

A lamínula para a fabricação da lamina de cada uma das amostras é colocada em placa de petri, as placas então são identificadas com números progressivos e preenchidas com água tamponada. O conteúdo, 0,200 $\mu \mathrm{l}$, é retirado de uma camada intermediaria de cada tubo com o auxílio de uma micropipeta e então é pipetado em uma placa de petri, anotando em qual placa está o conteúdo de cada tubo, portanto identificando cada amostra. As amostras então ficam em decantação por um período mínimo de $12 \mathrm{~h}$. Retira-se o excesso de água tamponada da placa de petri com o auxilio sifões feitos de papel e colocam-se as amostras em estufa, a aproximadamente $60^{\circ} \mathrm{C}$, para a secagem completa do material.

Após a secagem do material a lamínula é retirada da placa de petri com o auxilio de um bisturi, evitando o contato da mão com a amostra. A lamínula é então colocada sobre uma chapa aquecedora e uma gota de Bálsamo do Canadá é pingada sobre a lamínula e esta é virada sobre a lâmina finalizando sua preparação. A lamina do bisturi então é imersa em ácido clorídrico para remover qualquer conteúdo de carbonato que tenha acidentalmente a contaminado. A seguir, ela é imersa em água destilada, para evitar que sobre qualquer resquício de ácido clorídrico que vá dissolver organismos da próxima amostra, o bisturi então é seco e está pronto para ser utilizado na próxima amostra. Depois que da preparação das laminas a análise quantitativa dos 
cocolitoforídeos é realizada utilizando um microscópio óptico Olympus BX41 sob um aumento de $1000 \mathrm{X}$.

A estratégia de contagem por número de espécimes foi utilizada para a análise quantitativa dos cocolitoforídeos pelo método ser bem acurado e exigir menos tempo de laboratório quando comparado com o método de contagem por campos visuais (Quadros, 2007). Para este trabalho foram contabilizados 300 espécimes de campos visuais aleatórios, já que com este número de indivíduos podemos detectar espécies com níveis de abundância relativa de 1 a $2 \%$ da associação total, considerando um intervalo de confiança de 90 a $95 \%$ (Roth, 1994).

Os cocólitos da espécie $F$. profunda não foram contabilizados para a obtenção dos 300 espécimes mínimos de cada análise quantitativa, devido ao fato dessa espécie ser extremamente abundante e poder mascarar as variações das abundâncias relativas de espécies mais raras.

\subsection{Cronologia}

Como a maioria das amostras foi coletada com testemunhadores a pistão é necessário verificar se as amostras são representativas das condições oceanográficas atuais. Isto porque durante a amostragem com este tipo de testemunhador muitas das vezes a camada superficial de sedimentos é perdida e, portanto, não estaríamos analisando os sedimentos de superfície e sim sedimentos mais antigos.

Amostras de topo de testemunho nem sempre apresentam características atuais, ou seja, condições interglaciais características do Holoceno (Curry \& Lohman, 1982). Portanto é necessário avaliar se as amostras representam ou não as condições atuais do oceano.

Algumas das amostras já foram submetidas a datações de radiocarbono. Nestas amostras foi possível identificar se elas são representativas de períodos atuais apenas observando sua idade calendário.

Nas amostras nas quais não houve datação análises de equilíbrio isotópico com o $\delta^{18} \mathrm{O}$ foram efetuadas para determinar se o oxigênio das testas dos foraminíferos destas amostras foi precipitado em equilíbrio isotópico com a 
água atual, ou seja, se estavam representando os processos oceanográficos atuais.

\subsubsection{Datações radiocarbono}

$\mathrm{O}{ }^{14} \mathrm{C}$ é um isótopo radioativo do carbono produzido continuamente na alta atmosfera pela irradiação cósmica do ${ }^{14} \mathrm{~N}$. Uma vez formados, os átomos de ${ }^{14} \mathrm{C}$ são incorporados ao $\mathrm{CO}_{2}$ atmosférico e assimilados no ciclo do carbono dos organismos vivos, da mesma forma que os átomos dos dois isótopos estáveis, ${ }^{12} \mathrm{C}$ e ${ }^{13} \mathrm{C}$. Quando ele morre, essas trocas deixam de existir e $0{ }^{14} \mathrm{C}$ começa a se desintegrar continuamente, sem ser renovado.

Efeito reservatório é o efeito de envelhecimento aparente das datas radiocarbono, freqüente na datação de organismos marinhos. Ele é conseqüência do fato de que a taxa de renovação das águas oceânicas é muito mais lenta do que a da atmosfera, sobretudo para a água situada abaixo da termoclina.

Portanto, para estabelecer a cronologia nas amostras previamente analisadas pela equipe do LaPAS as datações radiocarbono $\left({ }^{14} \mathrm{C}\right)$ já existentes no banco de dados do laboratório foram utilizadas.

Estas datações foram realizadas em foraminíferos planctônicos da espécie Globigerinoides ruber (pink e white) no National Ocean Science Accelerator Mass Spectrometrer Facility (NOSAMS) no Woods Hole Oceanographic Institution (WHOI), Estados Unidos da América.

As idades radiocarbono foram então corrigidas para idades calendário a partir da subtração da idade reservatório (global) de 400 anos. Nas amostras nas quais o topo do testemunho não estava datado as duas datações mais próximas ao topo foram utilizadas para estimar a taxa de sedimentação e, com isso, estimar a idade da amostra de topo.

\subsubsection{Análises isotópicas}

O sinal isotópico de oxigênio nas testas de foraminíferos $\left(\delta^{18} \mathrm{O}\right)$ é amplamente utilizado em paleoceanografia para determinar a cronologia relativa de sedimentos marinhos e inferir períodos glaciais e interglaciais, pois este indicador está fortemente relacionado a parâmetros ambientais como volume de gelo continental, temperatura e salinidade (Rohling \& Cooke, 1999). 
Foraminíferos calcificam suas testas de carbonato de cálcio a partir da água do mar na qual estão inseridos, assim o sinal isotópico das testas dos foraminíferos reflete principalmente o sinal isotópico da água do mar (Mulitza et al., 2003). Com isso é possível avaliar se os foraminíferos existentes nas amostras de sedimentos de topo estão em equilíbrio com a água do mar atual, ou seja, se o sinal isotópico das amostras podem ser comparadas as variações dos parâmetros oceanográficos atuais. Para tal, foram estimados os sinais isotópicos de oxigênio da água $\left(\delta^{18} \mathrm{O}_{w}\right)$, na superfície e no fundo, e das testas de foraminíferos bentônicos ou planctônicos nas amostras nas quais não havia datação absoluta com base no método de radiocarbono.

A distribuição dos valores de $\delta^{18} \mathrm{O}_{\mathrm{w}}$ (VSMOW) nos oceanos mundiais é determinada pela advecção e mistura de massas de água de diferentes origens. Equações baseadas na regressão linear entre $\delta^{18} \mathrm{O}_{w}$ e salinidade, geradas por LeGrande \& Schmidt (2006), foram utilizadas para estimar o valor de $\delta^{18} \mathrm{O}_{w}$ ao longo dos primeiros $150 \mathrm{~m}$ e do fundo da coluna d'água, a partir dos dados de salinidade anual do WOA13. Sendo a Equação 1 utilizada para as amostras localizadas na AT ou ACAS e a Equação 2 para as amostras na localização da APAN.

$$
\begin{aligned}
& \delta^{18} O_{w}=0,51 * S-17,40 \\
& \delta^{18} O_{w}=0,51 * S-17,75
\end{aligned}
$$$$
\text { Equação } 1
$$

Equação 2

Para as amostras nas quais foram utilizados foraminíferos planctônicos, os valores da calcita precipitada em equilíbrio com a água do mar $\left(\delta^{18} \mathrm{O}_{\mathrm{eq}}\right)$ foram estimados, a partir dos valores de $\delta^{18} \mathrm{O}_{w}$ e temperatura, pela equação estabelecida por Mulitza (2003) e tendo como referencia o padrão VSMOW (Equação 3).

$$
\mathrm{T}=14,32-4,28\left(\delta^{18} \mathrm{O}-\delta^{18} \mathrm{O}_{\mathrm{w}}\right)+0,07\left(\delta^{18} \mathrm{O}-\delta^{18} \mathrm{O}_{\mathrm{w}}\right)^{2} \quad \text { Equação } 3
$$

No entanto, para as amostras analisadas a partir de foraminíferos bentônicos os valores de $\delta^{18} \mathrm{O}_{\text {eq }}$ da calcita foram estimados utilizando a equação de Kim \& O'neal (1997) (Equação 4), pois esta não apresenta desvios para o gênero Cibicidoides e os valores podem ser comparados diretamente com os valores medidos nos foraminíferos (Costa et al., 2006). 


$$
\mathrm{T}=16,10-4,64\left(\delta^{18} \mathrm{O}-\delta^{18} \mathrm{O}_{\mathrm{w}}\right)+0,09\left(\delta^{18} \mathrm{O}-\delta^{18} \mathrm{O}_{\mathrm{w}}\right)^{2} \quad \text { Equação } 4
$$

Para os valores serem comparáveis com os obtidos nas testas dos foraminíferos os valores de $\delta^{18} \mathrm{O}_{\text {eq }}$ com o padrão VSMOW foram convertidos para o VPDB $\left(\delta^{18} \mathrm{O}_{\text {calc }}\right)$ utilizando a Equação 5 estabelecida por Hut (1987).

$$
\delta^{18} \mathrm{O}_{(\mathrm{VPDB})}=\delta^{18} \mathrm{O}_{(\mathrm{SMOW})}-0,27 \quad \text { Equação } 5
$$

A abordagem para seleção destas amostras foi baseada no conteúdo de foraminíferos bentônicos, já que estes foraminíferos geram uma análise mais robusta e uma análise mais simples dos sinais isotópicos obtidos, portanto os foraminíferos planctônicos foram utilizados apenas nas amostras nas quais não foram encontrados foraminíferos bentônicos.

Para os foraminíferos bentônicos os espécimes do gênero Cibicidoides foram selecionados para as análises, uma vez que as espécies utilizadas deste gênero, $C$. wuellerstorfi e $C$. kullenbergi, calcificam em equilíbrio isotópico de oxigênio, apresentando uma pequena variabilidade isotópica ao redor do valor de equilíbrio $( \pm 0,2 \%$ ) (Costa et al., 2006). Portanto, para este tipo de análise os valores isotópicos obtidos do gênero Cibicidoides foram diretamente comparados com os valores de $\delta^{18} \mathrm{O}_{\text {calc }}$ estimados para a água do mar atual na profundidade e local de coleta das amostras.

Nas amostras nas quais não foram encontrados foraminíferos bentônicos foram utilizados os foraminíferos planctônicos Globigerinoides ruber. Nestas análises foi estimada a profundidade aparente de calcificação na coluna de água dos organismos de cada amostra. Portanto, nestas análises os valores isotópicos obtidos destes foraminíferos foram comparados com os valores de $\delta^{18} \mathrm{O}_{\text {eq }}$ para a coluna de água acima do local de coleta das amostras. Para determinar se uma amostra é representativa do período atual os valores de equilíbrio devem ser encontrados em profundidades que variam de 0 a $150 \mathrm{~m}$, pois estas foram as profundidades de calcificação desta espécie encontradas em estudos paleoceanográficos na região (Chiessi et al., 2007; Fraguas et al., 2011). 
Dentre as amostras utilizadas neste estudo, 18 delas não haviam sido datadas nem avaliadas quanto ao seu conteúdo de isótopos estáveis (Tabela 2). Estas amostras foram então analisadas no Laboratório de Isótopos Estáveis do Instituto de Geociências da Universidade de São Paulo.

Para a realização das análises as amostras foram peneiradas em malha de $350 \mu \mathrm{m}$ separando apenas os foraminíferos maiores a fim de obter um sinal isotópico melhor. Após a separação desta fração foram separados o número de testas necessários para as análises de foraminíferos bentônicos do gênero Cibicidoides. Quando estes não foram encontrados em número suficiente para a análise foram separados os foraminíferos planctônicos $G$. ruber na fração acima dos $350 \mu \mathrm{m}$ (Tabela 2).

Tabela 2 - Amostras analisadas quanto a isótopos estáveis, assim como a espécie de foraminífero e o número de indivíduos utilizados em cada amostra.

\begin{tabular}{ccc} 
Testemunho & Espécie & $\mathrm{N}^{0}$ de testas \\
\hline \hline KF-03 & Cibicidoides spp. & 2 \\
KF-04 & Cibicidoides spp. & 4 \\
KF-05 & Cibicidoides spp. & 2 \\
KF-06 & G. ruber & 10 \\
KF-07 & Cibicidoides spp. & 2 \\
KF-08 & G. ruber & 10 \\
KF-09 & Cibicidoides spp. & 2 \\
KF-10 & G. ruber & 10 \\
KF-11 & G. ruber & 10 \\
KF-24 & Cibicidoides spp. & 2 \\
KF-25 & G. ruber & 10 \\
KF-26 & Cibicidoides spp. & 2 \\
MD-01 & G. ruber & 10 \\
MD-02 & G. ruber & 10 \\
PC-04 & Cibicidoides spp. & 2 \\
PC-06 & Cibicidoides spp. & 7 \\
PC-08 & Cibicidoides spp. & 2 \\
PC-09 & G. ruber & 10
\end{tabular}

\subsection{Dissolução}

A dissolução de carbonato de cálcio em águas profundas pode modificar a composição taxonômica das assembleias recentes de microfósseis planctônicos (Thierstein, 1980), ao mesmo passo que assembleias 
sedimentares são significamente afetadas por dissolução e fragmentação (Samtleben et al., 1995). A profundidade média a partir da qual observa-se a dissolução de carbonato é denominada de lisoclina. A lisoclina no oceano Atlântico Sul atual é considerada como sendo a interface entre a APAN e a corrosiva Água de Fundo Antártica (AFA) e está localizada a cerca de $4.300 \mathrm{~m}$ de profundidade (Dittert et al., 1999).

Todas as amostras utilizadas neste estudo estão acima da profundidade da lisoclina para o Atlântico Sul, portanto é esperado que não ocorram efeitos significativos da dissolução nas assembleias de cocolitoforídeos.

Para estimar o efeito da dissolução nas amostras o Índice de Dissolução de Cocólitos (CEX') foi estabelecido de acordo com a fórmula gerada por Boeckel \& Baumann (2004). Este índice se baseia no comportamento de diferentes tipos de cocólitos frente à dissolução. A abundância relativa de cocólitos frágeis e comparativamente pequenos de Emiliania huxleyi e Gephyrocapsa ericsonii é comparada aos cocólitos fortemente calcificados de Calcidiscus leptoporus (Boeckel et al., 2006).

As abundâncias relativas das espécies podem ser afetadas pelas diferentes afinidades ecológicas das espécies envolvidas, mas ainda assim o CEX' fornece estimativas aproximadas para o nível de dissolução dos cocólitos, pois segundo Dittert et al. (1999) o índice provou-se comparável com um índices de dissolução baseados na ultraestrutura de foraminiferos. O índice então é calculado segundo a Equação 6:

CEX': $\frac{\text { E.huxleyi }+ \text { G.ericsonii }}{\text { E.huxleyi }+ \text { G.ericsonii }+ \text { C.leptoporus }}$ Equação 6

\subsection{Análise dos Dados}

Inicialmente foram feitas análises sobre as distribuições das principais espécies de cocolitoforídeos e depois estas distribuições foram comparadas com os parâmetros oceanográficos atuais para analisar suas relações.

Mapas de distribuição das principais espécies do oeste do Atlântico Sul fora, elaborados para analisar suas relações com os parâmetros oceanográficos da região estudada, bem como para visualizar suas distribuições ao longo da área de estudo. 
Todas as análises estatísticas citadas a seguir foram realizadas no software Palaeontological Statistics (PAST) versão 3.04 (Hammer et al. , 2001).

O primeiro passo da análise estatística foi verificar se as espécies de cocolitoforídeos possuem uma distribuição normal, pois a distribuição normal é um pré-requisito para o restante das análises estatísticas. Como não ocorreu tal distribuição, foram feitas transformações dos dados para a forma logarítmica, aproximando os dados de uma distribuição gausiana.

A seguir foi efetuada uma análise univariada de correlação para analisar a associação de cada espécie com cada variável ambiental individualmente. Para esta análise, a correlação de Pearson ( $r$ ) foi aplicada entre os logaritmos das abundâncias de cocolitoforídeos e os parâmetros ambientais um a um.

Devido ao caráter multivariado do oceano e seus efeitos no fitoplâncton, uma Análise de Correspondência Canônica (ACC) foi elaborada para integrar o extensivo número de variáveis ambientais e de espécies de cocolitoforídeos. Esta análise foi escolhida por ser estabelecida de forma que podemos observar o gradiente direto de uma espécie em relação as variáveis ambientais, sendo o gradiente das variáveis ambientais conhecido e as abundâncias das espécies são consideradas como uma resposta a este gradiente (Hammer et al., 2001).

Para realizar a ACC foram inseridos os logaritmos das espécies de cocolitoforídeos e os dados ambientais interpolados para as estações com a utilização do software Matlab X do mesmo modo que descrito no item 4.3.

Para determinar províncias biogeográficas uma análise de clusters foi realizada a fim de analisar as distâncias euclideanas entre as amostras, estabelecendo assim grupos de estações com assembleias similares.

Após a análise de clusters, uma Análise de Componentes Principais (ACP) foi calculada para verificar quais espécies controlam cada grupo separado pela análise de clusters. ACP é uma abordagem estatística que reduz o número de informações apresentadas a um importante número de variáveis originais em um menor número de dimensões, as componentes, com uma mínima perda de informação (Hair et al., 1992). Aplicando esta análise podemos identificar quantos membros, as componentes, estatisticamente independentes existem no nosso conjunto de dados e quais espécies são dominantes em cada fator. Durante as análises é necessário levar em conta 
que as variáveis, que no caso deste estudo são as diferentes estações hidrográficas, são extremamente correlacionadas entre si.

Com as variáveis separadas em componentes principais podemos investigar a relação entre cada componente obtida com diferentes parâmetros ambientais. Para isso uma correlação de Pearson entre cada um desses fatores e cada parâmetro foi realizada.

\section{Resultados}

\subsection{Cronologia e Dissolução}

\subsubsection{Datações Radiocarbono}

Os resultados das datações radiocarbono utilizadas neste estudo foram previamente realizadas pela equipe do LaPAS (Tabela 3). Com isso podemos observar que todas as amostras estão dentro do Holoceno e, por conseqüência disto, nenhuma das amostras foi retirada das análises segundo este critério.

Tabela 3 - Datações pelo método rabiocarbono considerando uma idade reservatório global de 400 anos.

\begin{tabular}{ccccccc} 
Testemunho & Latitude & Longitude & Prof. & Foraminífero & $\begin{array}{c}\text { Idade } \\
\text { Radiocarbono }\end{array}$ & $\begin{array}{c}\text { Idade } \\
\text { Calendário }\end{array}$ \\
\hline \hline KF - 01 & $-25,88$ & $-46,27$ & $3-5 \mathrm{~cm}$ & G. ruber & $60 \pm 30$ & $0 \pm 30$ \\
\hline KF - 02 & $-25,84$ & $-45,20$ & $0-4 \mathrm{~cm}$ & G. ruber & $615 \pm 30$ & $215 \pm 30$ \\
\hline KF - 12 & $-21,16$ & $-39,95$ & $10 \mathrm{~cm}$ & G. ruber & $1500 \pm 30$ & $1100 \pm 30$ \\
\hline KF - 13 & $-20,04$ & $-38,99$ & $0 \mathrm{~cm}$ & G.ruber(w+p) & $2780 \pm 30$ & $2380 \pm 30$ \\
\hline KF - 14 & $-20,02$ & $-39,28$ & $0 \mathrm{~cm}$ & G.ruber(w+p) & $1250 \pm 20$ & $850 \pm 30$ \\
\hline KF - 17 & $-23,49$ & $-41,13$ & $0 \mathrm{~cm}$ & G.ruber & $200 \pm 50$ & $0 \pm 50$ \\
\hline KF - 18 & $-25,21$ & $-42,62$ & $0 \mathrm{~cm}$ & G.ruber & $4250 \pm 35$ & $3850 \pm 35$ \\
\hline KF - 19 & $-25,18$ & $-44,72$ & $1 \mathrm{~cm}$ & G.ruber & $540 \pm 30$ & $140 \pm 30$ \\
\hline KF - 20 & $-24,93$ & $-42,52$ & $7 \mathrm{~cm}$ & G.ruber & $6690 \pm 30$ & $6290 \pm 30$ \\
\hline KF - A & $-14,40$ & $-38,82$ & $12 \mathrm{~cm}$ & G.ruber & $4010 \pm 40$ & $3610 \pm 40$ \\
\hline KF - B & $-7,48$ & $-34,33$ & $3,5 \mathrm{~cm}$ & G. ruber & $5890 \pm 35$ & $5490 \pm 35$ \\
\hline KF - C & $-8,37$ & $-34,45$ & $57 \mathrm{~cm}$ & G. ruber & $8050 \pm 120$ & $7650 \pm 120$ \\
\hline KF - D & $-23,97$ & $-41,35$ & $4,3 \mathrm{~cm}$ & G. ruber & $1580 \pm 50$ & $1180 \pm 50$ \\
\hline KF - E & $-20,95$ & $-39,53$ & $7 \mathrm{~cm}$ & G. ruber & $3370 \pm 30$ & $2970 \pm 30$ \\
\hline KF - F & $-14,43$ & $-38,58$ & $1 \mathrm{~cm}$ & G.ruber(w+p) & $1740 \pm 35$ & $1340 \pm 35$ \\
\hline KF - G & $-20,50$ & $-39,08$ & $1,5 \mathrm{~cm}$ & G.ruber(w+p) & $3540 \pm 50$ & $3140 \pm 50$ \\
\hline KF - I & $-24,43$ & $-42,28$ & 13 & G.ruber(w+p) & $3010 \pm 30$ & $2610 \pm 30$ \\
\hline & & & & & & \\
\hline
\end{tabular}


Mesmo as amostras do Holoceno podem não ser representativas dos processos oceanográficos atuais, o período deglacial dentro do Holoceno possui características oceanográficas muito diferentes das atuais, por isso mesmo as amostras datadas foram analisadas pelos métodos utilizando os isótopos estáveis de oxigênio a fim de assegurar essa representatividade do oceano atual.

\subsubsection{Análises de equilíbrio isotópico}

Para as amostras nas quais não havia datações radiocarbono a análise de equilíbrio isotópico, a partir de foraminíferos bentônicos, foi utilizada. Os resultados apresentados na Tabela 4 são com $0 \delta^{18} \mathrm{O}_{\mathrm{w}}$ calculado a partir das Equações 1 ou 2, dependendo da massa d'água, e em seguida estimados com a Equação 4 de Kim \& O'neal (1997).

Tabela 4 - Resultados da análise de equilíbrio isotópico para foraminíferos bentônicos. Em vermelho estão as amostras que não foram consideradas representativas do oceano atual.

\begin{tabular}{|c|c|c|c|c|c|}
\hline Testemunho & $\begin{array}{l}\text { Profundidade } \\
\text { da Amostra }\end{array}$ & Massa de Água & $\begin{array}{c}\delta^{18} \text { O Cibicidoides } \\
\text { spp. }\end{array}$ & $\begin{array}{c}\delta^{18} O_{\text {eq }} \text { Estimado - } \\
\text { Kim \& O'neal (1997) }\end{array}$ & $\begin{array}{r}\text { Obtido-Estimado } \\
\text { (Kim-O'neal 1997) }\end{array}$ \\
\hline$\overline{\mathrm{KF}-02}$ & 827 & ACAS & 2,170 & 2,327 & "-0,157 \\
\hline KF - 03 & 2173 & APAN & 2,373 & 2,747 & $-0,374$ \\
\hline KF - 04 & 2423 & APAN & 4,050 & 2,772 & 1,278 \\
\hline KF - 05 & 2270 & APAN & 2,957 & 2,760 & 0,197 \\
\hline KF - 07 & 2468 & APAN & 2,825 & 2,772 & 0,053 \\
\hline KF - 09 & 2215 & APAN & 2,842 & 2,733 & 0,109 \\
\hline $\mathrm{KF}-12$ & 1503 & ACAS & 3,022 & 2,877 & 0,145 \\
\hline $\mathrm{KF}-16$ & 1938 & APAN & 3,331 & 2,489 & 0,842 \\
\hline KF - 18 & 2220 & APAN & 3,128 & 2,684 & 0,444 \\
\hline KF - 19 & 848 & ACAS & 2,198 & 2,434 & $-0,236$ \\
\hline $\mathrm{KF}-20$ & 2225 & APAN & 2,800 & 2,684 & 0,116 \\
\hline $\mathrm{KF}-24$ & 1797 & APAN & 2,657 & 2,617 & 0,040 \\
\hline KF - 26 & 670 & ACAS & 2,179 & 2,057 & 0,122 \\
\hline PC-04 & 2000 & APAN & 3,523 & 2,514 & 1,008 \\
\hline PC-06 & 1500 & APAN & 4,336 & 2,883 & 1,454 \\
\hline PC-08 & 800 & ACAS & 2,680 & 2,399 & 0,282 \\
\hline$K F-A$ & 965 & APAN & 2,591 & 2,390 & 0,201 \\
\hline$K F-B$ & 1261 & APAN & 2,345 & 2,435 & $-0,090$ \\
\hline$K F-C$ & 1315 & APAN & 2,353 & 2,443 & $-0,090$ \\
\hline$K F-D$ & 1568 & APAN & 2,521 & 2,502 & 0,019 \\
\hline$K F-E$ & 1995 & APAN & 2,591 & 2,690 & $-0,099$ \\
\hline$K F-I$ & 1682 & APAN & 2,406 & 2,506 & $-0,100$ \\
\hline
\end{tabular}

Os valores foram obtidos a partir do gênero Cibicidoides. O limite para a diferença entre o valor obtido e o estimado foi de $\pm 0,400$. Das amostras analisadas apenas cinco demonstraram grandes desvios entre $0 \delta^{18} \mathrm{O}$ que foi estimado e o obtido nas testas dos foraminíferos, com isso foram consideradas 
do período deglacial-glacial e, portanto, não foram consideradas atuais e foram excluídas das análises posteriores (Tabela 4), sendo elas: KF-04, KF-16, KF18, PC-04 e PC-06.

O restante das amostras obtiveram desvios baixos nos resultados, por volta de 0,100 e 0,200, o que indica que seus foraminíferos bentônicos calcificaram em equilíbrio isotópico com a água do mar atual e que, portanto, a amostra está representando condições ambientais recentes.

Nas amostras nas quais não haviam foraminíferos do gênero Cibicidoides e nem datações radiocarbono foi realizada a análise de profundidade aparente de foraminíferos planctônicos da espécie G. ruber, com o $\delta^{18} \mathrm{O}_{w}$ calculado a partir da Equação 1, visto que estes foraminíferos habitam a coluna d'água. Em seguida os valores de $\delta^{18} \mathrm{O}$ foram estimados com a Equação 3 de Mulitza (2003), os resultados destas análises estão presentes na Tabela 5.

Tabela 5 - Resultados da análise de equilíbrio isotópico para foraminíferos planctônicos. Em vermelho estão as amostras que não foram consideradas representativas do oceano atual.

\begin{tabular}{|c|c|c|c|}
\hline Testemunho & $\delta^{18} \mathrm{O}$ G. ruber & $\begin{array}{c}\delta^{18} \mathrm{O}_{\text {eq }} \text { Estimado -Mulitza } \\
\text { et al (2003) }\end{array}$ & $\begin{array}{c}\text { Prof. De Calcificação } \\
\text { Aparente }\end{array}$ \\
\hline KF - 02 & "-1,359 & "-1,102 & $0 \mathrm{~m}$ \\
\hline KF - 06 & $-0,460$ & $-0,473$ & $150 \mathrm{~m}$ \\
\hline KF - 08 & $-0,564$ & $-0,558$ & $125 \mathrm{~m}$ \\
\hline $\mathrm{KF}-10$ & $-0,446$ & $-0,473$ & $150 \mathrm{~m}$ \\
\hline KF - 11 & $-0,298$ & $-0,343$ & $175 \mathrm{~m}$ \\
\hline $\mathrm{KF}-12$ & $-1,118$ & $-1,108$ & $50 \mathrm{~m}$ \\
\hline $\mathrm{KF}-13$ & $-1,280$ & $-1,272$ & $30 \mathrm{~m}$ \\
\hline KF - 14 & $-1,039$ & $-1,042$ & $65 \mathrm{~m}$ \\
\hline KF - 17 & $-1,273$ & $-1,253$ & $25 \mathrm{~m}$ \\
\hline $\mathrm{KF}-18^{*}$ & $-0,915$ & $-0,925$ & $25 \mathrm{~m}$ \\
\hline KF - 19 & $-1,250$ & $-1,100$ & $0 \mathrm{~m}$ \\
\hline KF - 20 & $-0,850$ & $-0,865$ & $30 \mathrm{~m}$ \\
\hline KF - 21 & $-1,305$ & $-0,761$ & $0 \mathrm{~m}$ \\
\hline KF - 25 & $-0,253$ & $-0,304$ & $100 \mathrm{~m}$ \\
\hline MP-01 & $-0,881$ & $-0,898$ & $75 \mathrm{~m}$ \\
\hline MP-02 & $-0,626$ & $-0,687$ & $90 \mathrm{~m}$ \\
\hline PC-09 & $-0,522$ & $-0,570$ & $150 \mathrm{~m}$ \\
\hline$K F-A$ & $-1,574$ & $-1,513$ & 0 até $15 \mathrm{~m}$ \\
\hline$K F-B$ & $-1,420$ & $-1,451$ & $90 \mathrm{~m}$ \\
\hline $\mathrm{KF}-\mathrm{C}$ & $-1,679$ & $-1,677$ & $75 \mathrm{~m}$ \\
\hline$K F-D$ & $-1,287$ & $-1,110$ & $0 \mathrm{~m}$ \\
\hline$K F-E$ & $-1,557$ & $-1,366$ & $0 \mathrm{~m}$ \\
\hline$K F-F$ & $-1,740$ & $-1,513$ & 0 até $15 \mathrm{~m}$ \\
\hline $\mathrm{KF}-\mathrm{G}$ & $-1,060$ & $-1,085$ & $60 \mathrm{~m}$ \\
\hline $\mathrm{KF}-\mathrm{H}$ & $-1,291$ & $-1,107$ & $0 \mathrm{~m}$ \\
\hline KF - I & $-1,191$ & $-1,107$ & $0 \mathrm{~m}$ \\
\hline
\end{tabular}


Os valores obtidos variaram entre -0,253 e -1,740, e as profundidades de calcificação aparente entre $0 \mathrm{~m}$ e 175m. Como estamos utilizando o limite de $150 \mathrm{~m}$, uma única amostra foi excluída por este método. A amostra KF-11 apresentou a profundidade de $175 \mathrm{~m}$ o que seria irreal para esta espécie de foraminífero e, com isso, a amostra seria de um período diferente do atual e os parâmetros ambientais que ela reflete não seriam recentes (Tabela 5).

A maioria das outras amostras atingiu os resultados esperados e ficaram com profundidades próximas as que estes organismos habitam, com exceção de quatro amostras que ficaram próximas ao limite, KF-06, KF-08, KF-10 e PC09 , contudo ainda foram consideradas de períodos recentes.

\subsubsection{Dissolução}

O estado de preservação de grande parte das amostras foi considerado excelente pelo uso do índice CEX', tendo em vista que os valores ficaram sempre entre 0,8 e 1,0 (Figura 32), o que caracteriza amostras sem influência de dissolução. Apenas duas amostras apresentaram o valor do índice CEX' considerado pequeno para este estudo, são elas: GeoB2207-2 e GeoB5110-5.

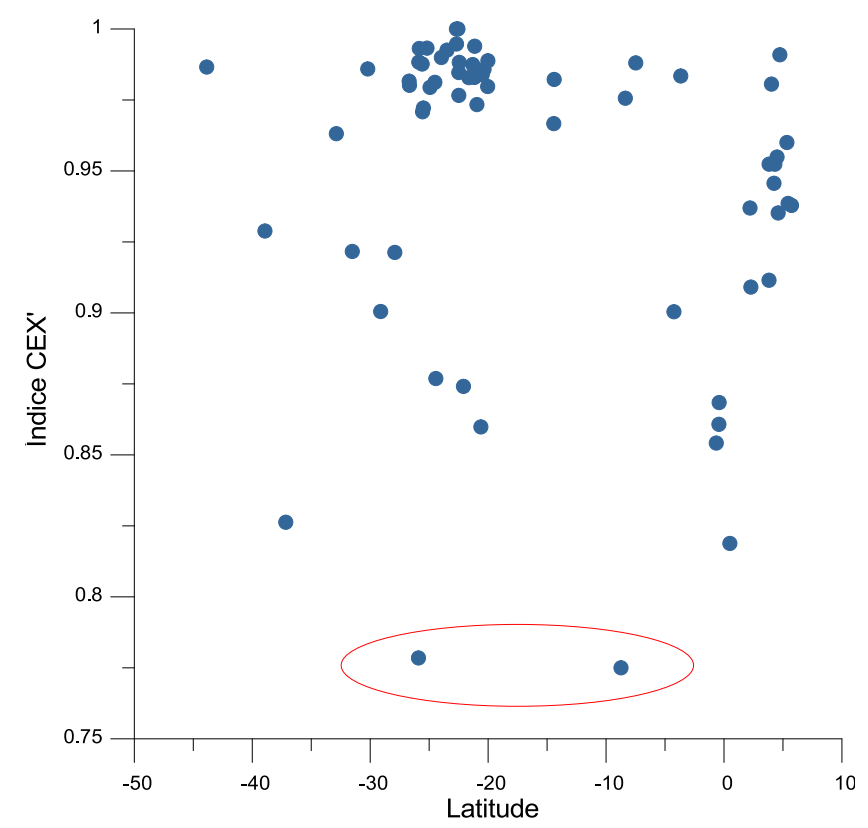

Figura 32 - Índice CEX' calculado na amostras analisadas. Circuladas em vermelho estão as amostras excluídas das análises por apresentarem indícios de dissolução. 
Na primeira amostra o que definiu o alto valor do CEX' foi a presença de poucos cocólitos pequenos, E. huxleyi e G. ericsonii, enquanto as quantidades de $C$. leptoporus permaneceu constante. Já na segunda amostra, a pouca quantidade de cocólitos frágeis somada a uma porcentagem considerada alta de C. leptoporus (7\%), fez com que 0 índice CEX' ficasse abaixo dos 0,8 definidos como limite para as análises das assembleias. A profundidade da amostra GeoB5110-5, 4182m , também foi determinante para sua exclusão das análises, devido ao fato de ela estar próxima ao valor da lisoclina atual.

\subsection{Distribuição das Espécies}

A partir das análises quantitativas de cocolitoforídeos foram encontrados 22 taxa, sendo que para as análises dos resultados apenas 14 espécies ou grupos de espécies serão apresentadas, devido ao fato dos outros grupos estarem presentes em uma pequena quantidade de amostras e quando encontrados apresentarem abundâncias relativas extremamente baixas, tornando-se assim extremamente raros e pouco representativos.

As espécies mais abundantes na área de estudo foram E. huxleyi, $F$. profunda e o gênero Gephyrocapsa, estando as três presentes em todas as amostras. Estes grupos foram responsáveis em média por $80 \%$ das abundâncias relativas das amostras. A seguir é apresentada uma descrição mais específica de cada espécie.

\section{Calcidiscus leptoporus}

A espécie Calcidiscus leptoporus apresentou valores de abundância relativa baixos, porém foi ausente em apenas uma amostra (MP-02). Este grupo obteve em média uma abundância relativa de 2,06\%, com maiores valores na região equatorial e ao sul de $30^{\circ} \mathrm{S}$, onde atinge seu valor máximo próximo a 14\% (Figura 33). 

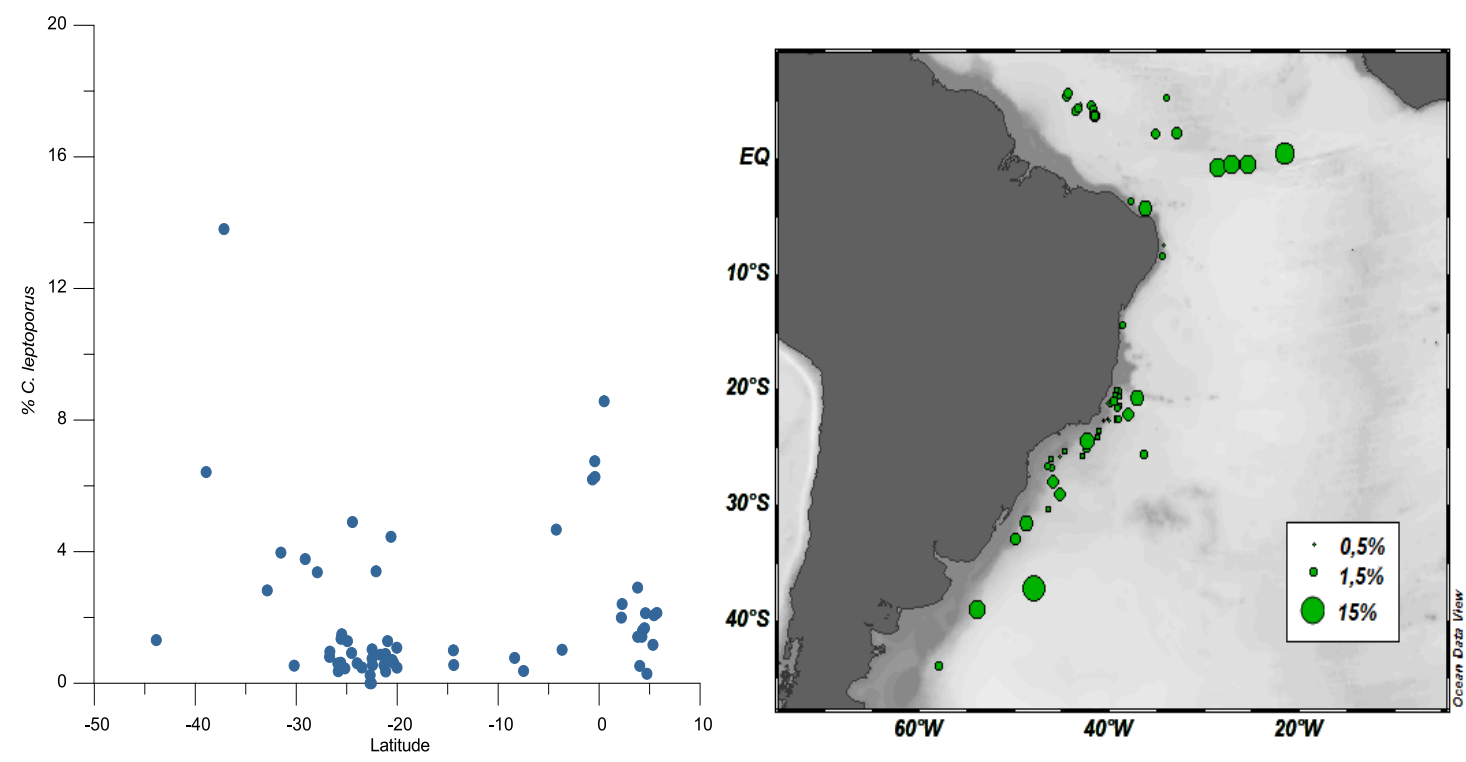

Figura 33 - À esquerda porcentagens da espécie $C$. leptoporus em relação à latitude. À direita mapa de distribuição de $C$. leptoporus ao longo da área de estudo.

\section{Calciosiolenia spp.}

O grupo Calciosiolenia spp. foi contabilizado apenas nas amostras analisadas no presente estudo e pela equipe do LaPAS, pois este grupo não foi analisado no estudo de Boeckel et al. (2006).

Neste grupo as principais espécies encontradas foram C. murrayi e $C$. brasiliensis, as espécies foram analisadas juntas devido à raridade dos espécimes bem como pela difícil identificação no microscópio óptico.

O grupo foi considerado raro nas observações, porém esteve presente em quase todas as amostras. Obteve valores de abundância relativa médios de $0,65 \%$, sendo seus valores máximos próximos a $2 \%$, na região subtropical (Figura 34). 

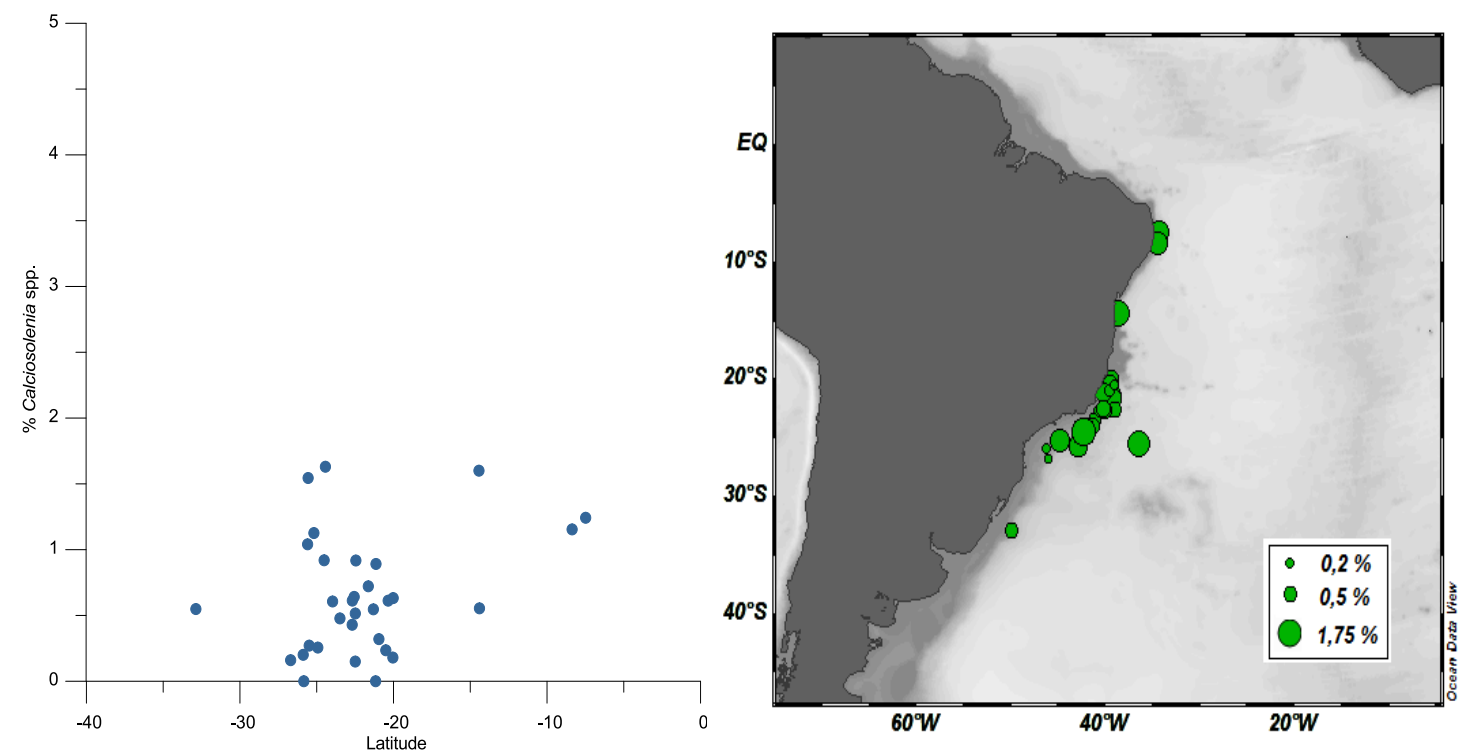

Figura 34 - À esquerda porcentagens da espécie Calciosolenia spp em relação à latitude. À direita mapa de distribuição de Calciosolenia spp ao longo da área de estudo.

\section{Discosphaera tubifera}

D. tubifera também foi uma espécie rara no registro, com média de $0,6 \%$ e valores máximos próximos aos $3 \%$, sendo ausente em muitas das amostras, porém com um padrão de distribuição no qual as maiores abundâncias relativas estão presentes na região equatorial e subtropical (Figura 35).
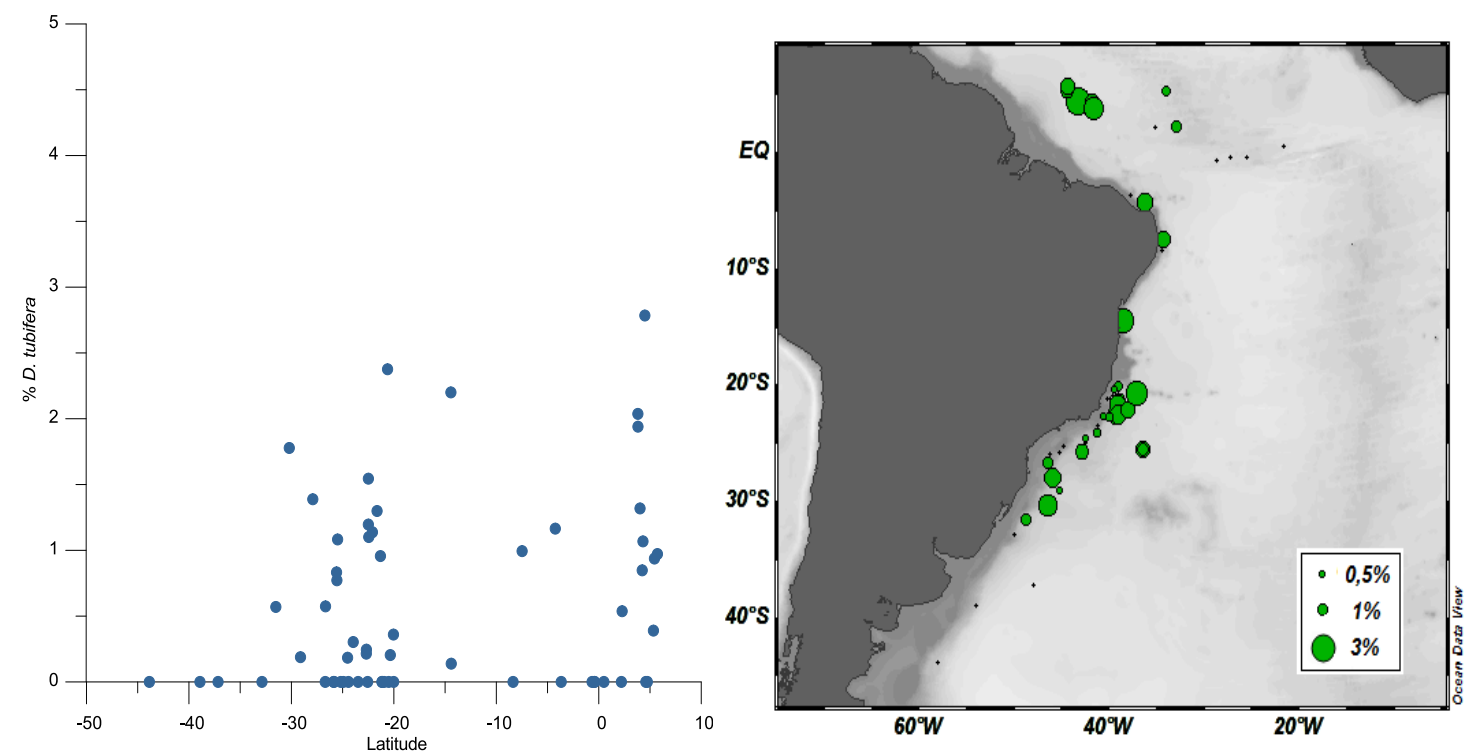

Figura 35 - À esquerda porcentagens da espécie $D$. tubifera em relação à latitude. À direita mapa de distribuição de $D$. tubifera ao longo da área de estudo. 


\section{Emiliania huxleyi}

E. huxleyi foi a espécie, em média $(34,84 \%)$, mais abundante na região de estudo e também a com o maior valor máximo de abundância relativa, chegando a ser $95 \%$ da associação total (Figura 36 ).

Esta espécie esteve presente em todas as amostras e apresentou um padrão de distribuição associado à latitude das amostras, sendo mais abundante nas regiões de altas latitudes, e com sua abundância relativa diminuindo gradativamente em direção ao equador.
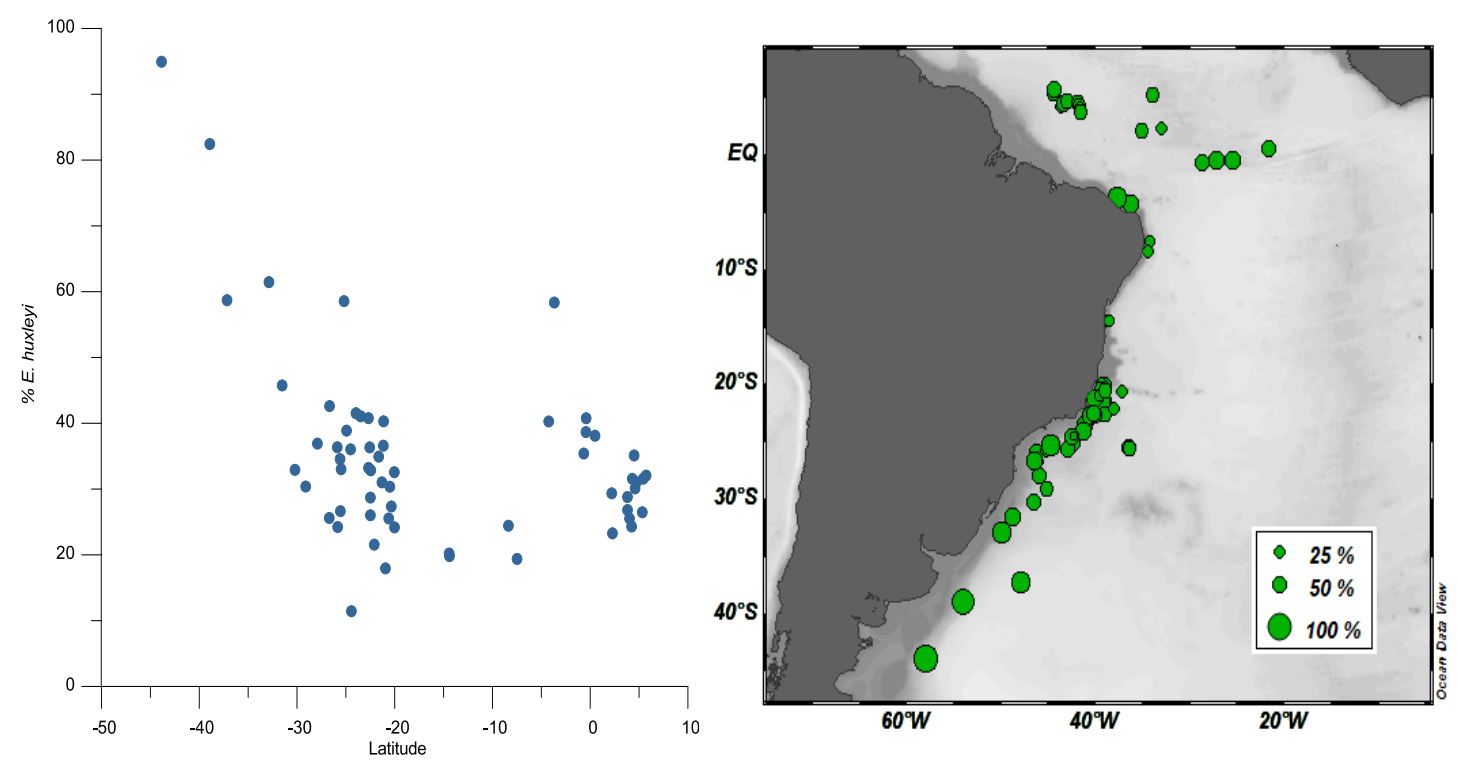

Figura 36 - À esquerda porcentagens da espécie E. huxleyi em relação à latitude. À direita mapa de distribuição de E. huxleyi ao longo da área de estudo.

\section{Florisphaera profunda}

F. profunda foi uma espécie abundante ao longo de toda área de estudo sendo representada em todas as amostras. Obteve uma abundância relativa média de 33,18\%, e com os valores máximos próximos aos 50\% (Figura 37).

A distribuição desta espécie foi praticamente o oposto da distribuição de E. huxleyi (Figura 36), F. profunda teve as maiores abundâncias nas regiões de baixas latitudes e foi diminuindo na direção das altas latitudes, até atingir um valor mínimo próximo a $1 \%$. 

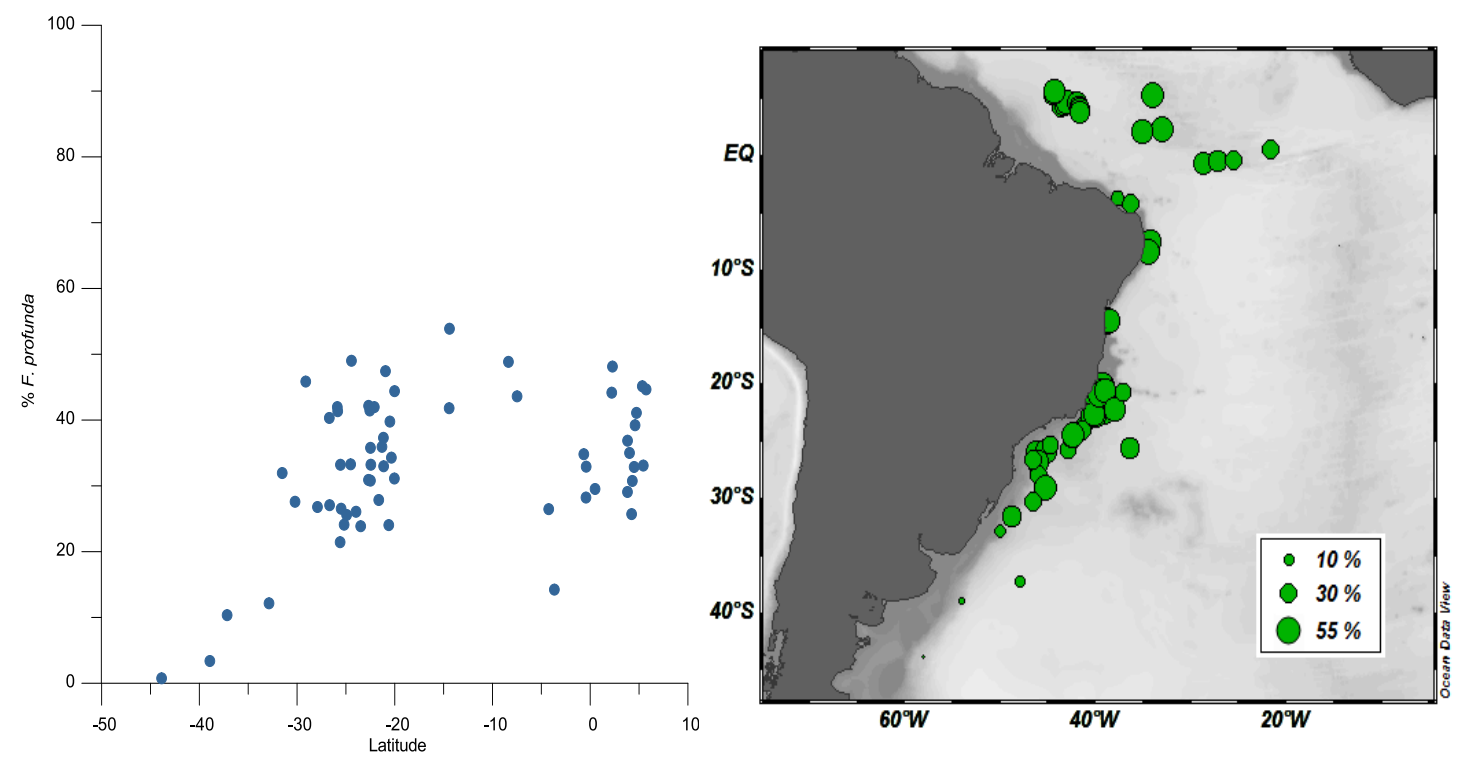

Figura 37 - À esquerda porcentagens da espécie F. profunda em relação à latitude. À direita mapa de distribuição de $F$. profunda ao longo da área de estudo.

\section{Gephyrocapsa spp.}

O gênero Gephyrocapsa spp. esteve presente em todas as amostras e obteve, em geral, maiores abundâncias na faixa entre $18^{\circ} \mathrm{S}$ e $30^{\circ} \mathrm{S}$. A espécie Gephyrocapsa oceanica foi a espécie mais abundante deste grupo, com as espécies Gephyrocapsa ericsonii e Gephyrocapsa muellerae mais raras, sendo a ultima ausente em muitas das amostras.

O grupo como um todo alcançou uma abundância relativa média de $10,22 \%$, porém seus valores variaram consideravelmente alcançando valores máximos próximos aos 30\% da assembléia total (Figura 38). 

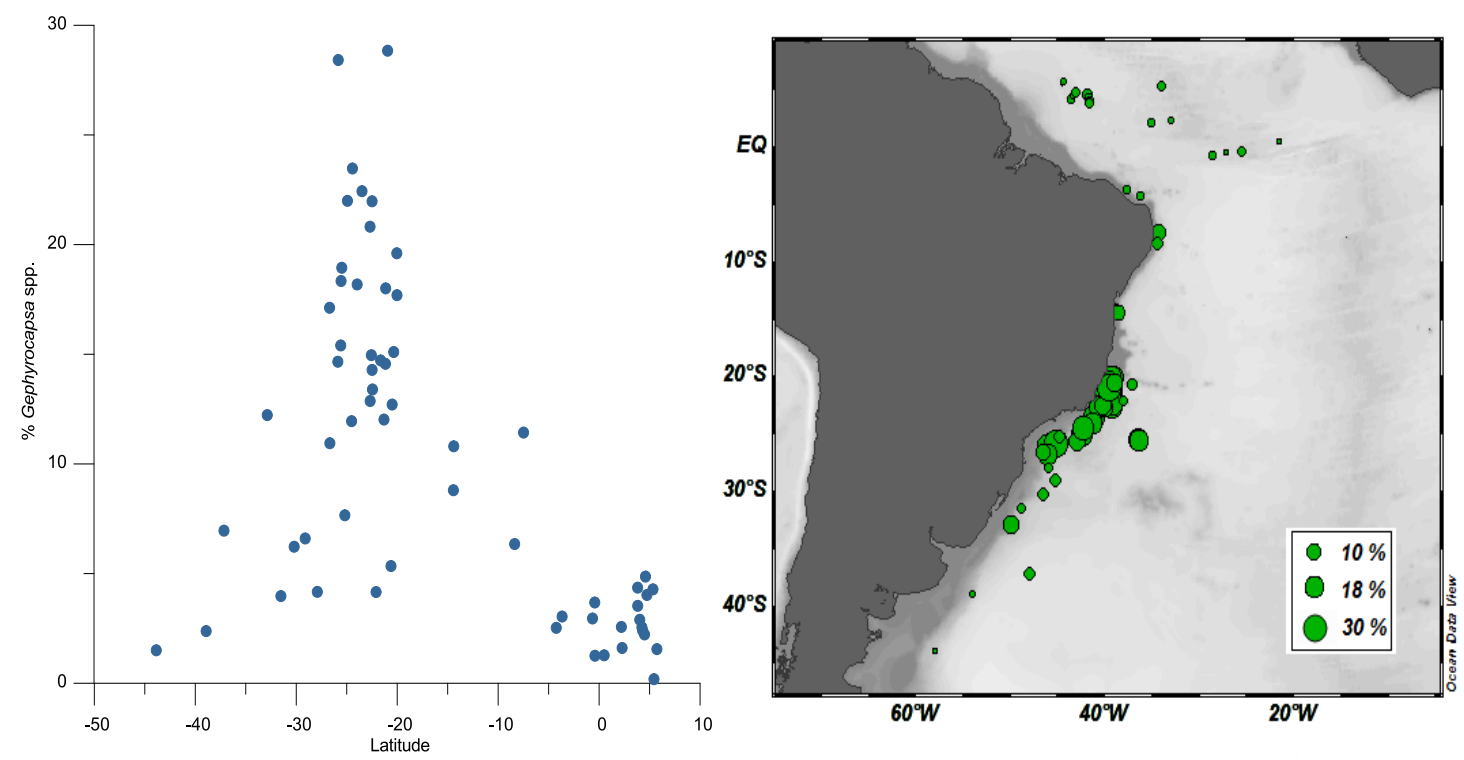

Figura 38 - À esquerda porcentagens da espécie Gephyrocapsa spp. em relação à latitude. À direita mapa de distribuição de Gephyrocapsa spp. ao longo da área de estudo.

G. oceanica por ser a espécie mais abundante do grupo apresentou uma distribuição similar a Gephyrocapsa spp. (Figura 39), no entanto com uma abundância relativa média menor (5,25\%).
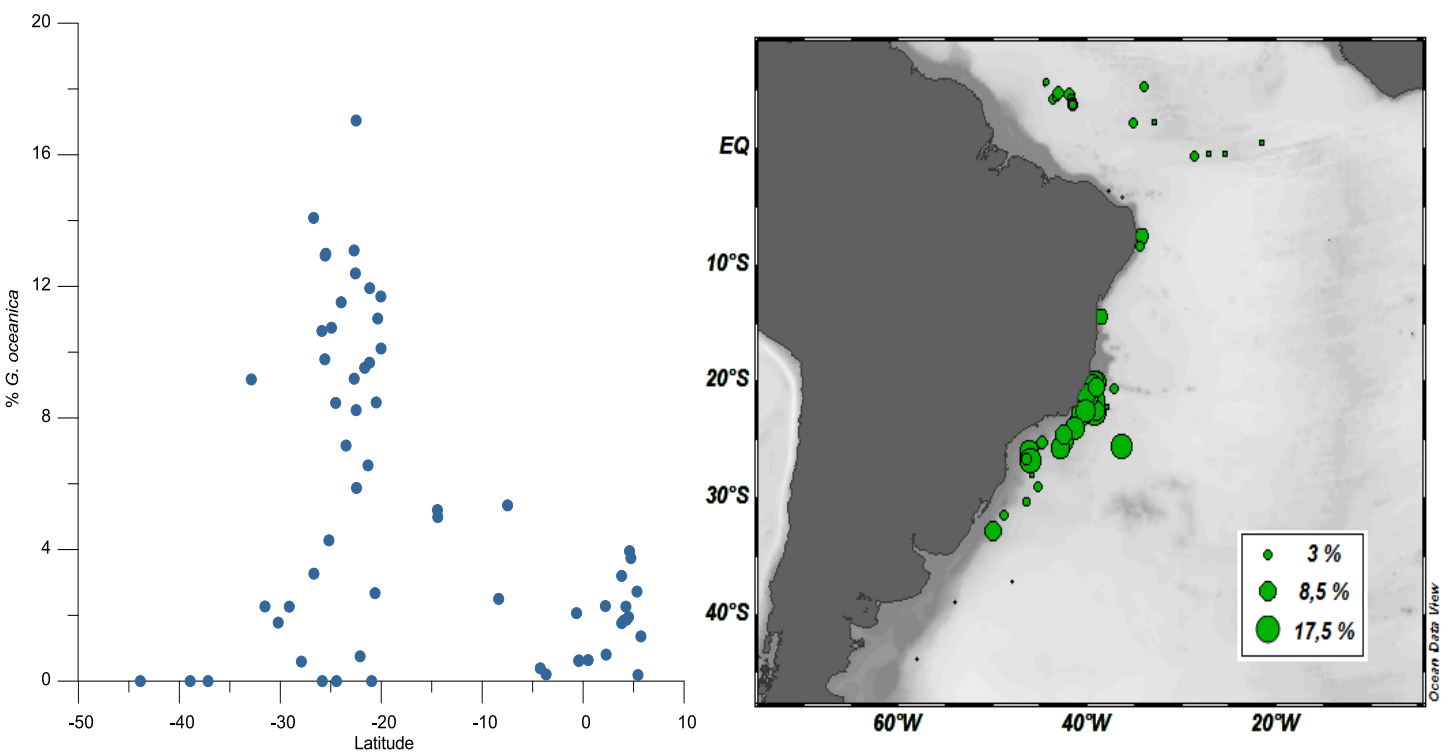

Figura 39 - À esquerda porcentagens da espécie G. oceanica em relação à latitude. À direita mapa de distribuição de G. oceanica ao longo da área de estudo. 
Já G. ericsonii revelou um padrão de distribuição distinto ao de Gephyrocapsa spp. e G. oceanica (Figura 40) e mais semelhante ao de E. huxleyi, no qual as maiores abundâncias relativas estão nas altas latitudes e vão decrescendo ao se irem se aproximando ao equador.

Suas abundâncias relativas foram muito menores quando comparadas a G. oceanica, com média de 1,60\%, e valores máximos entre 4\% e 7\%.
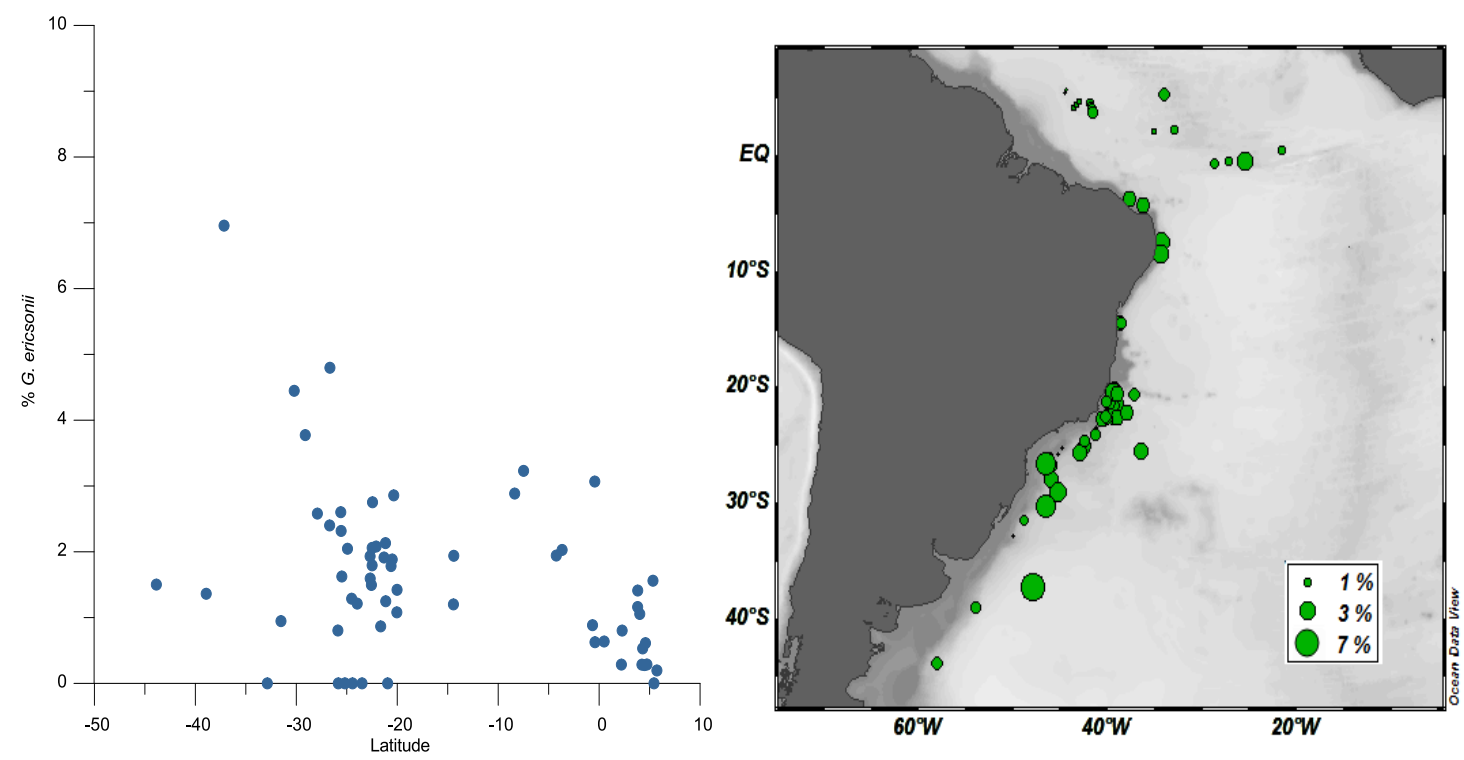

Figura 40 - À esquerda porcentagens da espécie G. ericsonii em relação à latitude. À direita mapa de distribuição de $G$. ericsonii ao longo da área de estudo.

\section{Gladiolithus flabellatus}

G. flabellatus foi uma espécie que em média pode ser considerada rara nas assembleias de cocolitoforídeos da região estudada, pois sua abundância relativa média foi de $3,63 \%$. Contudo os valores obtidos para esta espécie oscilam muito, estando ela ausente na maior parte das amostras das regiões mais ao sul, opondo-se a sua grande importância para a composição das assembleias nas regiões acima de $10^{\circ} \mathrm{S}$, nas quais alcança seus maiores valores chegando a abundâncias relativas próximas aos 25\% (Figura 41). 

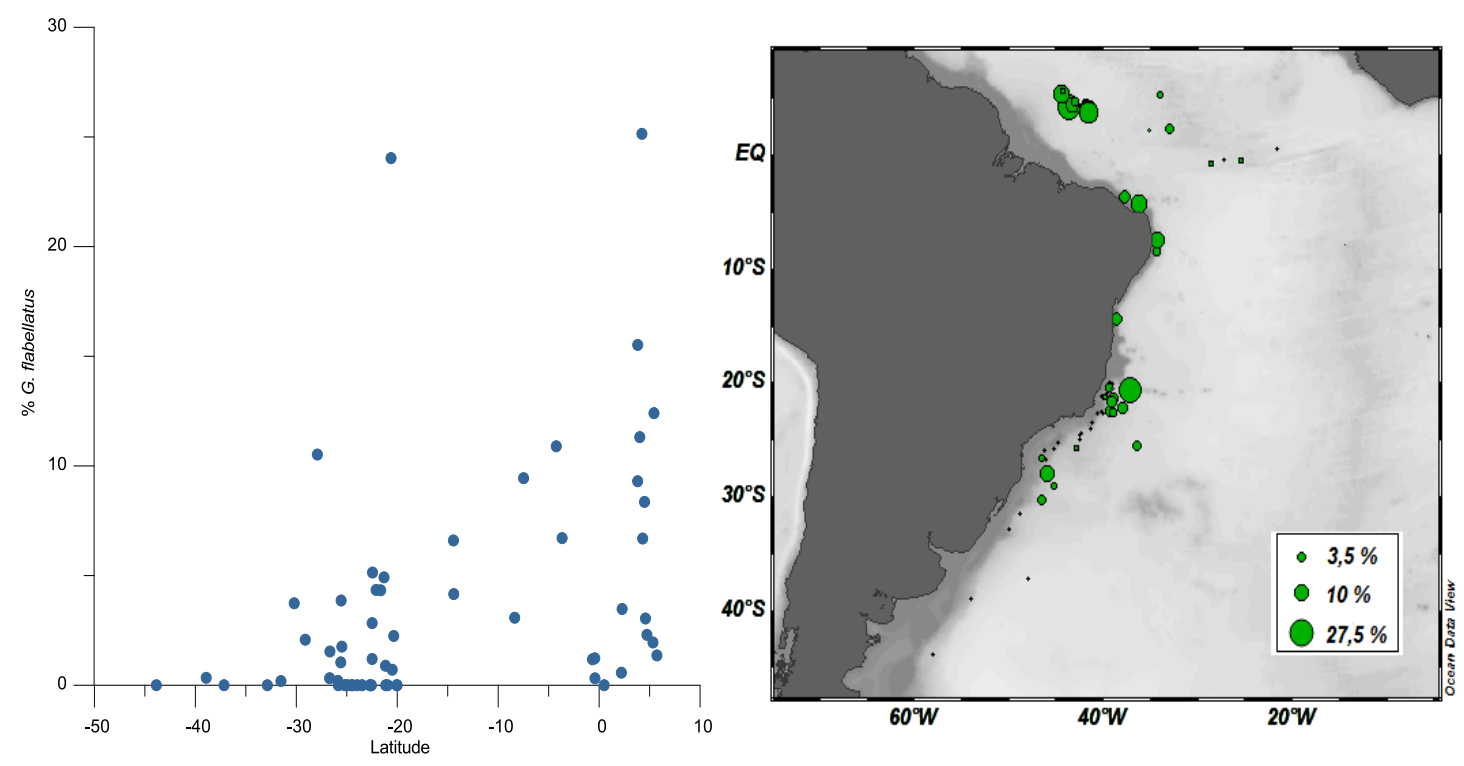

Figura 41 - À esquerda porcentagens da espécie G. flabellatus em relação à latitude. À direita mapa de distribuição de G. flabellatus ao longo da área de estudo.

\section{Helicosphaera spp.}

Referindo-se principalmente a espécie H. carteri este grupo, em geral, obteve baixas porcentagens, seu valor máximo de abundância relativa próximo a $3 \%$ e sua abundância relativa media $0,8 \%$ (Figura 42 ).

Seu padrão de distribuição não foi muito claro, no entanto pode-se notar uma preferência desta espécie pelas áreas próximas a $5^{\circ} \mathrm{N}$ e próximas a $25^{\circ} \mathrm{S}$, nas quais obteve suas maiores contribuições.
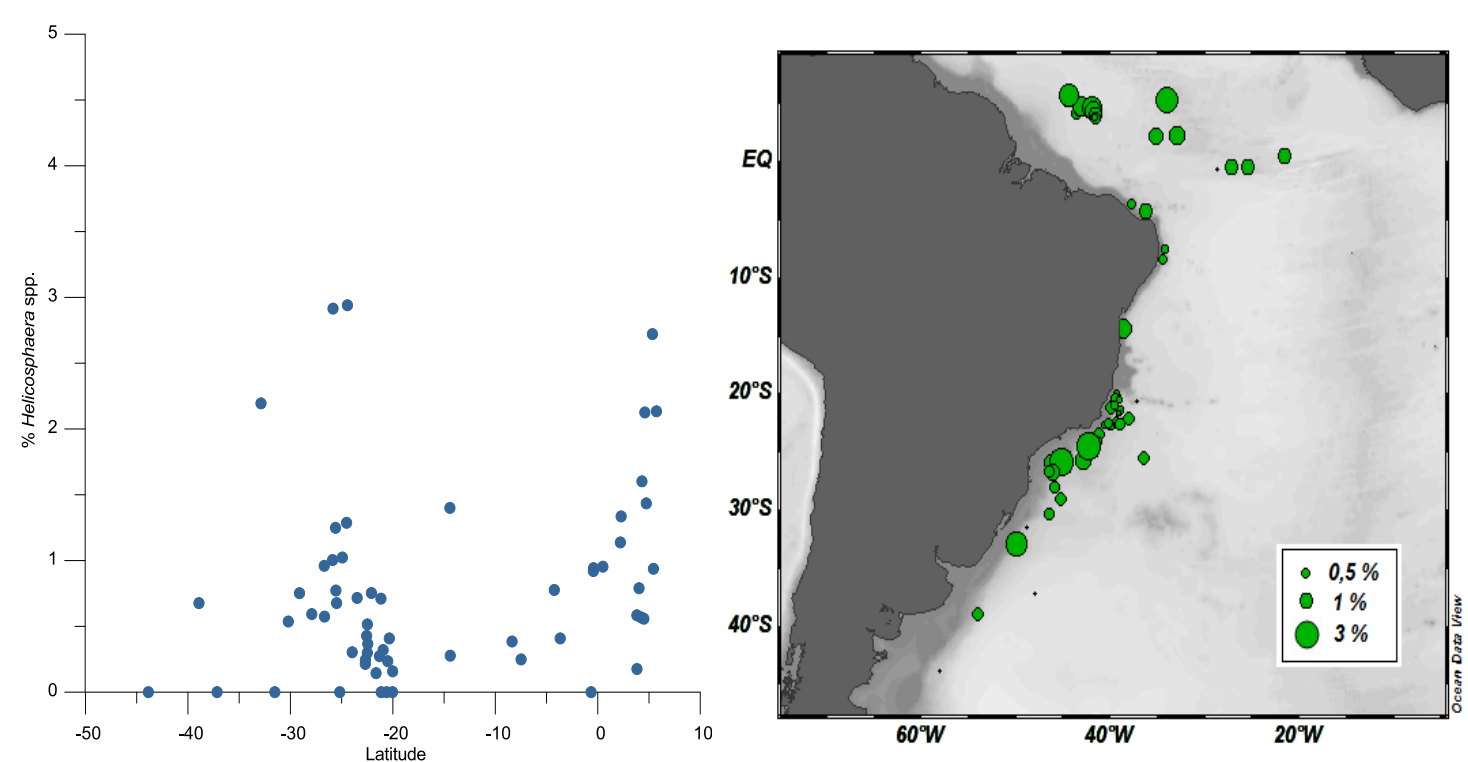

Figura 42 - À esquerda porcentagens da espécie Helicosphaera spp. em relação à latitude. À direita mapa de distribuição de Helicosphaera spp. ao longo da área de estudo. 


\section{Oolithotus fragilis}

$O$. fragilis apresentou padrões de distribuição semelhantes aos de $G$. flabellatus, com maiores valores na região equatorial (Figura 43). Todavia foi outra espécie considerada rara, conseqüentemente sua abundância relativa foi consideravelmente menor a de G. flabellatus, com a média dos valores atingindo apenas $1,5 \%$ e seu valor máximo chegando apenas a $10 \%$
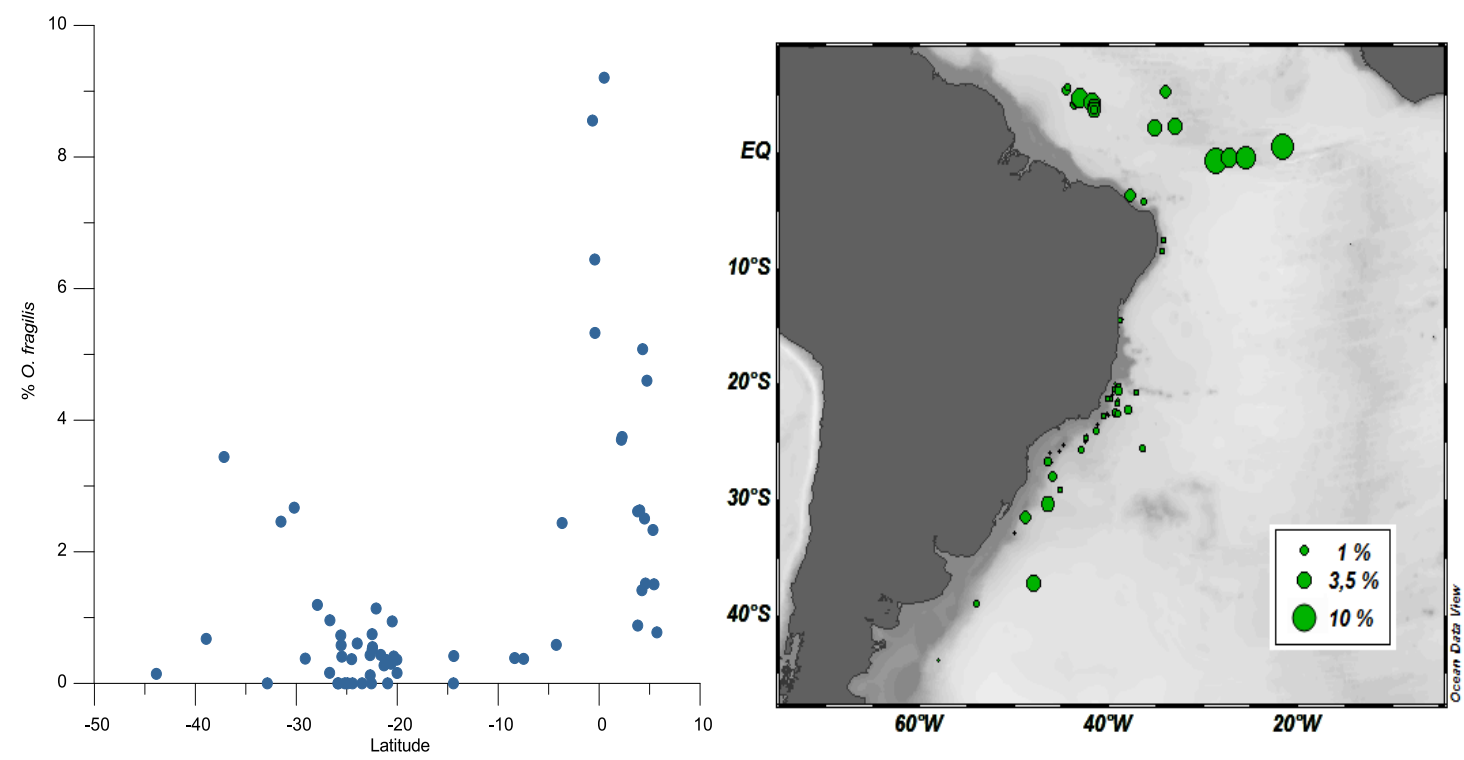

Figura 43 - À esquerda porcentagens da espécie $O$. fragilis em relação à latitude. À direita mapa de distribuição de $O$. fragilis ao longo da área de estudo.

\section{Rhabdosphaera spp.}

Este grupo foi composto pelas espécies $R$. clavigera var clavigera e $R$. clavigera var stylifera.

Rhabdosphaera spp não esteve presente em apenas três amostras e alcançou uma abundância relativa média de 1,67\%, deste modo foi considerada uma espécie frequente na área de estudo. Sua distribuição foi dispersa, entretanto, os maiores valores próximos a 4\%, ocorreram nas regiões tropicais e subtropicais, sendo ausente abaixo dos $35^{\circ} \mathrm{S}$ (Figura 44). 

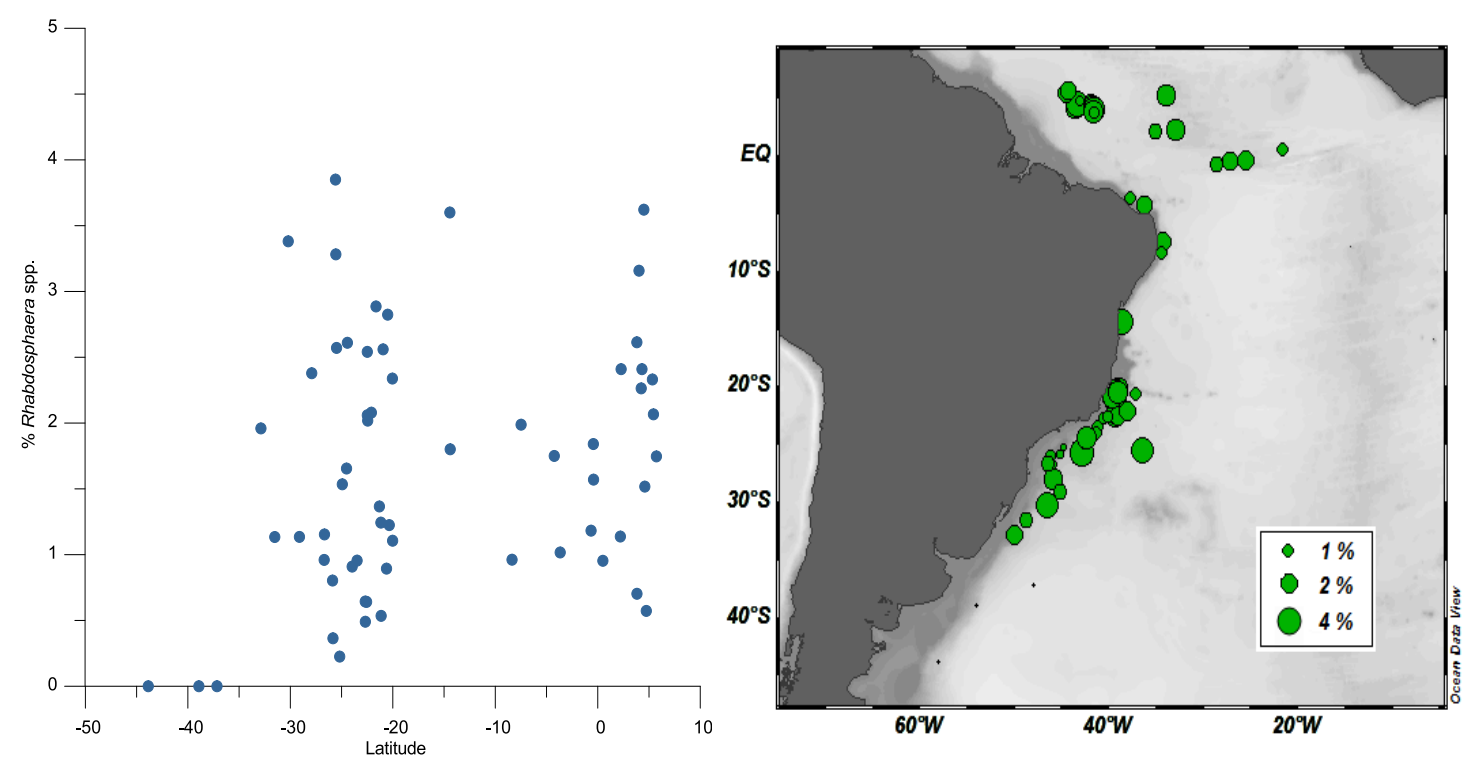

Figura 44 - À esquerda porcentagens da espécie Rhabdosphaera spp. em relação à latitude. À direita mapa de distribuição de Rhabdosphaera spp. ao longo da área de estudo.

\section{Syracosphaera spp.}

Composto principalmente pela espécie $S$. pulchra este grupo, assim como Rhabdosphaera spp., apresentou uma distribuição dispersa atingindo seus maiores valores $(4,5 \%)$ próximo a $10^{\circ} \mathrm{S}$. Syracosphaera spp. foi freqüente ao longo de toda a área de estudo com uma abundância relativa média de $1,56 \%$ (Figura 45 ).
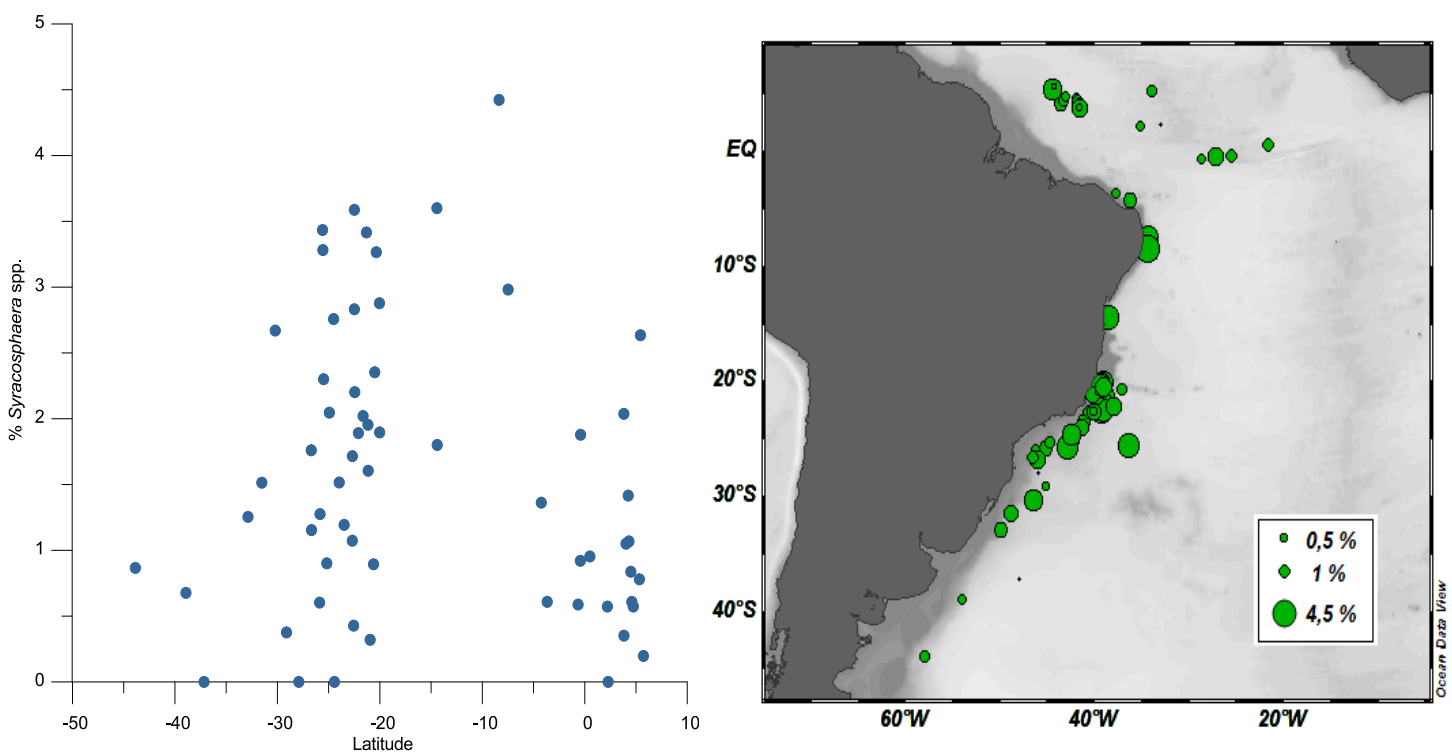

Figura 45 - À esquerda porcentagens da espécie Syracosphaera spp. em relação à latitude. À direita mapa de distribuição de Syracosphaera spp. ao longo da área de estudo. 


\section{Umbellosphaera spp.}

O grupo Umbellosphaera spp. é constituído pelas espécies $U$. tenuis e $U$. irregularis, com $U$. tenuis quase sempre mais abundante do que $U$. irregularis.

Umbellosphaera spp. foi considerado um grupo comum, pois não esteve presente em apenas duas contagens e obteve uma abundância relativa média de $3,5 \%$. A sua distribuição aparenta um acréscimo com o aumento da latitude, todavia os valores máximos próximos a 8-9\% estão ao lado da faixa subtropical (Figura 46).
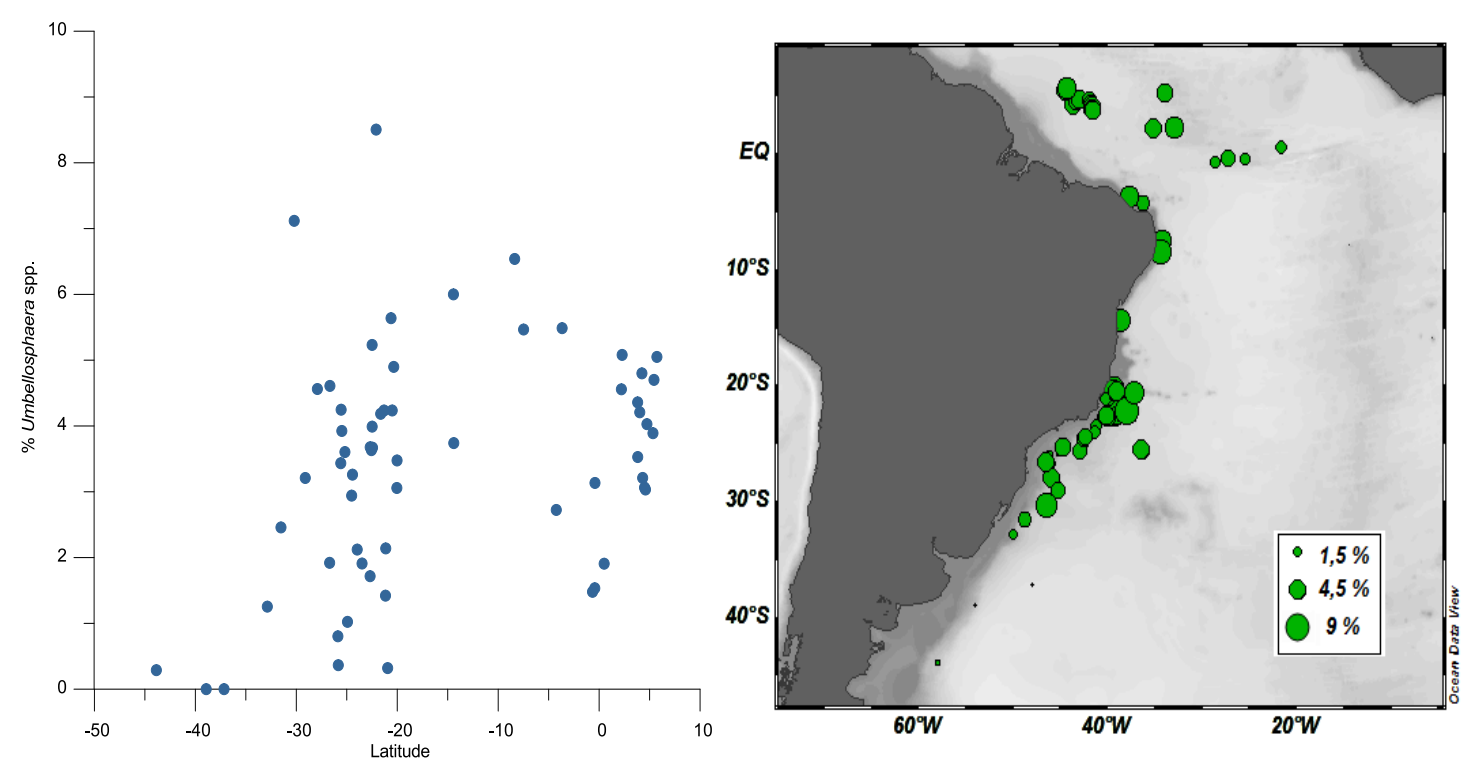

Figura 46 - À esquerda porcentagens da espécie Umbellosphaera spp. em relação à latitude. À direita mapa de distribuição de Umbellosphaera spp. ao longo da área de estudo.

\section{Umbilicosphaera spp.}

$U$. siboagae e $U$. foliosa são as duas principais espécies que compõe este grupo, sendo $U$ sibogae a espécie mais abundante.

Este grupo não demonstrou um claro padrão de distribuição, contudo atingiu as maiores abundâncias relativas próximas a $25^{\circ} \mathrm{S}$ e a $5^{\circ} \mathrm{N}$. Foi um grupo freqüente nas assembleias da área de estudo obtendo em média 3,9\% de abundância e com um valor máximo de 11,24\% (Figura 47). 

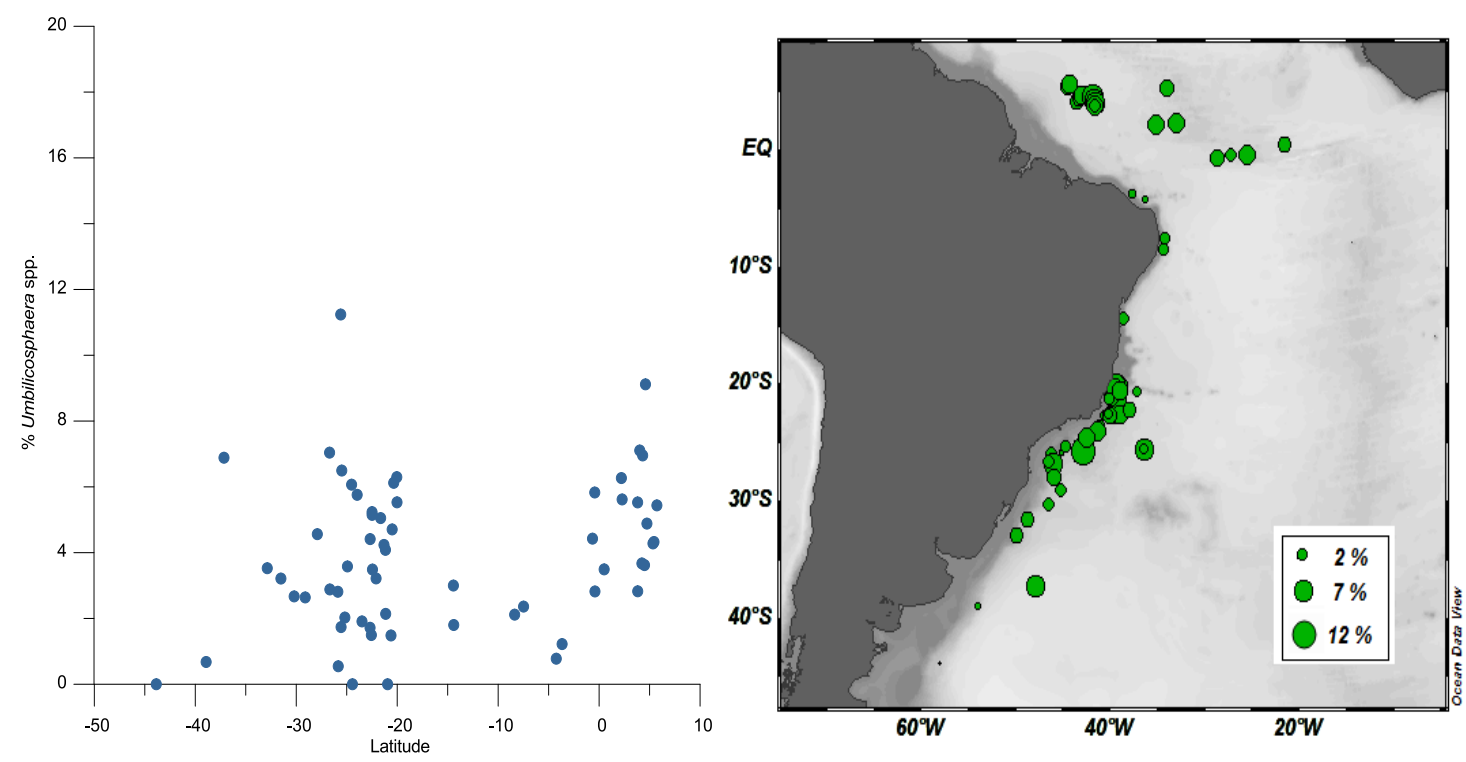

Figura 47 - À esquerda porcentagens da espécie Umbilicosphaera spp. em relação à latitude. À direita mapa de distribuição de Umbilicosphaera spp. ao longo da área de estudo.

\section{Grupo Subtropical}

Umbellosphaera spp., D. tubifera, Syracosphaera spp. e Rhabdosphaera spp. formam o grupo das espécies subtropicais, estas que possuem distribuições similares, com destaque para a característica de que suas maiores abundâncias ocorrem na região subtropical.

Quando somados estes taxa podem ser considerados comuns para as assembleias de cocolitoforídeos da região, já que sua abundância relativa média é de $7,23 \%$ e seus valores máximos próximos aos 16\% (Figura 48).
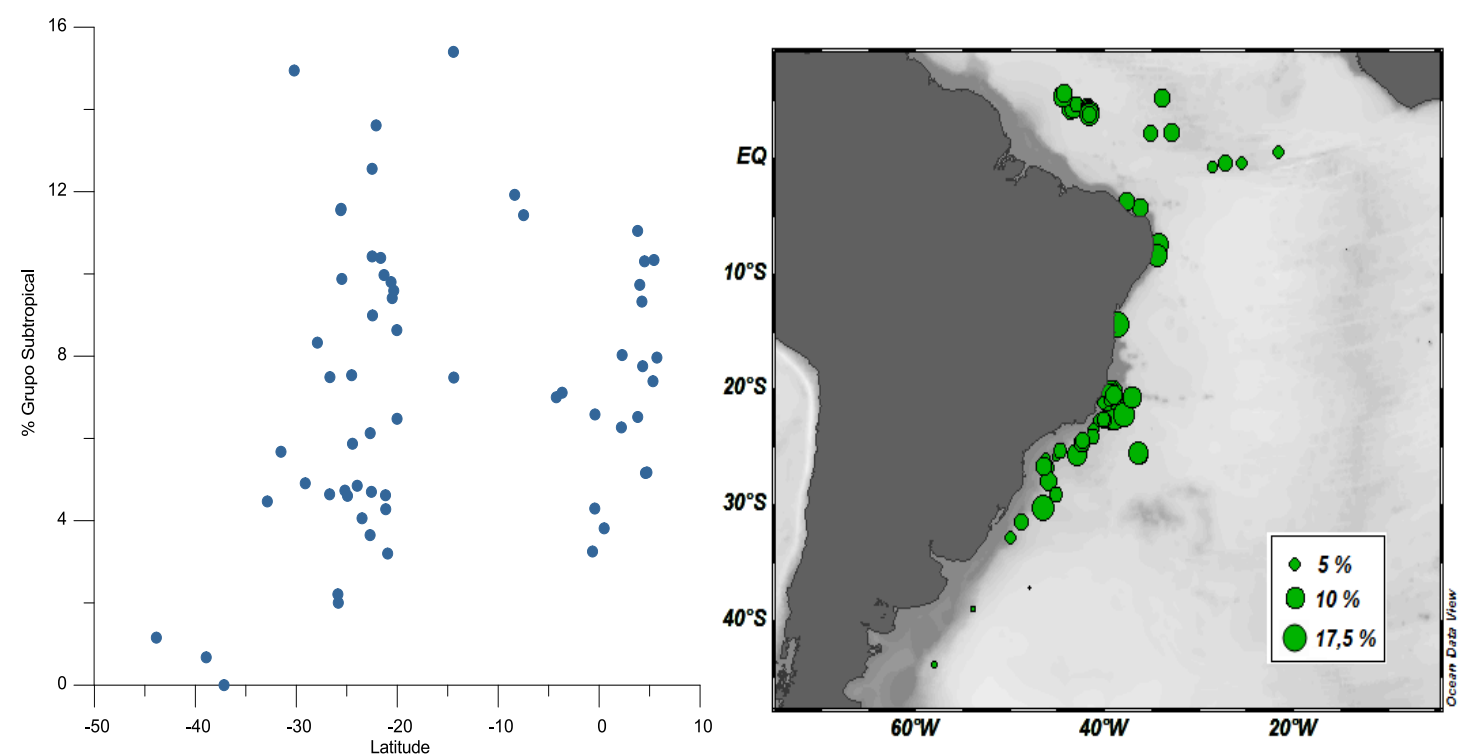

Figura 48 - À esquerda porcentagens das espécies do grupo Subtropical em relação à latitude. À direita mapa de distribuição do grupo Subtropical ao longo da área de estudo. 


\section{Discussão}

Após a análise dos dados de cronologia, tanto pelo método do radiocarbono quanto pela utilização de isótopos estáveis, as amostras mais antigas do que 6 mil anos ou consideradas não representativas do oceano atual foram excluídas das análises posteriores. Os últimos 6 mil anos foram determinados como limite, pois as condições de contorno do sistema climático não mudaram drasticamente quando comparadas a mudanças de escala interglacial-glacial (Wanner et al, 2008).

A dissolução não foi um parâmetro determinante nas amostras devido aos altos valores do índice CEX' (Figura 32). Além destes altos valores também ocorreram porcentagens consideráveis de espécies consideradas frágeis como $D$. tubifera, $O$. fragilis e $U$. irregularis, o que, mais uma vez, ressalta o bom estado de preservação das amostras quantificadas para as espécies de cocolitoforídeos.

\subsection{Preferências ecológicas dos principais taxa}

Seguindo a distribuição vertical dos cocolitoforídeos que estão principalmente na superfície e dentro da zona fótica, até aproximadamente $150 \mathrm{~m}$ de profundidade da coluna d'água, 14 parâmetros ambientais, separados em superfície e média entre 0 e $150 \mathrm{~m}$, foram selecionados para determinar as preferências ambientais de cada espécie, com isso os parâmetros escolhidos foram: concentração de Clorofila ( $\mathrm{Chl} 0 \mathrm{~m}$ e Chl 0-100m), Fosfato (Fosf Om e Fosf $0-150 \mathrm{~m}$ ), Nitrato (Nit Om e Nit 0-150m), Silicato (Sil Om e Sil 0-150m), Salinidade da Superfície do Mar (SSS Om e SSS 0-150m), Temperatura da Superfície do Mar (SST Om e SST 0-150m), Profundidade da Camada de Mistura (Prof. CDM) e Produtividade Primária Líquida (NPP).

Então uma matriz de correlação foi calculada a partir do logaritmo das abundâncias relativas das espécies de cocolitoforídeos $(\log X+1)$, dos parâmetros ambientais selecionados e dos dados de locais de coleta das amostras (profundidade) para determinar quais são as principais correlações de cada espécie. 
Uma das premissas para a realização da correlação de Pearson é a normalidade dos dados, como as porcentagens de cocolitoforídeos não foram gausianas, foi escolhida a transformação desses dados para a forma de logaritmos de $X+1$. A soma do valor 1 dá-se pela ocorrência de porcentagens nula $(0 \%)$ o que causaria problemas no caso de uma simples transformação em $\log X$, pois $\log 0=1$ e $\log 1=0$.

No caso das correlações com a profundidade de coleta os valores que foram inseridos eram negativos, portanto as amostras mais profundas têm os menores valores e as mais rasas os maiores. Para este parâmetro a intenção é uma comparação com a distância da quebra da plataforma continental, ou seja, as amostras que estão em regiões mais profundas estariam mais longe da plataforma continental e, portanto, em zonas menos turbulentas quando comparadas as amostras de regiões com menores profundidades, mais próximas a plataforma. Outro processo oceanográfico que pode influenciar nessa menor ou maior turbulência é a presença da $\mathrm{CB}$, que ao longo da costa brasileira acompanha a quebra da plataforma continental (Silveira et al., 2000) e é responsável por diversos processos de mesoescala (Calado et al, 2006; Soutelino et al, 2011; Arruda et al, 2013) influenciando diretamente algumas espécies de cocolitoforídeos.

Para o presente estudo consideraremos como padrão para a avaliação da intensidade de $r$ a escala sugerida por Callegari-Jacques (2003) levando em consideração cinco níveis de intensidade (Tabela 6).

Tabela 6 - Valores de re intensidade da correlação considerada. Modificado de CallegariJacques (2003)

\begin{tabular}{cc} 
valor de $r$ & intensidade da correlação \\
\hline \hline 0 & nula \\
$0,1-0,3$ & fraca \\
$0,3-0,6$ & moderada \\
$0,6-0,9$ & forte \\
1 & perfeita
\end{tabular}

A partir de agora cada espécie ou grupo de espécie será discutido separadamente conforme suas correlações com os parâmetros ambientais baseados na matriz de correlação (Tabela 7). Desde já deixa-se claro que as 
correlações não determinam relação de causa e efeito ou dependência elas determinam apenas a associação entre as duas variáveis, que neste caso são as abundâncias relativas e os parâmetros ambientais. Só serão discutidos os coeficientes de correlação de Pearson ( $r)$ que forem significativos, ou seja, aqueles nos quais o $p$-valor é menor do que 0,05 .

\section{Calcidiscus leptoporus}

A espécie $C$. leptoporus obteve correlação significativa com três parâmetros ambientais, sendo eles: profundidade de coleta, SSS e produtividade primária líquida (Tabela 7). Destas a correlação mais forte foi uma com intensidade regular com os valores de profundidade, -0,611, significando que esta espécie aumenta suas porcentagens conforme aumentamos a profundidade, ou seja, ela prefere as águas da zona fótica menos turbulentas de oceano aberto, quando comparadas as águas mais turbulentas próximas a plataforma continental. Tanaka (1991) em um estudo no Oceano Pacífico também definiu $C$. leptoporus como uma espécie de hábitos mais oceânicos.

As outras duas correlações foram fracas, tanto com SSS 0-150, -0,370, quanto com NPP, 0,240 (Tabela 7). No entanto estas correlações são importantes, pois nos dizem que esta espécie possui uma leve preferência por ambientes de águas menos salinas e mais produtivas, o que ocorre nas regiões temperadas e na região equatorial. Esta afinidade por águas menos salinas e mais produtivas no oceano Atlântico já havia sido observada por outros autores (Boeckel et al, 2006; Baumann et al, 2016), porém sendo associada a águas de clima temperado e subpolar.

\section{Calciosiolenia spp.}

O grupo Calciosiolenia spp. foi contabilizado apenas nas amostras provenientes do Lapas e correlacionou-se somente com a Profundidade da Camada de Mistura, ainda assim foi uma correlação regular de valor $r=0,402$ (Tabela 7). Isto indica que esta espécie está associada a ambientes com uma camada de mistura mais profunda, ou seja, a locais mais estratificados, que, por sua vez estão ligados a águas mais quentes e pobres e nutrientes com uma nutriclina profunda.

Esta correlação também pode estar diretamente ligada a posição desta espécie no zoneamento vertical, Calciosolenia brasiliensis é uma espécie da 
zona eufótica inferior (Poulton et al., 2017), portanto uma camada de mistura e uma nutriclina mais profundas contribuiriam para estes organismos obterem nutrientes e aumentarem suas populações.

\section{Coccolithus pelagicus}

Mesmo com as baixas porcentagens obtidas a espécie $C$. pelagicus associou-se a cinco variáveis ambientais, Chl 0-100m, Fosf 0-100m, Sil 0150m, SST 0-150m e NPP (Tabela 7).

Todos os valores de $r$ estão na faixa de correlação considerada fraca, contudo as associações que elas determinam demonstram um ambiente característico, as correlações foram positivas para os nutrientes (Fosfato e Silicato) e para os indicadores de produção primária (Clorofila e NPP), ao inverso da SST na qual a correlação foi negativa. Desta maneira fica clara preferência desta espécie por águas mais frias e eutróficas, característicos da região sul da área de estudo. Portanto esta espécie quando presente no registro, mesmo que em baixas abundâncias, revela um ambiente com tendências mais frias e eutróficas.

Boeckel et al (2006) também associaram $C$. pelagicus a locais mais dinâmicos e com mais nutrientes, assim como Cachão \& Moita (2000) que também observaram a preferência desta espécie por águas mais frias e ricas em nutrientes, porém correlacionando esta espécie a ambientes de ressurgência.

\section{Discosphaera tubifera}

D. tubifera distribui-se de maneira similar a G. flabellatus ao longo da área de estudo, com isso obteve correlações próximas aquelas apresentadas pela espécie citada, associando-se a nutrientes, temperatura, profundidade da Camada de Mistura e NPP (Tabela 7).

A maior correlação de $D$. tubifera foi moderada com a profundidade da Camada de Mistura, ou seja, a preferência por ambientes com os nutrientes em camadas mais profundas, mesmo sendo considerada uma espécie da zona fótica superior, habitando regiões até os $80 \mathrm{~m}$ de coluna d'água (Baumann et al, 2008). Essa afinidade também é observada pela correlação negativa com os nutrientes e positiva com a temperatura, sendo mais forte nos valores médios ao longo da zona fótica. 
Sendo assim a espécie $D$. tubifera é uma das espécies que apresenta preferência pelos ambientes pouco produtivos, quentes e oligotróficos da região tropical, o que também foi observado por Baumann et al (2008) que identifica esta espécie como característica das águas bem estratificadas do Giro Subtropical.

\section{Emiliania huxleyi}

A espécie mais cosmopolita na área de estudo, E. huxleyi, atingiu uma correlação significativa com praticamente todos os parâmetros ambientais da região, não sendo associada apenas as profundidades de coleta e da Camada de Mistura (Tabela 7). Esta espécie está associada positivamente a concentração de clorofila "a", a nutrientes e a produtividade primária liquida. Sendo associada negativamente a salinidade e a temperatura (Tabela 7).

Os maiores valores de $r$ obtidos por $E$. huxleyi foram nas correlações com NPP, temperatura e salinidade, demonstrando a preferência desta espécie por ambientes mais frios e eutróficos, o que também é demonstrado na correlação moderada e positiva com os nutrientes. Portanto E. huxleyi aumenta sua abundância relativa em regiões nas quais os nutrientes estão na camada fótica superior do oceano, ou seja, em regiões com uma nutriclina mais rasa.

A preferência ecológica desta espécie pode estar diretamente ligada ao fato dela ser uma grande competidora e ter uma ampla tolerância aos mais diversos ambientes (Mclntyre \& Bé, 1967; Brand 1994; Winter et al., 1994), fazendo com que ela possa competir com outras espécies do fitoplâncton, 0 que os outros cocolitoforídeos não são capazes de fazer. As correlações obtidas por este táxon também podem estar associadas à expansão desta espécie para as altas latitudes, em direção aos polos, ou seja, a regiões nas quais há mais nutrientes e uma maior produtividade primária.

\section{Florisphaera profunda}

Uma das espécies mais abundantes na região estudada, F. profunda, obteve as maiores correlações entre todos os grupos analisados (Tabela 7). Essa espécie correlacionou-se com praticamente todos os parâmetros ambientais, com exceção a profundidade de coleta, concentração de clorofila "a" e profundidade da Camada de Mistura (Tabela 7).

É importante destacar que as correlações obtidas por $F$. profunda foram todas correlações fortes, o que define bem a preferência ambiental desta 
espécie. Sendo ela correlacionada negativamente aos nutrientes em superfície e a NPP, e correlacionada positivamente à temperatura e salinidade. Com isso está espécie seria indicadora de zonas fóticas quentes e oligotróficas. Isso ocorre devido à zonação vertical desta espécie, F. profunda habita a zona fótica inferior, ou seja, as águas abaixo da termo/nutriclina. As regiões de clima quente têm a zona fótica superior oligotrófica, pois sua nutriclina é profunda, com isso os organismos que habitam a zona fótica superior são menos abundantes, favorecendo assim o aumento da abundância relativa de $F$. profunda.

Sua principal correlação foi com a produtividade primaria liquida, $r=$ 0,823 , ou seja, esta espécie está associada aos ambientes nos quais ocorrem uma baixa produtividade, o que está de acordo com o Índice de Paleoprodutividade estabelecido por Beaufort et al. (1997), fazendo com que a variação da Paleoprodutividade calculada por este índice seja válida para a área de estudo. Contudo, apenas com a análise pela correlação de Pearson não é possível sugerir sobre os valores quantitativos.

É importante observar que as abundâncias relativas de $F$. profunda estão negativamente correlacionadas a NPP e sequer são significativas para a concentração de clorofila, o que demonstra que esta espécie pode ser utilizada como indicador de produtividade, mas não de biomassa fitoplanctônica.

As correlações estabelecidas por $F$. profunda são o inverso das obtidas por E. huxleyi. As duas espécies são as mais abundantes da área de estudo e representam dois ambientes opostos, sendo E. huxleyi mais abundante em ambientes mais frios e eutróficos, enquanto $F$. profunda é mais abundante em regiões mais quentes e oligotróficas. As duas espécies estão correlacionadas diretamente a diferenças na profundidade da termo/nutriclina, enquanto $E$. huxleyi tem afinidade por regiões nas quais a nutriclina é mais rasa e os nutrientes estão disponíveis na zona fótica superior, diluindo a abundância relativa de $F$. profunda, que por outro lado tem preferência por nutriclinas mais profundas nas quais os nutrientes estão disponíveis principalmente para os organismos que habitam a zona fótica inferior ou a zona sub-eufótica.

\section{Gephyrocapsa spp.}

O gênero Gephyrocapsa obteve correlações significativas com a profundidade de coleta, com a salinidade e com profundidade da Camada de 
Mistura (Tabela 7). A correlação mais forte foi a com a profundidade de coleta, 0,853 , o que indica que este grupo está associado a menores profundidades de coleta, ou seja, ele tem preferência pelas regiões mais costeiras da área de estudo, o que também pode ser notado na correlação negativa com a profundidade da Camada de Mistura, pois seus menores valores ocorreram nos locais mais próximos a plataforma continental.

No entanto este grupo apresentou uma correlação positiva moderada com a salinidade (Tabela 7), o que poderia rejeitar a hipótese de que ele tem preferência pelas águas mais próximas a plataforma, pois estas estariam sobre a influência de águas menos salinas quando comparadas ao oceano aberto. Contudo suas maiores abundâncias relativas estão no sudeste brasileiro, região que tem altos valores de salinidade mesmo em baixas profundidades quando comparados as outras localidades da área de estudo, portanto a correlação com a salinidade não refuta a hipótese de que este grupo tem preferência por habitats mais próximos a plataforma, ou seja, de menores profundidades.

A correlação com menores profundidades e com a Camada de Mistura (Tabela 7), além de estar ligada a proximidade da plataforma, pode estar no fato desta espécie ser abundante próxima a ocorrência dos vórtices ciclônicos de mesoescala na região sudeste e a meandramentos da $\mathrm{CB}$, com isso Gephyrocapsa spp. estaria ligada a ambientes mais turbulentos e com um alto índice de nutrientes na zona fótica superficial, sendo beneficiada por estes vórtices. Portanto Gephyrocapsa spp. é uma boa indicadora da variação da termo/nutriclina, pois suas maiores abundâncias ocorrem quando a camada de mistura é mais rasa, ou seja, a nutriclina fica mais próxima a superfície, o que está de acordo com a Razão N proposta por Flores et al (2000) tornando esta espécie, em conjunto com E. huxleyi e $F$. profunda, um importante indicador para a posição da nutriclina na região equatorial e sudoeste do oceano Atlântico.

Quando analisamos as espécies deste gênero separadamente, observamos que a espécie G. muellerae é pouco abundante no registro, praticamente ausente, logo não será discutida.

A espécie $G$. oceanica por ser a mais abundante deste gênero obteve correlações similares as do grupo como um todo com modificações apenas na 
intensidade das associações, portanto, ela exerce a mesma preferência ecológica. No Pacífico oeste também foram encontradas maiores abundâncias de G. oceanica em regiões costeiras e mares marginais (Okada, 1992), assim como no Mar da Arábia onde esta espécie foi considerada com maior afinidade a águas mais costeiras e eutróficas (Andruleit \& Rogalla, 2002).

Por sua vez $G$. ericsonii demonstra uma distribuição diferente, com um padrão mais próximo de $E$. huxleyi, o que é similar ao encontrado em outros trabalhos que chegam a contabilizar os cocólitos menores do que $3 \mu \mathrm{m}$ das duas espécies em conjunto (Flores et al, 2000; Saavedra-Pellitero et al, 2010).

\section{Gladiolithus flabellatus}

Esta espécie correlacionou-se com os nutrientes, com temperatura, com a profundidade da Camada de Mistura e com NPP. Sendo as principais correlações com a profundidade da Camada de Mistura e com a temperatura (Tabela 7).

A principal associação de G. flabellatus foi uma forte correlação positiva com a profundidade da Camada de Mistura, ou seja, quanto maior a profundidade da termo/nutriclina, maiores são as abundâncias relativas desta espécie. Isto devido a dinâmica entre os nutrientes e a zonação vertical desta espécie, por ser da zona fótica inferior (Poulton et al., 2017) G. flabellatus aumenta suas populações quando os nutrientes estão em maiores profundidades da zona fótica, pois quando estes nutrientes estão disponíveis a toda camada fótica eles são absorvidos preferencialmente por espécies de cocolitoforídeos mais competitivas.

Representante da região tropical de Mclntyre \& Bé (1967), G. flabellatus, apresentou uma moderada associação positiva a temperaturas médias da zona fótica, o que condiz tanto com sua biogeografia quanto com sua zonação vertical.

Além destas correlações $G$. flabellatus também tem uma fraca associação negativa a profundidade, nutrientes e a NPP, todavia demonstrando claramente sua preferência ambiental pelas águas mais quentes, oligotróficas e estratificadas da região tropical, concordando com o observado em diversos outros estudos (Kinkel et al, 2000; Boeckel et al, 2006)

\section{Helicosphaera spp.}


Este gênero foi pouco abundante ao longo do registro, e com isso sua interpretação deve ser cuidadosa. Ainda assim houveram quatro correlações, todas fracas, significativas para este grupo, com os nutrientes e com a salinidade (Tabela 7).

Helicosphaera spp. esteve presente nas amostras nas quais houve mais diversidade, o que está diretamente ligado ao conteúdo de nutrientes. Uma grande diversidade de cocolitoforídeos está associada a áreas mais oligotróficas (Boeckel et al, 2006), o que está de acordo com sua correlação inversa com os nutrientes.

Esta correlação obtida para os nutrientes é o oposto da encontrada em outros trabalhos que correlacionam Helicosphaera spp. a águas mais ricas em nutrientes (Baumann et al, 2000; Boeckel et al, 2006). No entanto Brand (1994) relata que Helicosphaera spp. não aumenta em abundância em áreas de ressurgência ou em regiões de altas concentrações de nutrientes no oceano, o que seria um indicador de um extremo K-estrategismo em condições oligotróficas, condições estas que observamos na área de estudo e condizem com os resultados obtidos nesta análise univariada.

Portanto como as correlações para com os nutrientes desta espécie são fracas e sua distribuição demonstra a presença de Helicosphaera spp. próxima a regiões com índices de nutriente ligeiramente mais altos na área de estudo, Helicosphaera spp. quando analisada univariadamente possui características de uma espécie mesotrófica, sendo presente em regiões onde não há concentrações extremas de nutrientes. O que também foi observado por Ziveri et al (2004) no Atlântico, por Saavedra-Pellitero et al (2010) no Pacifico e por Andruleit \& Rogalla (2002) no oceano Índico.

\section{Oolithotus fragilis}

A espécie $O$. fragilis foi outra espécie pouco abundante ao longo da área de estudo, ainda assim obteve correlação com seis parâmetros ambientais (Tabela 7). Sua principal associação foi uma forte correlação direta com a profundidade, ou seja, a presença de $O$. fragilis é maior em ambientes mais oceânicos.

As outras correlações foram todas fracas, com esta espécie sendo correlacionada inversamente aos nutrientes e a salinidade, ambos na superfície, e correlacionada diretamente a temperatura na superfície e a 
profundidade da Camada de Mistura. Portanto esta espécie está ligada a ambientes quentes, oligotróficos e, principalmente, a ambientes estratificado ou com pouca turbulência, devido à correlação com a Camada de Mistura e aos parâmetros superficiais, mesmo que esta espécie seja considerada da Zona Fótica Inferior por Baumann et al. (2008).

\section{Rhabdosphaera spp.}

Composto na área de estudo por $R$. clavigera e $R$. stylifera este gênero correlacionou-se com praticamente todos os parâmetros, com a exceção da profundidade de coleta e concentração de clorofila na superfície (Tabela 7). Por mais que estas espécies sejam da zona fótica superior (Baumann et al. 2008) suas correlações mais fortes foram com as médias da zona fótica o que revela sua distribuição ao longo desta região e, por sua vez, demonstra que este grupo reflete de maneira mais clara as propriedades da coluna superficial como um todo.

Rhabdosphaera spp. obteve correlações positivas com temperatura, salinidade e profundidade da Camada de Mistura, e negativas com os nutrientes e com os dois indicadores de produtividade primária: clorofila e NPP. As associações mais fortes são as com a temperatura e com os nutrientes, com isso podemos inferir que os ambientes preferenciais deste grupo são os quentes e oligotróficos, com uma leve tendência a preferir os ambientes de baixa produtividade.

Por sua vez a correlação positiva com a profundidade da camada de mistura em conjunto com a correlação negativa para nutrientes pode ser considerada como uma preferência por regiões nas quais existe uma nutriclina mais profunda. Portanto esta espécie está associada a uma camada superficial com menos produtividade e menos nutrientes, assim como também foi observado por Saavedra-Pellitero et al (2010) no oceano Pacífico.

\section{Syracosphaera spp.}

Syracosphaera spp. obteve correlação com seis parâmetros ambientais, sendo eles: profundidade de coleta, concentração de clorofila, fosfato e silicato, salinidade e produtividade primária líquida. As associações foram moderadas com a profundidade de coleta, com a concentração de clorofila e com a salinidade, e fracas com os nutrientes e NPP (Tabela 7). 
Deste modo este gênero apresentou afinidade por regiões mais próximas a plataforma, salinas e com baixa produtividade, ou seja, em geral Syracosphaera spp. esteve correlacionada a águas com menores índices de produtividade, podendo também ser associada as regiões mais oligotróficas da área de estudo. Esta associação a regiões oligotróficas está de acordo com outros autores (Young, 1994; Andruleit \& Rogalla, 2002).

\section{Umbellosphaera spp.}

Representado por $U$. irregularis e $U$. tenuis este gênero foi uma das espécies subtropicais mais abundantes na área de estudo. Este grupo apresentou correlações significantes com sete parâmetros ambientais, sendo eles: nutrientes de 0 a $150 \mathrm{~m}$, salinidade de 0-150 m, temperatura de 0 a $150 \mathrm{~m}$, profundidade da Camada de Mistura e NPP (Tabela 7). O grupo, mesmo sendo considerado da zona fótica superior (Winter et al., 1994; Baumann et al., 2008; Poulton et al., 2017), correlacionou-se particularmente com os parâmetros médios da zona eufótica, o que nos revela esta espécie como uma indicadora da camada fótica como um todo e não apenas da zona superficial.

As principais associações ocorreram com NPP, temperatura e com os nutrientes (Tabela 7). As correlações com NPP e nutrientes foram negativas, enquanto no caso da temperatura a correlação foi positiva. Com isso podemos afirmar a afinidade destas espécies por águas quentes e com poucos nutrientes, levando a uma baixa produção primária. Essas características são observadas em ambientes como as águas oligotróficas do Giro Subtropical ou as próximas ao nordeste da margem Brasileira.

A mesma preferência por águas quentes e oligotróficas foi observada por Kinkel et al (2000), utilizando amostras apenas do Atlântico Equatorial, e por Boeckel et al (2006), utilizando amostras do Atlântico Sul inteiro.

\section{Umbilicosphaera spp.}

Composto principalmente por $U$. sibogae este grupo foi caracterizado pelas correlações com NPP, temperatura e nutrientes em superfície (Tabela 7). Sua associação mais relevante foi a correlação negativa com os nutrientes em superfície, em especial com os silicatos, o que pode ser uma demonstração por afinidade ligada a águas com menores concentrações destes elementos, ou seja, na área de estudo, são aquelas distante da influência de descargas fluviais. A associação a locais de pouca produtividade primária líquida também 


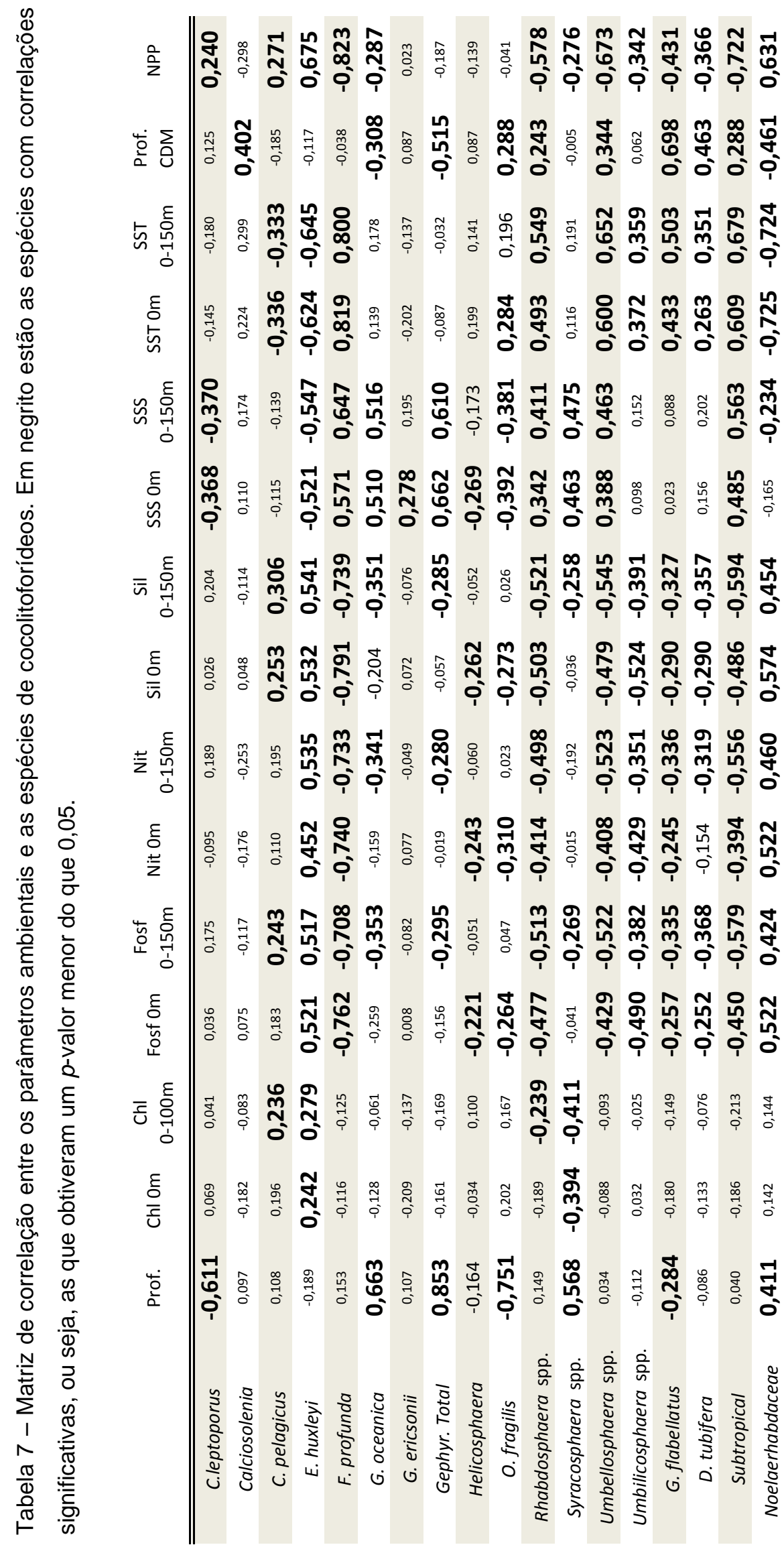


fortalece esta hipótese, uma vez que as regiões nas quais há considerável descarga fluvial ocorrem altas taxas de NPP. Com isso esta espécie demonstra uma leve afinidade a ambientes mais oceânicos de menor turbulência, fato que também foi observado por Okada (1992) em um estudo na região costeira do Pacífico Ocidental, porém esta preferência não foi observada por Tanaka (1997) em amostras de armadilhas de sedimento do Mar da China.

No que se diz respeito à temperatura este gênero tem uma leve preferência por maiores temperaturas em superfície. Umbilicosphaera spp. esteve associado aos parâmetros em superfície, o que não condiz com sua zonação vertical, pois diferentes autores destacam estas espécies como da zona fótica logo abaixo a superior (Baumann et al., 2008; Poulton et al., 2017).

Portanto Umbilicosphaera spp. pode ser considerada uma espécie com preferência por águas superficiais mais quentes e oligotróficas, o que também é observado em outros estudos (Boeckel et al, 2006; Saavedra-Pellitero et al, 2010; Baumann et al, 2016).

\section{Grupo Subtropical}

Composto por D. tubifera, Umbellosphaera spp, Rhabdosphaera spp. e Syracosphaera spp. o grupo Subtropical atingiu correlações significantes com praticamente todos os parâmetros ambientais, com exceção da profundidade de coleta e da concentração de clorofila (Tabela 7).

As correlações obtidas por este grupo estiveram mais próximas as observadas nas espécies Rhabdosphaera spp. e Umbellosphaera spp., sendo mais distante dos padrões observados em $D$. tubifera e Syracosphaera spp. Muito provavelmente devido ao fato das duas primeiras espécies serem mais abundantes na maioria das amostras.

As principais associações obtidas por este grupo foram a negativa com NPP e a positiva com a temperatura, com ambas sendo fortes e demonstrando a preferência pelas águas quentes e pouco produtivas da região subtropical. Para reafirmar essa afinidade o grupo também tem uma fraca correlação com a profundidade da Camada de Mistura, ou seja, ele está associado a maiores profundidades da termo/nutriclina com os nutrientes presentes em maiores profundidades da zona fótica. 
Também é interessante observar as correlações negativas e moderadas com os nutrientes, fato que também comprova a afinidade por ambientes mais oligotróficos.

\section{Grupo Noelaerhabdaceae}

Este grupo é formado pela soma das abundâncias relativas de E. huxleyi $e$ do genêro Gephyrocapsa spp. O grupo alcançou correlações significativas com diversos parâmetros (Tabela 7), sendo as principais com temperatura, NPP, profundidade da Camada de Mistura e nutrientes em superfície, com exceção a temperatura e a profundidade da Camada de Mistura, todas as correlações foram positivas.

O conjunto dessas espécies então caracteriza águas mais frias, turbulentas e com camadas de mistura mais rasas, ou seja, uma nutriclina mais rasa, caracterizando uma zona de alta produção primária e rica em nutrientes.

\subsubsection{Análise Multivariada}

Como visto nas sessões anteriores diversos parâmetros ambientais controlam a distribuição dos cocolitoforídeos, com isso uma análise multivariada que leve em consideração essas variações, bem como a própria variação das assembleias, se faz necessária. Para tal a Análise de Correspondência Canônica (ACC) foi escolhida, pois esta análise permite aliar estas duas partes da análise. A ACC foi calculada a partir dos logaritmos das abundâncias relativas das espécies de cocolitoforídeos, assim como no item anterior, e pelo mesmo motivo.

Os dois primeiros eixos da ACC (Figura 49) foram os únicos utilizados para este estudo tendo em vista que juntos correspondem a $74,15 \%$ da variabilidade total dos dados (Tabela 8 ). No intuito de avaliar quais parâmetros estão relacionados a cada eixo uma correlação de Pearson foi elaborada utilizando os scores retirados da ACC e, portanto, correlacionando os eixos aos parâmetros (Tabela 8).

Tabela 8 - Porcentagem da variância explicada por cada eixo da Análise de Correspondência Canônica.

\begin{tabular}{cc} 
Eixo & $\%$ \\
\hline \hline 1 & 42,16 \\
2 & 31,99
\end{tabular}


Com esta análise foi possível notar que o eixo 1 está correlacionado a profundidade de coleta das amostras $(r=-0,786)$ e a profundidade da Camada de Mistura $(r=0,586)$. Enquanto o eixo 2 está correlacionado a presença de todos os nutrientes $(r \approx 0,6)$, profundidade da Camada de Mistura $(r=-0,404)$ temperatura $(r=-0,698)$, salinidade $(r=-0,530)$ e a NPP $(r=0,713)$, ou seja, o eixo 2 está correlacionado principalmente a zonas de alta produção primária, frias $\mathrm{e}$ com um alto índice de nutrientes (Tabela 9).

É importante destacar a presença da profundidade da Camada de Mistura em ambos os eixos, sendo a correlação no Eixo 1 positiva e no Eixo 2 negativa, o que nos leva a interpretação de que as amostras com valores positivos do Eixo 1 e negativos do Eixo 2 são extremamente correlacionadas a uma Camada de Mistura profunda, com o inverso sendo válido, ou seja, valores negativos do eixo 1 e positivos no eixo 2 revelam a preferência por menores Camadas de Mistura.

Tabela 9 - Correlação entre cada eixo da Análise de Correspondência Canônica e os parâmetros ambientais. Em negrito estão os valores significativos.

\begin{tabular}{ccc} 
& Eixo 1 & Eixo 2 \\
\hline \hline Profundidade & $\mathbf{- 0 , 7 8 6}$ & $-0,135$ \\
Chl 0m & 0,073 & 0,228 \\
Chl 0-100m & 0,057 & 0,196 \\
Fosf 0m & $-0,140$ & 0,452 \\
Fosf 0-150m & 0,029 & $\mathbf{0 , 6 2 7}$ \\
Prof. da CDM & $\mathbf{0 , 5 8 6}$ & $\mathbf{- 0 , 4 0 4}$ \\
Nit 0m & $-0,226$ & 0,371 \\
Nit 0-150m & 0,022 & $\mathbf{0 , 6 1 8}$ \\
Sil 0m & $-0,200$ & 0,496 \\
Sil 0-150m & 0,032 & $\mathbf{0 , 6 4 2}$ \\
SSS 0m & $-0,458$ & $-0,444$ \\
SSS 0-150m & $-0,411$ & $\mathbf{- 0 , 5 3 0}$ \\
SST 0m & 0,251 & $-0,611$ \\
SST 0-150m & 0,218 & $\mathbf{- 0 , 6 9 8}$ \\
NPP & $-0,057$ & $\mathbf{0 , 7 1 3}$
\end{tabular}

Portanto as espécies que estão nos maiores valores do Eixo 1 são as que têm afinidade com águas mais oceânicas e camadas de mistura mais 
profundas. As espécies mais alinhadas ao Eixo 1 e a este tipo de ambiente foram Helicosphaera spp., Umbilicosphaera spp. e G. flabellatus (Figura 49).

Por sua vez as espécies com menores valores deste eixo representam águas mais costeiras e com menores camadas de mistura, destacando principalmente a espécie G. oceanica e, por consequência, Gephyrocapsa spp.

Nos maiores valores do Eixo 2 ficam evidenciadas as espécies $E$. huxleyi, C. leptoporus e C. pelagicus (Figura 49), pois estas espécies estão alinhadas a este tipo de ambiente, o que podemos notar também é a presença de $G$. ericsonii próxima a $E$. huxleyi, demonstrando a relação próxima destas duas espécies.

C. leptoporus, E. huxleyi, C. pelagicus e $G$ ericsonii demonstraram associação a águas com uma maior quantidade de nutrientes, pois ficaram do lado positivo do Eixo 2, com isso também ressaltaram a preferência por regiões mais produtivas, no entanto $C$. leptoporus ao contrário das outras espécies esteve do lado positivo do Eixo 1, local que está relacionado a uma camada de mistura mais profunda. Provavelmente pelo fato desta espécie ser mais abundante na região tropical. Por sua vez C. pelagicus, E. huxleyi e G. ericsonii apresentam uma maior afinidade a nutrientes na superfície (Figura 49).

Gephyrocapsa spp. e Helicosphaera spp. também exibiram relação a regiões com mais nutrientes, porém com uma menor intensidade, sendo apenas uma leve tendência, estando associadas a ambientes superficiais mais turbulentos, assim como observado por Boeckel et al. (2006).

As espécies do gênero Gephyrocapsa, bem como o grupo considerado como um todo, estão alinhadas ao eixo 2 e em valores positivos do eixo 1 , evidenciando sua preferência por águas mais dinâmicas e com camadas de mistura mais rasas e, por consequência, com mais nutrientes na zona fótica. Vale destacar que Gephyrocapsa spp. está alinhada ao eixo das salinidades, o que revela uma afinidade deste grupo com maiores valores deste parâmetro (Figura 49).

Outro fato que chama a atenção é a espécie $G$. ericsonii estar mais próxima e, portanto, mais relacionada a $E$. huxleyi do que a $G$. oceanica, demonstrando que a contagem de placólitos pequenos, somando $E$. huxleyi e G. ericsonii, não leva a uma análise ambiental tendenciosa, afinal estas espécies estão de acordo quanto trata-se de preferências ecológicas. 
Mais uma vez fica clara a preferência de C. pelagicus e E. huxleyi por regiões com maiores taxas de NPP, alto conteúdo de nutrientes na superfície, principalmente Nitrato, e regiões de menores temperaturas.

G. flabellatus e $D$. tubífera possuem uma forte associação a águas com camadas de mistura mais profundas, ou seja, águas superficiais mais pobres em nutrientes, favorecendo organismos da zona fótica inferior, podendo ser boas espécies para a utilização, juntamente com $F$. profunda, como indicadores da profundidade da termo/nutriclina. Isso pode ser notado pela posição bastante positiva no eixo 1 e a proximidade com o eixo da profundidade da camada de mistura (Figura 49).

As espécies do grupo Subtropical ficaram próximas e ligadas diretamente à temperatura, tanto na média da coluna d'água superior quanto em superfície, demonstrando a alta correlação deste grupo com este parâmetro, bem como a correlação negativa deste grupo com nutrientes em superfície, portanto, mesmo que, espécies como D. tubífera e Umbellosphaera spp., sejam espécies consideradas da zona fótica superior elas estão correlacionadas a uma menor quantidade de nutrientes nesta camada, caracterizando-as como espécies de regiões oligotróficas.

Deste grupo Syracosphaera spp. foi a espécie que ficou mais distanciada desta caracterização estando mais próxima a ambientes oligotróficos, com baixas quantidades de clorofila, Chl 0-150m, e a ambientes com maior salinidade, isto por estar presente em maior número na região da CB a qual transporta em superfície águas mais salinas e da região tropical na direção sul.

Por sua vez as outras três espécies: Umbellosphaera spp. e Rhabdosphaera spp. atingiram uma caracterização similar ao grupo como um todo, estando ligadas a maiores temperaturas, maior estratificação e poucos nutrientes em superfície. 


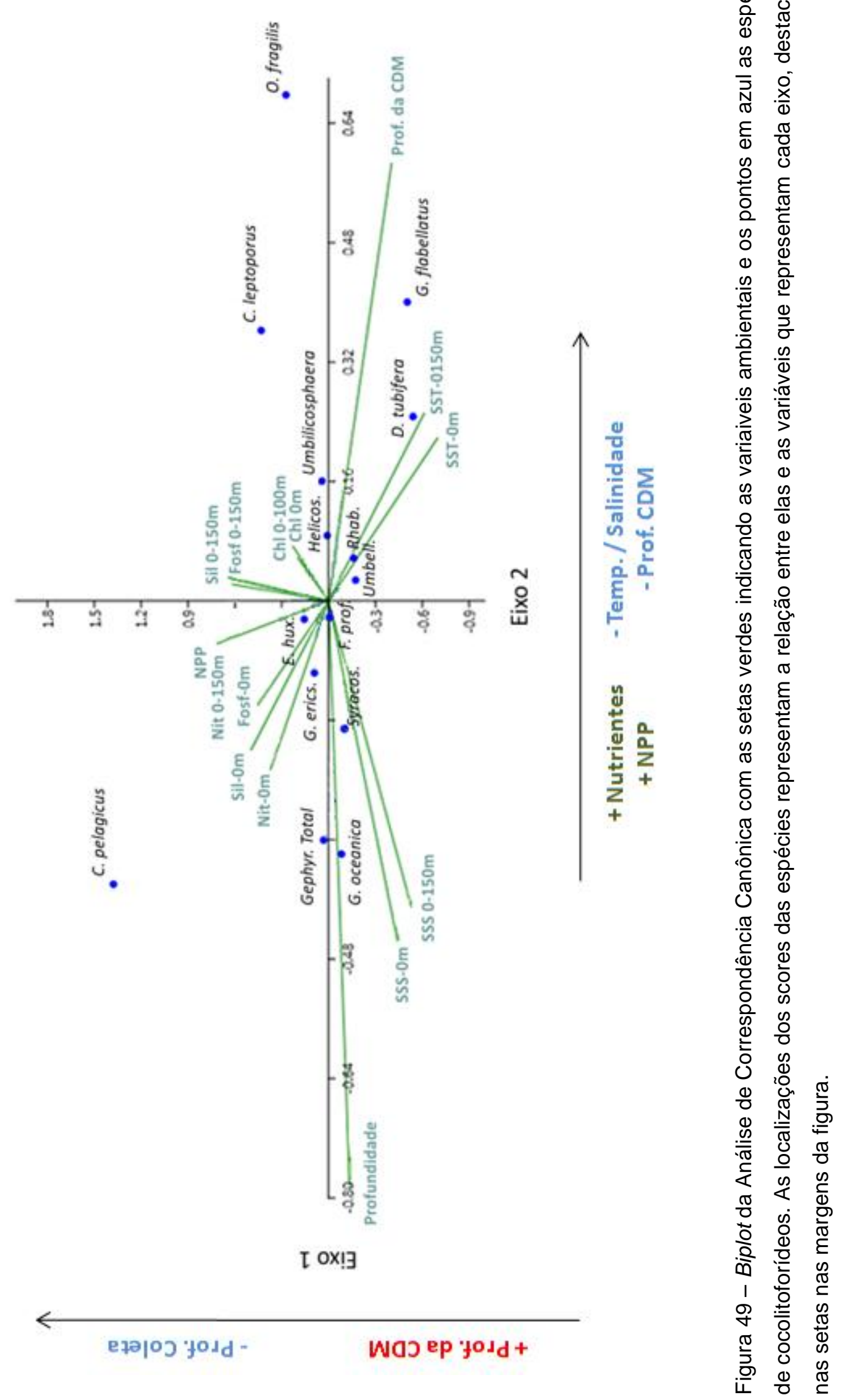


Para agrupar as espécies que representam ambientes similares uma análise de clusters, a partir da correlação entre as espécies foi realizada (Figura 50). Os grupos seguiram a ACC e foram separados em quatro diferentes associações.

O primeiro grupo foi representado por Helicosphaera spp., $O$. fragilis e $C$. leptoporus, estas espécies alcançaram leves correlações com os nutrientes, porém com uma camada de mistura mais profunda. Sendo $O$. fragilis e $C$. leptoporus mais abundantes na região equatorial.

As espécies $E$. huxleyi e $C$. pelagicus formam o segundo grupo que é caracterizado por afinidades a águas mais frias e maiores taxas de nutrientes e produtividade na área de estudo.

O terceiro grupo é o representante das espécies de clima quente e águas oligotróficas, com F. profunda e Rhabdosphaera spp. representando mais a região subtropical, enquanto $G$. flabellatus e Umbellosphaera spp. a região tropical. Neste grupo deve-se tomar cuidado com a espécie Umbilicosphaera spp, por esta ser característica de ambientes de transição, e não apenas de ambientes quentes e oligotróficos

O quarto grupo consiste das espécies mais costeiras e salinas, sendo representado por G. ericsonii, G. oceanica e Syracosphaera spp. Este grupo destaca-se pela preferência por águas mais salinas e costeiras, porém ele diverge no que se refere a nutrientes ou produtividade com as Gephyrocapsas preferindo ambientes mais dinâmicos e com uma menor camada de mistura, enquanto Syracosphaera spp. tem mais afinidade por regiões oligotróficas e de pouca produção primária. 


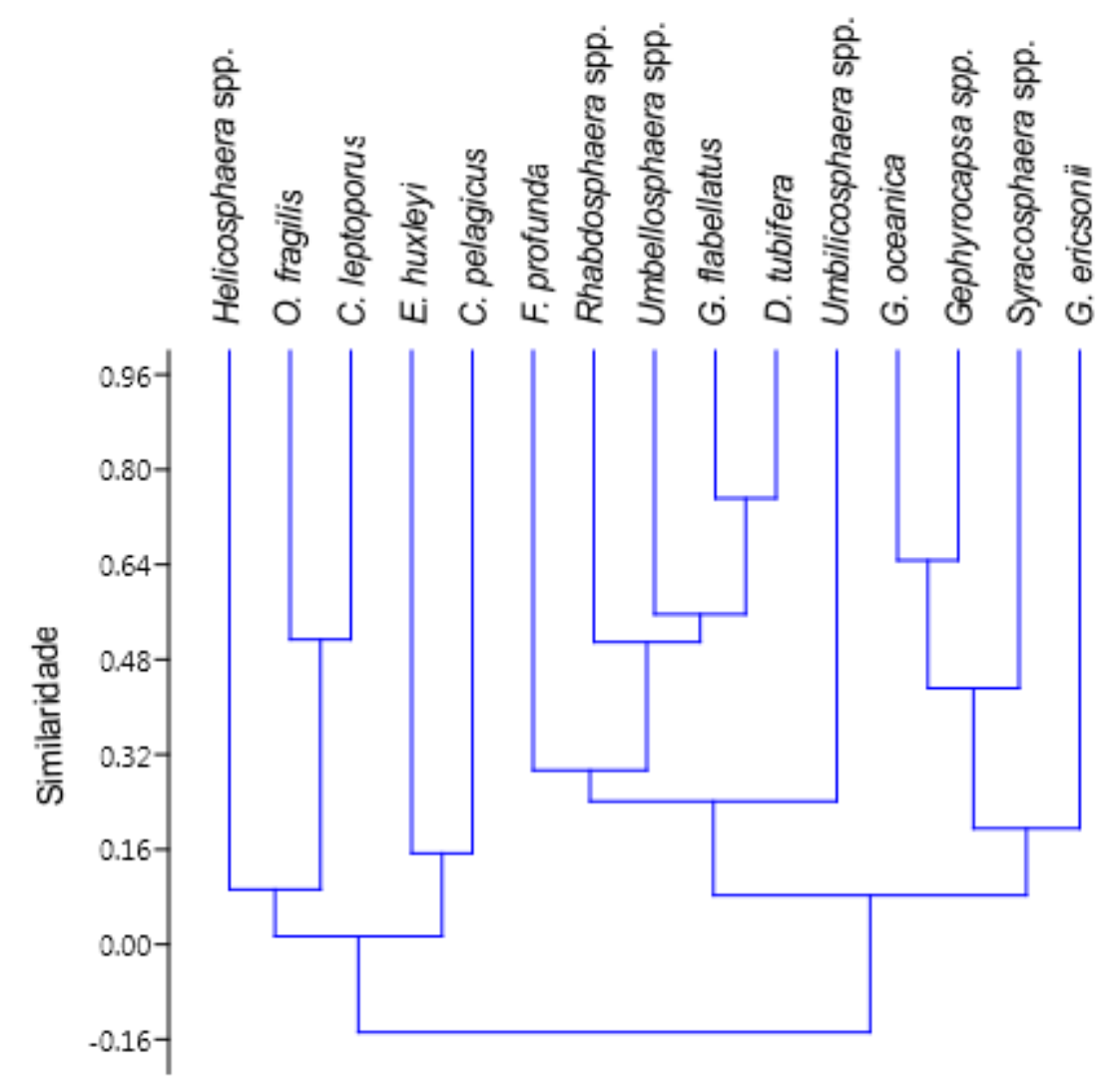

Figura 50 - Análise de Clusters realizada pelo método da Similaridade determinando 4 grupos entre as espécies de cocolitoforídeos com um grau de Coeficiente de Correlação de 0,707.

\subsection{Distribuição dos cocólitos}

A análise de cluster realizada para determinar a distância entre as estações foi feita baseada nas espécies acima, exceto para o gênero Gephyrocapsa, no qual apenas Gephyrocapsa total foi utilizado, ao invés de se utilizar cada espécie deste grupo, uma vez que estas espécies não foram contabilizadas separadamente em todas as amostras.

Antes da realização dos agrupamentos as estações foram separadas em 5 províncias geográficas diferentes, sendo a azul escura as amostras de extremo sul, acima de $35^{\circ} \mathrm{S}$, a azul clara e a verde as amostras entre $35^{\circ} \mathrm{S}$ e $15^{\circ} \mathrm{S}$, separadas pelo critério de profundidades menores que $2000 \mathrm{~m}$ e maiores, respectivamente. Por fim, as amostras entre $15^{\circ} \mathrm{S}$ e $5^{\circ} \mathrm{S}$ são as de cor amarela e as acima de $5^{\circ} \mathrm{S}$ as de vermelho (Figura 51). 


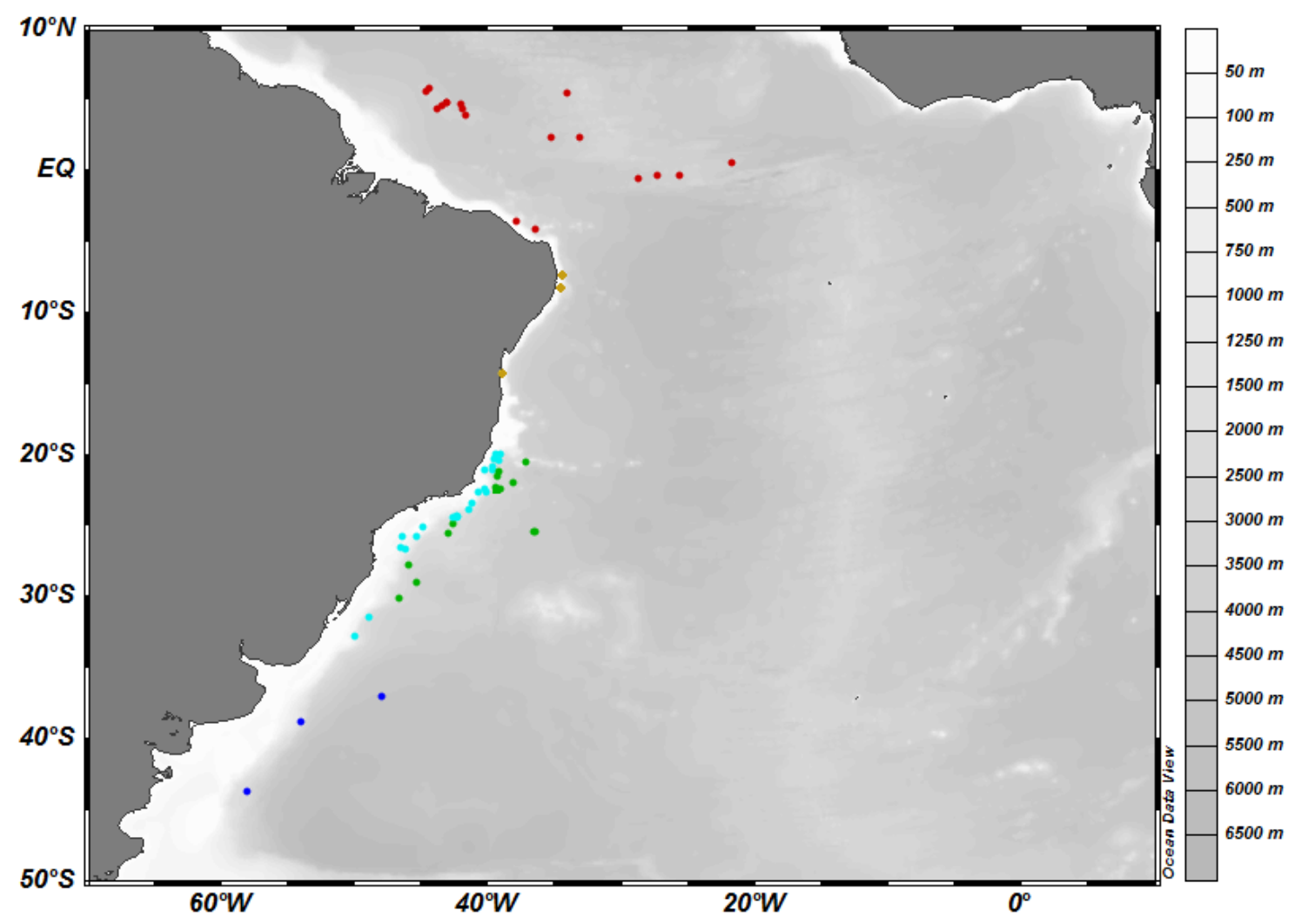

Figura 51- Mapa demonstrando a separação das amostras pelo critério geográfico descrito anteriormente.

Um dendrograma foi elaborado pelo método da distância euclideana, a partir do logaritmo das abundâncias relativas das espécies de cocolitoforídeos, a análise foi considerada significativa pelo alto valor do coeficiente de correlação $(0,808)$, e foram obtidos 5 grupos diferentes (Figura 52). Eles foram separados, conforme 0 esperado, pelas províncias geográficas, com algumas exceções.

As principais diferenças entre a separação geográfica e da análise de cluster foram as amostras destacadas em amarelo, que foram todas agrupadas junto com as amostras em verde e três amostras da província azul clara que foram colocados em preto. 


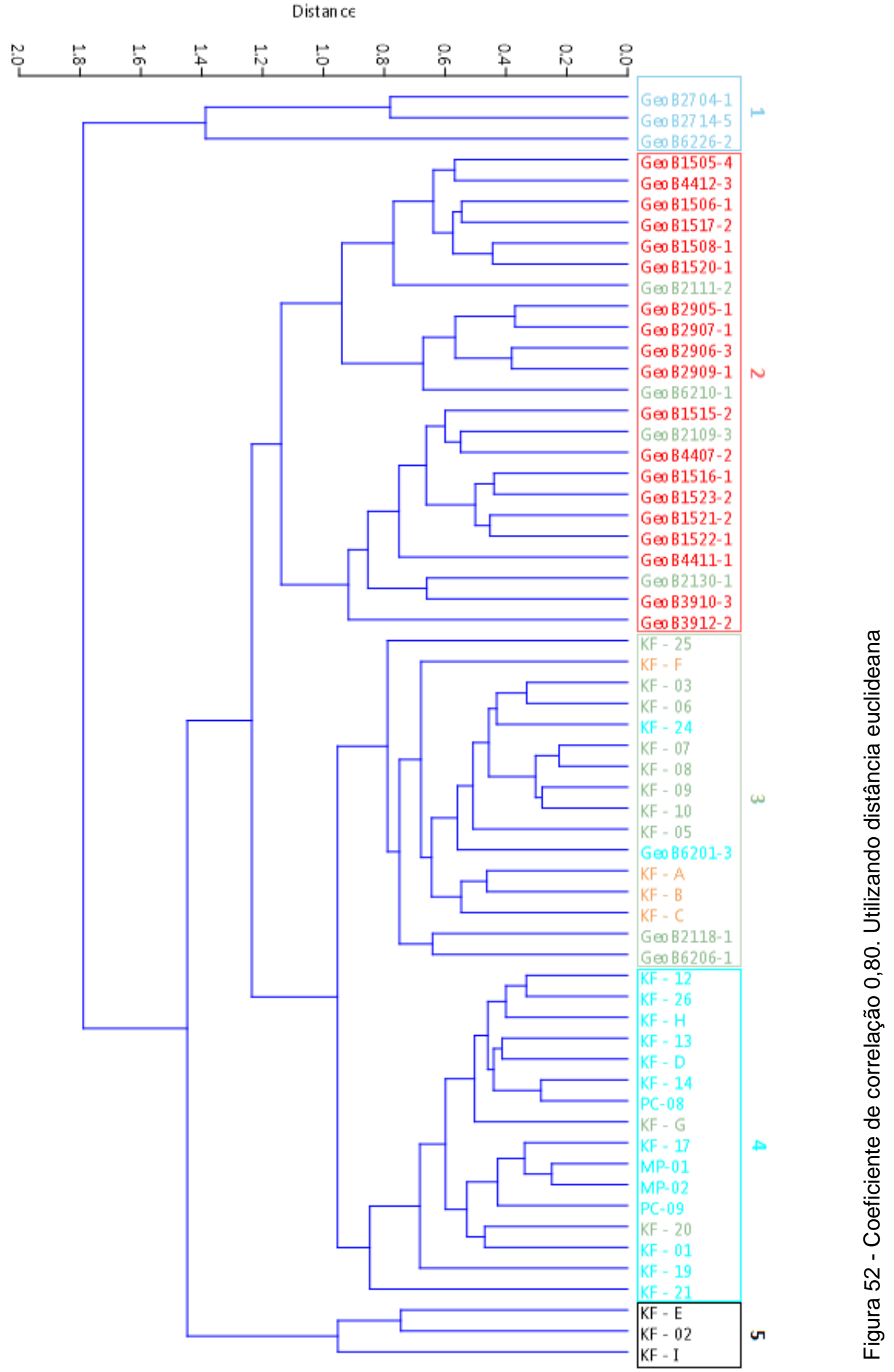


Para determinar quais espécies estavam controlando a separação destes grupos foi realizada uma Análise de Componentes Principais. As duas primeiras Componentes Principais (CP) foram responsáveis por explicar 62\% da variância dos dados compostos dessa análise (Tabela 10). As cores dos pontos (estações) na ACP (Figura 53) foram determinadas pelos grupos observados na análise de clusters (Figura 52).

Tabela 10 - Porcentagem da variância explicada por cada componente principal.

\begin{tabular}{cc} 
CP & \% variância \\
\hline \hline 1 & 37,4 \\
2 & 24,6
\end{tabular}

Para determinar com qual parâmetro cada componente principal está correlacionada foi realizada uma correlação de Pearson entre os scores das componentes principais e os parâmetros ambientais (Tabela 11). Após esta etapa os loadings da ACP (Tabela 12) foram comparados com as correlações obtidas.

Tabela 11 - Matriz de Correlação entre as componentes principais e os parâmetros ambientais. Em negrito estão os valores de $r$ considerados significativos com um $p$-valor menor do que 0,05 .

\begin{tabular}{|c|c|c|c|c|c|c|c|c|c|c|c|c|}
\hline & $\begin{array}{c}\text { Fosf } \\
\text { Om } \\
\end{array}$ & $\begin{array}{c}\text { Fosf } \\
0-150 m \\
\end{array}$ & Prof. CDM & $\begin{array}{l}\text { Nit } \\
\text { Om } \\
\end{array}$ & $\begin{array}{c}\text { Nit } \\
0-150 m \\
\end{array}$ & $\begin{array}{l}\text { Sil } \\
\text { Om } \\
\end{array}$ & $\begin{array}{c}\text { Sil } \\
0-150 m \\
\end{array}$ & $\begin{array}{c}S S M \\
O m \\
\end{array}$ & $\begin{array}{c}\text { SSM } \\
0-150 m \\
\end{array}$ & $\begin{array}{c}\text { TSM } \\
\mathrm{Om} \\
\end{array}$ & $\begin{array}{c}\text { TSM } \\
0-150 m \\
\end{array}$ & $N P P$ \\
\hline$P C 1$ & $-0,011$ & $-0,134$ & 0,355 & $-0,175$ & $-0,095$ & $-0,220$ & $-0,137$ & $-0,226$ & $-0,111$ & 0,258 & 0,249 & $-0,122$ \\
\hline$P C 2$ & $-0,669$ & $-0,792$ & 0,022 & $-0,619$ & $-0,812$ & $-0,708$ & $-0,826$ & 0,604 & 0,699 & 0,630 & 0,687 & $-0,766$ \\
\hline
\end{tabular}

Observando a Tabela 11 podemos notar que a Componente Principal 1 está mais correlacionada a variações na profundidade da Camada de Mistura também alcançando correlações baixas, porém significantes, com a SST e com a SSS. Isso ocorreu devido ao fato de que a Componente Principal 1 é controlada positivamente pelas espécies $G$. flabellatus e $D$. tubifera e negativamente pelo gênero Gephyrocapsa spp (Tabela 12). O que era esperado já que todos os grupos envolvidos estão correlacionados com a profundidade da Camada de Mistura, como visto na sessão anterior.

Portanto as amostras com valores mais positivos no eixo da Componente Principal 1 estão representadas pelas espécies em regiões com 
camadas de misturas mais profundas, enquanto as com menores valores com camadas mais rasas (Figura 53).

Tabela 12 - Loadings de todas as espécie em cada componente principal, demonstrando qual espécie é mais representativa em cada componente principal. Em negrito estão os principais valores.

\begin{tabular}{c|cc} 
& PC 1 & PC 2 \\
\hline \hline C.leptoporus & 0,154 & $-0,388$ \\
C. pelagicus & $-0,163$ & $-0,252$ \\
E. huxleyi & $-0,087$ & $\mathbf{- 0 , 5 3 5}$ \\
F. profunda & $\mathbf{0 , 0 6 4}$ & $\mathbf{0 , 7 1 4}$ \\
Gephyr. Total & $\mathbf{- 0 , 5 4 3}$ & 0,396 \\
Helicosphaera spp. & $\mathbf{0 , 0 7 2}$ & 0,055 \\
O. fragilis & $\mathbf{0 , 2 5 2}$ & $-0,185$ \\
Rhabdosphaera spp & $\mathbf{0 , 2 1 9}$ & $\mathbf{0 , 4 4 9}$ \\
Syracosphaera spp & $\mathbf{0 , 0 9 5}$ & 0,215 \\
Umbellosphaera spp & 0,290 & $\mathbf{0 , 4 9 1}$ \\
Umbilicosphaera spp & $\mathbf{0 , 1 4 0}$ & $\mathbf{0 , 3 2 3}$ \\
G. flabellatus & $\mathbf{0 , 5 0 7}$ & $\mathbf{0 , 2 5 1}$ \\
D. tubifera & $\mathbf{0 , 3 2 5}$ & $\mathbf{0 , 2 5 8}$
\end{tabular}

No caso da Componente Principal 2 a correlação se deu com diversos parâmetros, porém todos convergem para um ambiente quente e oligotrófico, já que as correlações foram negativas com os nutrientes e com a Produtividade Primária Líquida, e positiva com temperatura e salinidade (Tabela 11). Com isso as amostras que apresentam os menores valores do eixo da Componente Principal 2 estão representadas por espécies que refletem ambientes com mais nutrientes e menores temperaturas, enquanto as com menores valores os locais quentes e oligotróficos (Tabela 12).

O grupo 1, em azul escuro na Figura 53, contém as três amostras do extremo sul da área de estudo, estando presente na região transicional de McIntyre \& Bé (1967). Este grupo é marcado pela extrema dominância de $E$. huxleyi e um aumento nas porcentagens de $C$. pelagicus, o que corrobora com as preferências ecológicas destas espécies por águas mais eutróficas e ricas em nutrientes. 


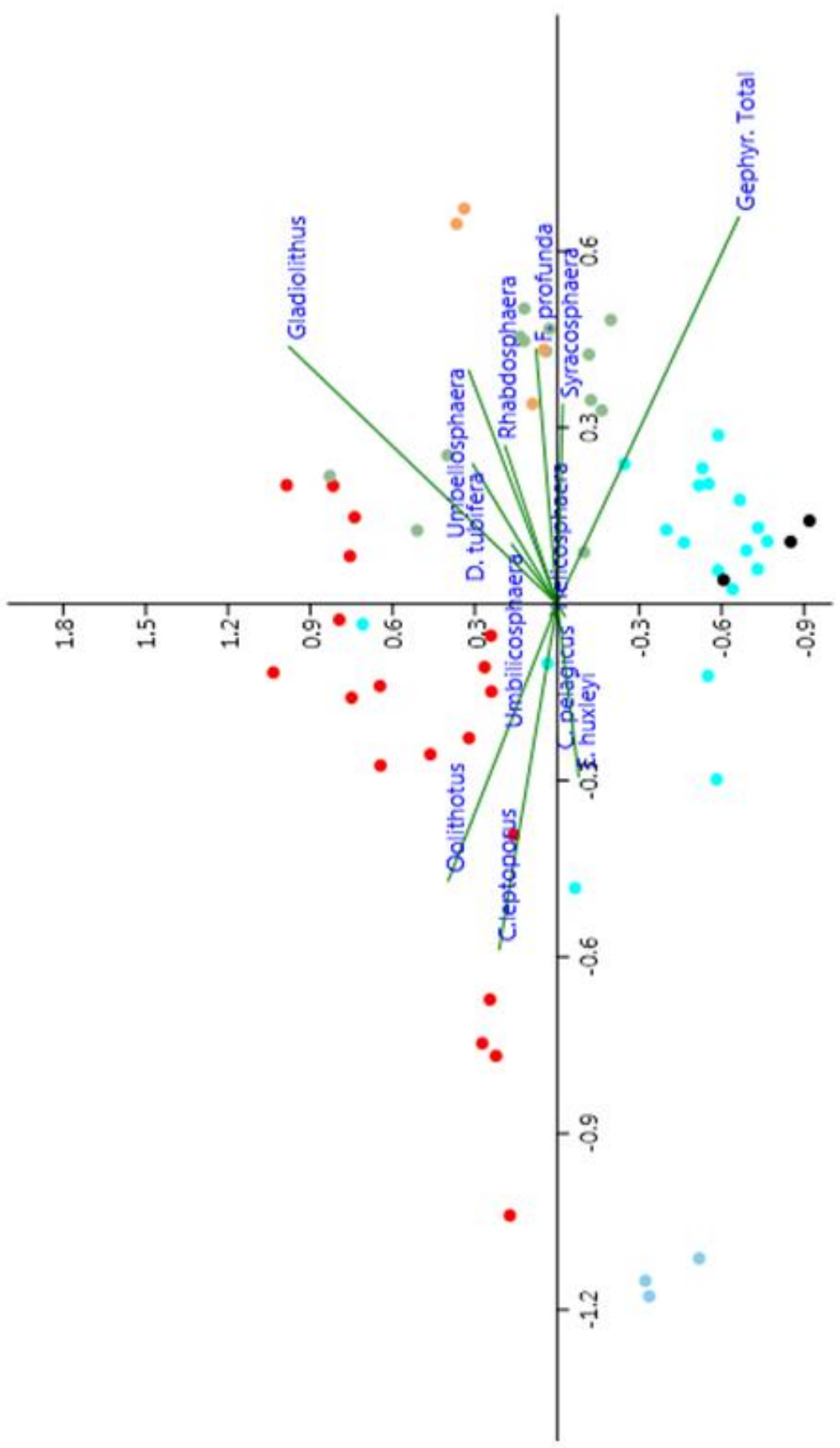

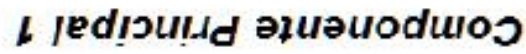

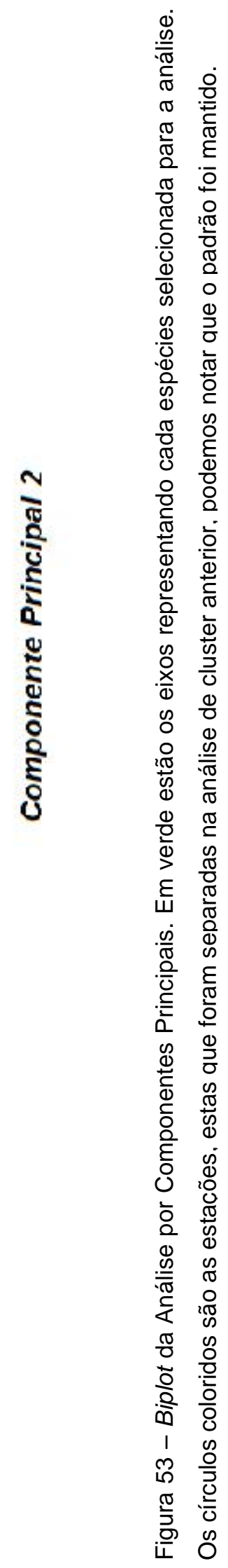


No grupo 2, em vermelho na Figura 53, estão contidas as amostras da região mais ao norte da área de estudo, principalmente da região equatorial, ou seja, a região tropical de McIntyre \& Bé (1967). Neste grupo são observadas as maiores abundâncias de $O$. fragilis e de $C$. leptoporus, devido principalmente as águas quentes favorecerem a primeira espécie, porém com um índice de nutrientes mais elevado do que na região subtropical, devido a divergência equatorial, a segunda espécie é favorecida. Outro fator que caracteriza este grupo é a presença em maiores quantidades de G. flabellatus que, assim como $O$. fragilis, está ligada a ambientes quentes e de camadas de misturas mais profundas, ou seja, nutriclinas mais profundas.

Já para o grupo 3, em verde e amarelo na Figura 53, temos as amostras mais profundas da região subtropical em conjunto com as amostras da região nordeste Brasil, representando claramente o padrão subtropical retratado em Mclntyre \& Bé (1967). A principal característica deste grupo é a grande quantidade de $F$. profunda e das espécies subtropicais, o que está relacionado a uma camada de mistura profunda na qual os nutrientes estão abaixo da termoclina, favorecendo estes organismos e aumentando a diversidade de espécies quando comparado ao grupo 4.

No grupo 4, em azul claro na Figura 53, estão as amostras mais rasas da região central da área de estudo, o que se destaca nestas amostras é a grande presença de espécies do gênero Gephyrocapsa. Este gênero já foi correlacionado a águas costeiras (Aizawa et al., 2004; Okada, 1992) o que também foi observado neste estudo. Nas regiões mais próximas a plataforma temos menores profundidades da Camada de Mistura e uma menor estabilidade da mesma devido a alta hidrodinâmica deste ambiente, o que favorece maiores abundâncias de Gephyrocapsa spp. Além disso, nestas regiões estão presentes vórtices de mesoescala como o Vórtice de Vitória ou a ressurgência de Cabo Frio, podendo em situações especiais levar nutrientes da plataforma continental para a camada fótica destes locais.

O grupo 5, em preto na Figura 53, conteve apenas três amostras consideradas discrepantes das demais, sendo exibidas em preto, estas amostras tem em comum uma grande abundância relativa de Gephyrocapsa spp. com porcentagens acima dos $25 \%$ o que o diferenciou dos demais. 


\section{Conclusões}

O presente estudo reforçou o uso de diversas espécies de cocolitoforídeos como proxies para diferentes variáveis ambientais, demonstrando que estes organismos são extremamente úteis para analisar oscilações de inúmeros processos paleoceanográficos que ocorrem na zona fótica da área de estudo.

Os parâmetros ambientais influenciaram diretamente as assembléias de cocolitoforídeos na área de estudo de modo que diferenças nos parâmetros oceanográficos estimularam diferentes espécies, aumentando ou diminuindo suas abundâncias relativas.

Os cocolitoforídeos refletiram os parâmetros oceanográficos das águas sobrejacentes as suas regiões de coleta, sendo que cada uma de suas espécies obteve correlações significativas com diferentes variáveis ambientais. Portanto estes organismos podem ser utilizados como indicadores das mudanças destas variáveis na zona fótica dos oceanos ao longo do tempo, auxiliando na compreensão da oscilação de diferentes processos oceanográficos, sendo principalmente indicadores de variações do conteúdo de nutrientes na zona fótica, de oscilações da termo/nutriclina, da Paleoprodutividade, da temperatura e salinidade da superfície do mar, assim como de outras características da zona fótica.

Com os resultados obtidos a partir das abundâncias relativas de cocolitoforídeos foi possível agrupar os organismos em 4 províncias diferentes, sendo elas: extremo sul, região tropical, região subtropical e região subtropical rasa. Cada província é caracterizada por diferenças em suas assembléias sendo, respectivamente:

A primeira sendo caracterizada pela extrema dominância de $E$. huxleyi e pela presença de $C$. pelagicus. A segunda pelas maiores porcentagens de $G$. flabellatus e $C$. leptoporus em relação às outras províncias. A terceira foi representada pela dominância de $F$. profunda e pelas maiores abundâncias das espécies subtropicais, D. tubifera, Rhabdosphaera spp., Syracosphaera spp. e Umbellosphaera spp. A quarta sendo caracterizada pelas maiores abundâncias de Gephyrocapsa spp. 


\section{Referências}

Ahagon, N., Tanaka \& Y., Ujiie H. 1993. Florisphaera profunda, a possible nannoplankton indicator of late Quaternary changes in sea-water turbidity at the northwestern margin of the Pacific. Marine Micropalaeontology, 22: 255-273.

Aizawa, C., Oba T. \& Okada, H. 2004. Late Quaternary paleoceanography deduced from coccolith assemblages in a piston core recovered off the central Japan coast. Marine Micropaleontology 52, pp 277 - 297.

Andruleit H \& Rogalla U. 2002. Coccolithophores in surface sediments of the Arabian Sea in relation to environmental gradients in surface waters. Mar Geol 31 (32): 1-22.

Antunes, R.L. 1997. Introdução ao estudo dos nanofósseis calcários. Rio de Janeiro: UFRJ, $115 \mathrm{pp}$.

Antunes, R. L. 2007. Nanofósseis calcários do Quartenário da margem continental brasileira. Petrobrás.

Arruda, W. Z., Campos, E. J. D., Zharkov, V., Soutelino, R. G. \&. Silveira, I. C. A. 2013. Events of equatorward translation of the Vitoria Eddy. Continental Shelf Research, v.70, p.61-73.

Baumann, K.-H., Cepek, M. \& Kinkel, H. 1999. Coccolithophores as indicators of ocean water masses, surface-water temperature, and paleoproductivityexamples from the South Atlantic. In: Fischer, G., Wefer, G. (Eds.), Use of Proxies in Paleoceanography: Examples from the South Atlantic. Springer, Berlin, Heidelberg, pp. 117-144.

Baumann, K.H., Andruleit, H. \& Samtleben, C. 2000. Coccolithophores in the Nordic Seas: comparison of living communities with surface sediment assemblages. Deep-Sea Research II: Topical Studies in Oceanography 47, pp. 1743-1772.

Behrenfeld, M.J. \& Falkowski, P.G. 1997. Photosynthetic Rates Derived from Satellite-Based Chlorophyll Concentration Limnology and Oceanography, Vol. 42, No. 1 (Jan., 1997), pp. 1-20. 
Berger, W.H., Adelseck, C.G. \& Mayer, L.A. 1976. Distribution of carbonate in surface sediments of the Pacific Ocean. Journal of Geophysical Research 81, pp. 2617-2627.

Billard, C. \& Inouye I. 2004. What is new in coccolithophore biology? In: Coccolithophores: From Molecular Processes to Global Impact, Thierstein, H., and J. Young, eds. Springer Verlag, Berlin. Pp.: 2-29

Boeckel, B. \& Baumann, K-H. 2004. Distribution of coccoliths in surface sediments of the south-eastern South Atlantic Ocean: ecology, preservation and carbonate contribution. Marine Micropaleontology, 51(3-4), 301-320.

Boeckel, B., Baumann, K.-H., Henrich, R. \& Kinkel, H. 2006. Coccolith distribution patterns in South Atlantic and Southern Ocean surface sediments in relation to environmental gradients. Deep-Sea Research I: Oceanographic Research Papers 53, pp. 1073-1099.

Bollmann, J. 1997. Morphology and biogeography of Gephyrocapsa coccoliths in Holocene sediments. Mar. Micropaleontol., 29(3/4), 319-350.

Bollmann, J. \& Klaas, C. 2008. Morphological variation of Gephyrocapsa oceanica Kamptner 1943 in plankton samples; implications for ecologic and taxonomic interpretations. Protist, 159, pp. 369-381.

Bown P.R. \& Young J.R. 1998. Introduction. In: Bown P.R. ed. 1998. Calcareous Nannofossil Biostratigraphy. London: British Microp. Soc. Series. Chapman and Hall/Kluwer Acad. Publ. pp. 1-15.

Braarud, T., Gaarder K., Markali \& J.,Nordli E. 1952. Coccolithophorids studied in the electron microscope. Observations on Coccolithus huxleyi and Syracosphaera carterae. Nytt Mag. Botan.,1: 129-134.

Brand, L.E. 1994. Physiological ecology of marine coccolithophores. In: Winter A., Siesser W.G (eds) Coccolithophores. Cambridge University Press, Cambridge, pp 39-49 
Cachão, M. \& Moita, M. T. 2000. Coccolithus pelagicus, a productivity proxy related to moderate fronts off Western Iberia. Marine Micropaleontology, 39: 131-155.

Calado, C., Gangopadhyay, A. \& Silveira, I. C. A. 2006. A parametric model for the Brazil Current meanders and eddies off southeastern Brazil. Geophys. Res. Lett.,33, L12602.

Callegari-Jacques, S. M. 2003. Bioestatística: princípios e aplicações. Porto Alegre: Artmed. 255 pp.

Chalrlson, R.J., Lovelock, J.E., Andreae, M.O. \& Warren, S.G. 1987. Oceanic phytoplankton, atmospheric sulphur, cloud albedo and climate. Nature, 326, pp. 655-661.

Chiessi, C. M.; Ulrich, S.; Mulitza, S.; Patzold, J. Wefer, G. 2007. Signature of the Brazil-Malvinas Confluence (Argentine Basin) in the isotopic composition of planktonic foraminifera from surface sediments. Marine Micropaleontology, 64, 52-66.

Conkright, M.E. \& Boyer, T. P. 2002: World Ocean Atlas 2001: Objective Analyses, Data Statistics, and Figures, CD-ROM Documentation. National Oceanographic Data Center, Silver Spring, MD, 17 pp.

Costa, K. B.; Toledo, F. A. L.; Pivel, M. A. G.; Moura, C. A. V. \& Chemale, F. Jr. 2006. Evaluation of two genera of benthic foraminifera for down-core paleotemperature studies in the western South Atlantic. Brazilian Journal of Oceanography, 54 (1), 75-84.

Curry, W. B. \& Lohman, G. P. 1982. Carbon isotopic changes in the benthic foraminifera from the Western South Atlantic: Reconstruction of glacial abyssal circulation patterns. Quaternary Research, 18, 218 - 235.

Damuth, J. E. \& Palma J. C. 1979. Geomorfologia do fundo atlântico equatorial oeste. Geomorfologia da Margem continental Brasileira e das áreas oceânicas adjacentes. Rio de Janeiro, Série Projeto REMAC 7: pp. 53-88. 
de Vargas, C., Aubry, M. P., Probert, I., \& Young, J. 2007. Origin and evolution of coccolithophores: from coastal hunters to oceanic farmers. In: Evolution of primary producers in the sea, 12, 251-285.

Dittert, N., Baumann, K.-H., Bickert, T., Heinrich, R., Huber, R., Kinkel, H. \& Meggers, H. 1999. Carbonate Dissolution in the Deep-Sea: Methods, Quantification and Paleoceanographic Application. In: Fischer, G., Wefer, G. (Eds.), Use of proxies in Paleoceanography: Examples from the South Atlantic. Berlin: Springer-Verlag. pp. 255-284.

Flores, J.A. \& Sierro, F.J. 1997. Revised technique for calculation of calcareous nannofossil accumulation rates. Micropaleontology, 43(3), pp. 321-324.

Flores, J. A., Barcena, M. A., \& Sierro, F. J. 2000. Ocean-surface and wind dynamics in the Atlantic Ocean off Northwest Africa during the last 140000 years, Paleogeogr. Paleoclimatol. Paleoecol., 161, 459-478.

Fraguas, P. F., Costa, K. B. \& Toledo, F. A. L. 2011. Relationship between isotopic composition ( $\Delta 180$ and $\Delta 13 C$ ) and planktonic foraminifera test size in core tops from the Brazilian Continental Margin. Braz. j. oceanogr., São Paulo, v. 59, n. 4 , p. 327-338.

França, A. M. C.,1979. Geomorfologia da margem continental leste brasileira e da bacia oceânica adjacente. Série Projeto REMAC, 7, pp. 92-123.

Garcia, H. E., Locarnini, R. A., Boyer, T. P., Antonov, J. I., Baranova, O.K., Zweng, M.M., Reagan, J.R. \& Johnson, D.R. 2014. World Ocean Atlas 2013, Volume 4: Dissolved Inorganic Nutrients (phosphate, nitrate, silicate). S. Levitus, Ed., A. Mishonov Technical Ed.; NOAA Atlas NESDIS 76, 25 pp.

Geitzenauer, K.R., Roche, M.B \& Mclntyre, A. 1977. Coccolith biogeography from North Atlantic and Pacific surface sediments. In: Oceanic Micropaleontology, ed. A.T.S. Ramsey, pp. 973-1008. Academic Press, London.

Giraudeau, J. 1992. Distribution of Recent nannofossils beneath the Benguela system: southwest African continental margin. Marine Geology,108, 219-237. 
Hair, J.F., Anderson, R.E., Tatham, R.L. \& Black, W.C. 1992. Multivariate Data Analysis with Readings. Macmillan Publishing Company, New York.

Hagino, K., Okada H. \& Matsuoka H. 2000. Spatial dynamics of coccolithophore assemblages in the equatorial West-Central Pacific Ocean Mar. Micropaleontol., 39, pp. 53-72.

Hammer, Ø., Harper, D.A.T. \& Ryan, P.D. 2001. PAST: Paleontological Statistics Software Package for Education and Data Analysis. Palaeontologia Electronica 4 (1), 9 p.

Honjo, S. 1976. Coccoliths: production, transportation and sedimentation. Marine Micropaleontology 1 (1), pp. 65-79.

Hut, G., 1987. Consultants group meeting on the stable isotope reference samples for geochemical and hydrological investigations, Rep, to Dir. Ge., Int. At. Energy Agency, Vienna, 42pp.

Jin, X., Liu, C., Poulton, A. J., Dai, M. \& Guo, X. 2016. Coccolithophore responses to environmental variability in the South China Sea: species composition and calcite content. Biogeosciences, 13, 4843-4861.

Kim, S. T. \& O’Neil, J. R. 1997. Equilibrium and nonequilibrium oxygen isotope effects in synthetic carbonates. Geochimical Cosmochimical Acta, 61, 34613475.

Kinkel, H., Baumann, K.-H. \& Cepek, M. 2000. Coccolithophores in the equatorial Atlantic Ocean: response to seasonal and Late Quaternary surface water variability. Marine Micropaleontology 39, pp. 87-112.

LeGrande, A. N. \& Schmidt, G. A. 2006. Global gridded data set of the oxygen isotopic composition in seawater. Geophysical research letters, 33, L12604, doi: 10.1029/2006GL026011.

Levitus, S., 1982. Climatological Atlas of the World Ocean, NOAA Professional Paper No. 13, U.S. Gov. Printing Office, 173 pp.

Locarnini, R. A., Mishonov, A. V., Antonov, J. I., Boyer, T. P., Garcia, H. E., Baranova, O. K., Zweng, M. M., Paver, C. R., Reagan, J. R., Johnson, D. R., 
Hamilton, M. \& Seidov, D. 2013. World Ocean Atlas 2013, Volume 1: Temperature. S. Levitus, Ed., A. Mishonov Technical Ed.; NOAA Atlas NESDIS 73, $40 \mathrm{pp}$.

Lourenço, O. S. \& Marques-Junior, A. N. 2002. Produção primária marinha. In: Pereira, R. C. e Soares-Gomes, A. Biologia Marinha. Rio de Janeiro. Ed. Interciência, pp 195-277.

McGillicuddy, D. J. Jr. 2016. Mechanisms of Physical-BiologicalBiogeochemical Interaction at the Oceanic Mesoscale.Annu. Rev. Mar. Sci. 8:125-59.

Mclntyre, A. \& Bé, A.W.H., 1967. Modern coccolithophoridae of the Atlantic Ocean. Placoliths and Cyrtoliths. Deep-SeaResearch 14, 561-597.

Milliman, J. D. 1993. Production and accumulation of calcium carbonate in the ocean: budget of a non-steady state. Global Biogeochemical Cycles 7, pp. 927957.

Mjaaland, G.1956. Some laboratory experiments on the Coccolithophorid, Coccolithus huleyi. Oikos, 7: 251-255.

Molfino, B. \& Mclntyre, A. 1990a. Precessional forcing of nutriclina dynamics in the Equatorial Atlantic. Science 249, 766-769.

Molfino, B. \& Mclntyre, A. 1990b. Nutricline variation in the equatorial Atlantic coincident with the Younger Dryas. Paleoceanography 5, 997-1008.

Mulitza, S.; Donner, B.; Fischer, G.; Paul, A.; Patzold, J.; Ruhlemann, C. \& Segl, M. 2003. The South Atlantic oxygen isotope record of planktonic foraminifera. In The South Atlantic in the Late Quaternary: Reconstruction of Material budgets and current systems. Wefer, G., Mulitza, S. Ratmeyer, V (eds.). Springer-Verlag Berlin Heidelberg New York Tokyo, 121-142.

Nishida, S. 1979. Atlas of Pacific Nannoplanktons. Micropaleontol. Soc. Osaka. Spec. Paper, No. 3. 
Okada, H. 1983. Modern nannofossil assemblages in sediments of coastal and marginal seas along the western Pacific Ocean. Utrecht Micropaleontol. Bull., 30: 171-187.

Okada, H. \& Honjo, S. 1973. The distribution of oceanic coccolithophorids in the Pacific. Deep-sea Res., 20: 355-374.

Okada, H. \& Mclntyre, A. 1979. Seasonal distribuition of modern coccolithophores in western North Atlantic Ocean. Mar. boil., 54: 319-328.

Okada, H. 1992. Biogeographic control of modern nannofossil assemblages in surface sediments of Ise Bay, Mikawa Bay and Kumano-nada, off coast of Central Japan. Mem. Sci. Geol. 43, 431- 449.

Patti, E. J. 2001. A geração dos anéis da Corrente Norte do Brasil devido ao forçamento pelo vento em um modelo isopicnal. Tese de Doutorado, Universidade de São Paulo, 115 pp.

Peterson, R.G. \& Stramma, L., 1991. Upper level circulation in the South Atlantic Ocean.Progress in Oceanography, 26,(1), pp. 1-73.

Poulton, A. J., Holligan, P. M., Charalampopoulou, A. \& Adey, T. R. 2017. Coccolithophore ecology in the tropical and subtropical Atlantic Ocean: New perspectives from the Atlantic meridional transect (AMT) programme. Progress in Oceanography, 158, pp 150-170.

Quadros, J. P. 2007. Nanofósseis calcários da margen continental nordeste do Brasil: uma contribuição à Paleoceanografia do Atlântico Sul. Tese de mestrado. Universidade de São Paulo - USP. Instituto Oceanográfico. São Paulo, SP, Brasil. 180 pp.

Rohling, E. J. \& Cooke, S. 1999. Stable oxygen and carbon isotopes in foraminiferal carbonate shells, in Barun, K Sen Gupta (ed.). Modern foraminifera, 239-258. Kluwer Academic Publishers. Printed in Great Britain.

Roth, P.H. 1994. Distribution of coccoliths in oceanic sediments. In: Winter A, Siesser W.G.(eds) Coccolithophores. Cambridge University Press, Cambridge, pp 199-218. 
Saavedra-Pellitero, M., Flores, J. A., Baumann, K.-H. \& Sierro, F. J., 2010.Coccolith distribution patterns in surface sediments of equatorial and southeastern Pacific Ocean. Geobios 43, pp. 131-149.

Saavedra-Pellitero, M., Flores, J.A., Baumann, K.-H., Boeckel, B. \& Sierro, F.J. 2011. Comparison of different preparation and analysis techniques for quantitative coccolith studies focusing on biogeographic patterns of species. Micropaleontology, 57 (2), 139-161.

Samtleben, C., Schaefer, P., Andruleit, H., Baumann, A., Baumann, K.-H., Kohly, A., Matthiessen, J. \& Schroeder-Ritzrau, A. 1995. Plankton in the Norwegian-Greenland Sea: from living communities to sediment assemblages-an actualistic approach. Geol. Rundsch. 84, pp. 108-136.

Schlitzer, R. 2017. Ocean Data View, odv.awi.de.

Siesser, W.G. \& Winter, A. 1994. Composition and morphology of coccolithophores skeletons. In: Winter, A. \& Siesser, W. (Eds.), Coccolithophores. Cambridge University Press, pp. 51-62.

Silveira, I. C. A., Miranda, L. B. \& Brown, W. S., 1994. On the origins of the North Brazil Current. Journal of Geophysical Research, 99 (C11),22.50122.512 .

Silveira, I. C. A. D., Schmidt, A. C. K., Campos, E. J. D., Godoi, S. S. D. \& Ikeda, Y. 2000. A corrente do Brasil ao largo da costa leste brasileira. Revista Brasileira de Oceanografia, 48(2), pp. 171-183.

Soutelino, R. G., Silveira, I. C. A., Gangopadhyay, A., \& Miranda, J. A. 2011. Is the Brazil Current eddy- dominated to the north of $20^{\circ} S$ ? Geophys. Res. Lett., 38, L03607.

Stoll, H.M. \& Ziveri, P., 2002. Separation of monospecific and restricted coccolith assemblages from sediments using differential settling velocity. Marine Micropaleontology 46, pp. 209-221.

Stramma, L. \& England, M. 1999. On the water masses and mean circulation of the South Atlantic Oceano J. Geophys. Res., 104(C9): 20863-20883. 
Stramma, L.; Ikeda, Y. \& Peterson, R. G. 1990. Geostrophic transport in the Brazil Current region. Deep-Sea. Res., 37(1 A): 1875-1886.

Tanaka, Y. 1991. Calcareous nannoplankton thanatocoenoses in surface sediments from seas around Japan. Sci. Rep. Tohoku Univ. 2nd Ser., Geol. 61, 127-198.

Tanaka, Y. 1997. Sedimentary processes from the shelf edge to the Okinawa Trough in the East China Sea based on the coccolith assemblages. J. Sedimentol. Soc. Jpn. 44, 33- 41 (em Japones com o resumo em inglês).

Tanaka, Y. \& Kawahata, H. 2001. Seasonal occurrence of coccoliths in sediment traps from West Caroline Basin, equatorial West Pacific Ocean. Mar. Micropaleontol., 43, 273-284.

Thierstein, H.R. 1980. Selective dissolution of late cretaceous and earliest tertiary calcareous nannofossils: Experimental evidence. Cretaceous Research 1, pp. 165-176.

Toledo, F. A. L. 2000. Variações Paleoceanográficas nos últimos 30.000 anos no oeste do Atlântico Sul: isótopos de oxigênio, assembleias de foraminíferos planctônicos e nanofósseis calcários. Tese de doutorado. Universidade Federal do Rio Grande do Sul - UFRGS. Instituto de Geociências. Curso de Pós Graduação em Geociências, Porto Alegre, RS, Brasil. 245 pp.

Urbano, D. F., Almeida, R. A. F. D. \& Nobre, P. 2008. Equatorial Undercurrent and North Equatorial Countercurrent at $38^{\circ} \mathrm{W}$ : A new perspective from direct velocity data. Journal of Geophysical Research, 113, C04041.

Wanner, H, Beer, J \& Bütikofer, J. 2008. Mid to Late-Holocene climate change: An overview. Quaternary Science Reviews 27(19-20): 1791-1828

Wefer, G., Verger, W.H., Bijma, J. \& Fischerm, G. 1999. Clues to Ocean History: a Brief Overview of Proxies. In: Fischer, G., Wefer, G. (Eds.). Use of proxies in Paleoceanography: Examples from the South Atlantic. Berlin: Springer-Verlag. pp. 1-68. 
Winter, A., Jordan, R.W. \& Roth, P.H., 1994. Biogeography of living coccolithophores in ocean waters. In: Winter, A., Siesser, W.G. (Eds.), Coccolithophores. Cambridge University Press, Cambridge, pp. 161-177.

Young, J.R. 1994. Functions of coccoliths. In: Winter, A \&Siesser, W. (Eds.). Coccolithophores. Cambridge: Cambridge University Press, pp. 63-82.

Young, J.R., Bown P.R. \& Lees J.A. 2014. Nannotax3 website. International Nannoplankton Association. URL: http://ina.tmsoc.org/Nannotax3.

Young, J. R., Geisen, M., Cros, L., Kleijne, A., Sprengel, C., Probert, I., \& Østergaard, J. 2003. A guide to extant coccolithophore taxonomy. Journal of Nannoplankton Research, 1(1), 1-125.

Zembruscki, S. G. 1979. Geomorfologia da margem continental sul brasileira e das áreas oceânicas adjacentes. Série Projeto REMAC, vol. 7, pp. 129-174.

Ziveri, P., Baumann, K.H., Boeckel, B., Bollmann, J. \& Young, J.R., 2004. Biogeography of selected Holocene coccoliths in the Atlantic Ocean. In: Thierstein, H.R., Young, J.R. (Eds.), Coccolithophores, from molecular processes to global impact. Springer-Verlag, Berlin, pp. 403-428.

Zweng, M.M., Reagan, J.R., Antonov, J.I., Locarnini, R.A., Mishonov, A.V., Boyer, T.P., Garcia, H.E., Baranova, O.K., Johnson, D.R.,.Seidov, D \& Biddle, M.M. 2013. World Ocean Atlas 2013, Volume 2: Salinity. S. Levitus, Ed., A. Mishonov Technical Ed.; NOAA Atlas NESDIS 74, 39 pp. 